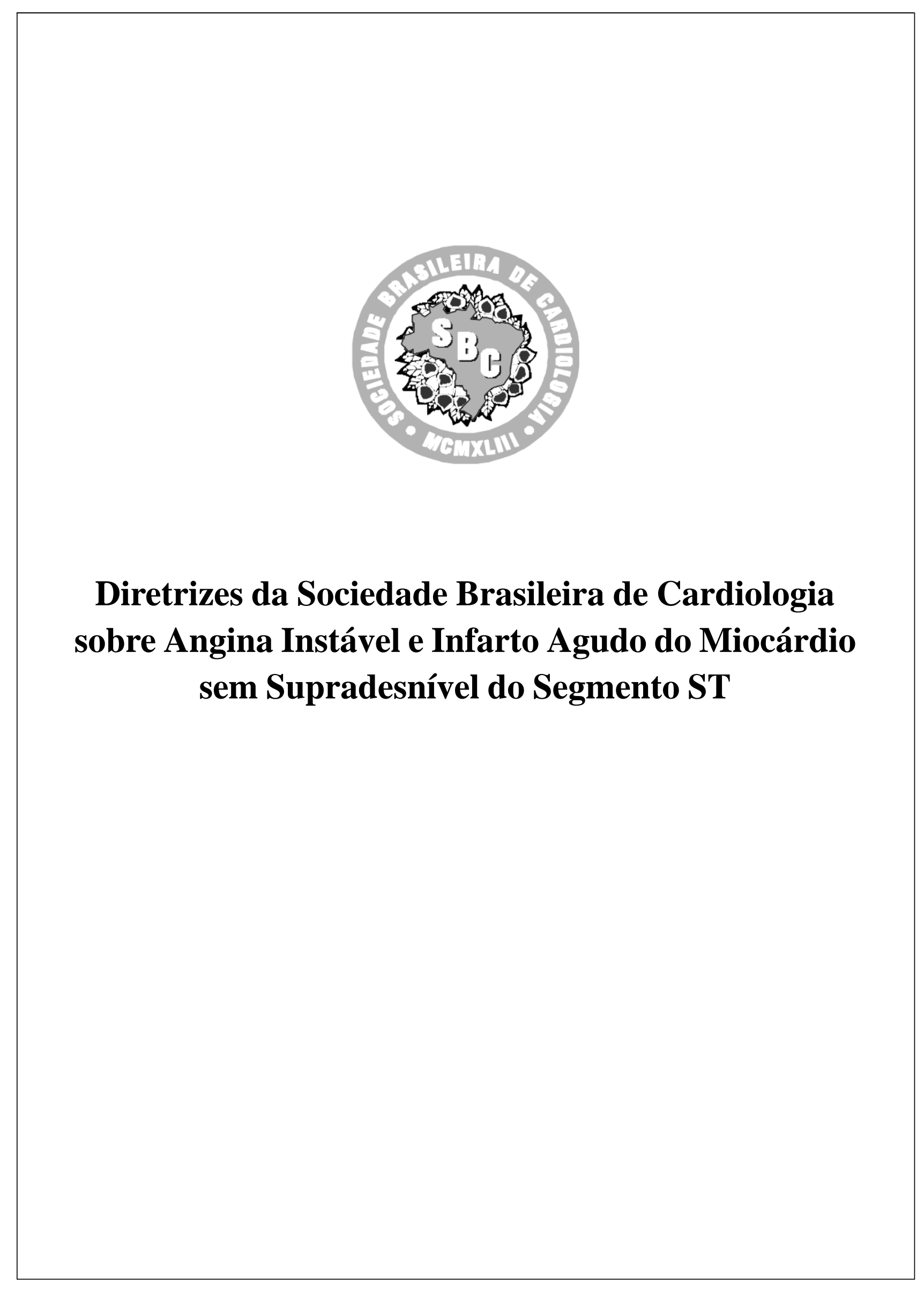




\title{
Diretrizes da Sociedade Brasileira de Cardiologia sobre Angina Instável e Infarto Agudo do Miocárdio sem Supradesnível do Segmento ST
}

\author{
José Carlos Nicolau \\ Luiz Antonio Machado Cesar \\ AriTimerman \\ Leopoldo Soares Piegas \\ José Antonio Marin-Neto
}

Correspondência: Diretoria Científica

Sociedade Brasileira de Cardiologia

Rua Ipú, 32 - Botafogo - Cep 22281-040 - Rio de Janeiro - RJ

Fax:(021)286-9128

E-mail: sbcgeral@ cardiol.br 


\section{Grupos de Trabalho}

\section{GRUPO I}

Estratificação de risco e condutas nas primeiras 12h após a chegada do paciente ao hospital

Ari Timerman (Coordenador)

Antonio Carlos de Camargo Carvalho

Brivaldo Markman Filho

Carisi Anne Polanczyk

Maurício da Rocha Pantoja

PauloFerreira Leite

Roberto Esporcatte

Roberto Luiz Marino

Ricardo Vivacqua Cardoso Costa

\section{GRUPO II}

Condutas no paciente com angina instável de risco intermediário

Leopoldo Soares Piegas (Coordenador)

Anis Rassi Jr.

Cesar Cardoso de Oliveira

Dalton Bertolin Precoma

Edson Stefanini

Gilson Soares Feitosa

Luís Alberto Piva e Mattos

Paulo Ernesto Leães

Pedro Ferreira de Albuquerque

Wilson Mathias Jr.

\section{GRUPO III}

Condutas no paciente com angina instável de alto risco e infarto agudo do miocárdio sem supradesnível do segmentoST

José Antônio Marin-Neto (Coordenador)

Álvaro Avezum

Carlos Vicente Serrano Jr.

Denílson Campos de Albuquerque

Fernando Antônio de Portugal Morcerf

José Cláudio Meneghetti

Marco Antônio Perin

Otávio Rizzi Coelho

Oscar Pereira Dutra

Romeu Sérgio Meneghelo

\section{COORDENAÇÃO GERAL}

José Carlos Nicolau e Luiz Antonio Machado César

Nota:

Deve ser salientado que estas Diretrizes se prestam a informar e não a substituir o julgamento clínico do médico que, em última análise, deve determinar otratamento apropriado para cada indivíduo. 


\title{
Graus de Recomendações e Níveis de Evidências utilizados neste documento
}

\section{Graus de Recomendações}

Graus

\author{
Definição
}

A) Definitivamente recomendada (evidência excelente)

Sempre aceitável e segura; definitivamente útil; eficácia e efetividade comprovadas

B) Aceitável

Aceitável e segura, clinicamente útil, não confirmado definitivamente ainda

$\mathrm{B}^{1}$ ) Evidência muito boa

Considerado tratamento de escolha

$B^{2}$ ) Evidência razoável

Considerado tratamento opcional ou alternativo

C) Inaceitável

Clinicamente sem utilidade; pode ser prejudicial

\section{Níveis de Evidências}

Níveis

Definição

1

Dados derivados de múltiplos estudos randomizados envolvendo grande número de pacientes

2

Dados derivados de um número limitado de estudos randomizados que incluíram pequeno número de pacientes, ou de análise cuidadosa de estudos não-randomizados ou registros observacionais

3

Quando a base primária para a recomendação se baseou em um consenso de especialistas 


\section{PARTE I \\ Estratificação de Risco e Condutas nas primeiras 12 horas após a chegada do paciente ao Hospital}

\section{1) História da doença atual e pregressa. Exame físico}

\section{Introdução}

Nos Estados Unidos a angina instável (AI) é a causa cardiovascular mais comum de internação hospitalar, e também a responsável pela maioria das internações em unidades coronarianas ${ }^{1}$. Durante a evolução, uma parte desses pacientes desenvolve elevações nos marcardores bioquímicos de dano miocárdico, configurando o quadro de infarto agudo do miocárdio (IAM) sem supradesnível do segmento ST. Estas duas entidades (AI e IAM), compõem as síndromes isquêmicas miocárdicas instáveis (SIMI) sem supradesnível do segmento ST, objeto desta Diretriz. O paciente com AI tem prognóstico variável quanto a eventos desfavoráveis, como IAM, óbito, recorrência de angina e necessidade de revascularização miocárdica ${ }^{2}$. Em virtude da ampla variação das manifestações clínicas das SIMI sem supradesnível do segmento ST, sua estratificação de risco ajuda a determinar estratégias para tratamento ambulatorial ou hospitalar ${ }^{3}$, propiciando uma adequação de custos em função de maior eficácia terapêutica ${ }^{4-6}$.

\section{a) História da doença atual e pregressa}

\section{História de doença atual}

A história clínica do paciente com SIMI sem supradesnível do ST desempenha importante papel na estratificação de risco. A classificação da AI mais utilizada é a proposta por Braunwald ${ }^{7,8}$. Seu valor prognóstico e terapêutico tem sido validado em numerosos estudos clínicos prospectivos, alcançando, por isso, alto grau de aceitação ${ }^{9.10}$, uma vez que leva em conta a gravidade dos sintomas anginosos, as circunstâncias clínicas de sua ocorrência e a intensidade do tratamento utilizado (tab. I). Esse autor propõe também uma classificação baseada em critérios clínicos, onde os pacientes são divididos em subgrupos de alto, intermediário e baixo risco para óbito ou IAM não fatal ${ }^{8}$ (tab. II). A classificação de Braunwald evidencia as diferenças no prognóstico dos pacientes conforme o subgrupo em que eles se situam ${ }^{7}$. Entretanto, alguns dos critérios dessa classificação não estão suficientemente apoiados em evidências clínicas disponíveis na literatura, ocorrendo também dificuldades do ponto de vista prático para a inclusão de certos pacientes em determinados subgrupos. Alguns estudos não têm encontrado boa correlação entre os diferentes subgrupos e a estimativa de risco para eventos cardíacos maiores ${ }^{11,12}$. Miltenburg-van Zijle cols. ${ }^{10}$ observaram 417 pacientes com AI e os seguiram por seis meses. Óbito e IAM ocorreram mais frequientemente nos subgrupos de angina recente e com dor em repouso, e nos pacientes com angina pós-infarto (classe C). Nesse estudo, os pacientes na classe C tiveram sobrevida significativamente menor $(80 \%)$ comparados às classes $\mathrm{A}(97 \%) \mathrm{eB}(89 \%)$. A sobrevidalivre de infartoou necessidade de intervenção foi maior na classe II (72\%), intermediáriana classe I(53\%), emenornaclasse III (35\%). A presença de alterações eletrocardiográficas, a necessidade de terapêutica antianginosa máxima, e a presença de isquemia

Tabela I - Classificação de Braunwald para angina instável ${ }^{7}$

1) Gravidade dos sintomas

Classe I - Angina de início recente (menos de 2 meses), freqüente ou de grande intensidade (3 ou mais vezes ao dia), acelerada (evolutivamente mais freqüente ou desencadeada por esforços progressivamente menores)

Classe II - Angina de repouso subaguda (1 ou mais episódios em repouso nos últimos 30 dias, o último episódio ocorrido há mais de 48h)

Classe III - Angina de repouso aguda (um ou mais episódios em repouso nas últimas 48h).

2) Circunstâncias das manifestações clínicas

Classe A - Angina instável secundária (anemia, febre, hipotensão, hipertensão não controlada, emoções não rotineiras, estenose aórtica, arritmias, tireotoxicoses, hipoxemia, etc).

Classe B - Angina instável primária.

Classe C - Angina pós- infarto do miocárdio (mais de 24h e menos de 2 semanas).

3) Intensidade do tratamento

Classe 1 - Sem tratamento ou com tratamento mínimo.

Classe 2 - Terapia antianginosa usual.

Classe 3 - Terapia máxima. 


\begin{tabular}{|c|c|c|}
\hline Risco alto & Risco intermediário & Risco baixo \\
\hline $\begin{array}{l}\text { Deve estar presente pelo menos } \\
\text { um dos seguintes achados: }\end{array}$ & $\begin{array}{l}\text { Nenhum achado de alto risco mas deve } \\
\text { ter qualquer dos seguintes: }\end{array}$ & $\begin{array}{l}\text { Nenhum achado de risco alto ou intermediário } \\
\text { mas deve ter qualquer um dos seguintes: }\end{array}$ \\
\hline $\begin{array}{l}\text { Dor em repouso prolongada } \\
(>20 \mathrm{~min}) \text { e contínua }\end{array}$ & $\begin{array}{l}\text { Angina em repouso ausente no momento da } \\
\text { avaliação mas não probabilidade baixa de DAC }\end{array}$ & $\begin{array}{l}\text { Angina aumentada em freqüência, gravidade } \\
\text { ou duração }\end{array}$ \\
\hline Edema pulmonar & $\begin{array}{l}\text { Angina de repouso (>20 min ou melhorada } \\
\text { com repouso ou nitroglicerina) }\end{array}$ & Angina desencadeada com limiar baixo de esforço \\
\hline Angina com sopro de insuficiência mitral & Angina noturna & $\begin{array}{l}\text { Angina de início recente no intervalo de } 2 \\
\text { semanas a } 2 \text { meses }\end{array}$ \\
\hline $\begin{array}{l}\text { Angina com } 3^{\text {a }} \text { bulha à ausculta } \\
\text { cardíaca ou estertores }\end{array}$ & $\begin{array}{l}\text { Angina de início recente grau III ou IV (CCS) nas últimas } \\
\text { duas semanas passadas mas baixa probabilidade de DAC }\end{array}$ & Eletrocardiograma normal ou não alterado \\
\hline Angina com hipotensão & $\begin{array}{l}\text { Ondas Q ou depressão de } \mathrm{ST} \geq 1 \mathrm{~mm} \text { em várias derivações } \\
\text { Idade }>65 \text { anos }\end{array}$ & \\
\hline $\begin{array}{l}\text { Angina em repouso com alts. } \\
\text { Dinâmicas } S T \geq 1 \mathrm{~mm}\end{array}$ & Angina com alterações dinâmicas da onda $\mathrm{T}$ & \\
\hline
\end{tabular}

recorrente ou refratária, são também fatores de risco independentes para mau prognóstico. No estudo ECLA III ${ }^{13}$, a angina refratária foi o melhor fator prognóstico independente para infarto e óbito. Os pacientes que tiveram alívio da angina após a admissão constituíram um subgrupo de risco muito baixo. Nesse subgrupo, as incidências de IAM e óbito foram, respectivamente, de $1,8 \%$, e 1,5\%; por outro lado, nos pacientes que evoluíram com angina refratária após tratamento clínico adequado, as incidências de IAM e óbito foram, respectivamente, de $15 \%$ e $14 \%$. No GUSTO IIB ${ }^{14}$, dos 3.513 pacientes com IAM não Q analisados 36\% evoluíram com isquemia recorrente, sendo que $79 \%$ responderam ao tratamento clínico. Aqueles com isquemia refratária apresentaram, em 30 dias de seguimento, incidências de reinfarto e óbito de $29 \%$ e $16 \%$, respectivamente. No subgrupo com isquemia recorrente responsiva ao tratamento clínico, essas incidências foram de $12 \%$ e $6 \%$; e no subgrupo que não apresentou isquemia, as incidências foram, respectivamente, de $3 \%$ e $4,3 \%$. Nesse mesmo estudo, incluíram-se 4.488 pacientes com AI. Desses, $34 \%$ tiveram isquemia recorrente, dos quais $82 \%$ responderam ao tratamento clínico. As incidências de IAM em até 30 dias nos subgrupos com isquemia recorrente refratária, com isquemia responsiva a tratamento clínico e sem isquemia recorrente, foram de $22 \%, 7,2 \%$ e 2,3\%, respectivamente. E as incidências de óbito foram de $8,2 \%, 2,9 \%$ e $1,6 \%$, respectiva-

\begin{tabular}{|c|c|c|c|}
\hline & Alto risco & Risco intermediário & Risco baixo \\
\hline Achados & $\begin{array}{l}\text { Deve estar presente pelo menos um } \\
\text { dos seguintes: }\end{array}$ & $\begin{array}{l}\text { Nenhum achado de alto risco mas } \\
\text { deve ter qualquer dos seguintes: }\end{array}$ & $\begin{array}{l}\text { Nenhum achado de alto risco ou intermediário } \\
\text { mas deve ter qualquer um dos seguintes: }\end{array}$ \\
\hline História & $\begin{array}{l}\text { Sintomas isquêmicos agravando-se } \\
\text { nas últimas } 48 \mathrm{~h}\end{array}$ & $\begin{array}{l}\text { Infarto ou revascularização prévios, } \\
\text { doença cerebrovascular ou periférica; } \\
\text { uso prévio de aspirina }\end{array}$ & \\
\hline $\begin{array}{l}\text { Característica } \\
\text { da dor }\end{array}$ & $\begin{array}{l}\text { Dor em repouso prolongada } \\
\text { (>20min) e contínua }\end{array}$ & $\begin{array}{l}\text { Angina em repouso }(>20 \mathrm{~min}) \text {, responsiva, } \\
\text { com probabilidade alta ou moderada de doença } \\
\text { coronariana. Angina em repouso }(<20 \mathrm{~min}) \text { ou } \\
\text { aliviada com repouso ou nitrato SL. }\end{array}$ & $\begin{array}{l}\text { Angina de início recente, classe III ou IV (CCS), } \\
\text { nas últimas } 2 \text { semanas, com probabilidade alta } \\
\text { ou moderada de doença coronariana }\end{array}$ \\
\hline Achados clínicos & $\begin{array}{l}\text { Edema pulmonar relacionado à } \\
\text { isquemia. Sopro de insuficiência } \\
\text { mitral recente ou agravado. } 3^{\text {a }} \text { bulha } \\
\text { ou estertores. Hipotensão, bradicardia, } \\
\text { taquicardia. Idade > } 75 \text { anos }\end{array}$ & Idade $>70$ anos & \\
\hline $\begin{array}{l}\text { Achados eletro- } \\
\text { cardiográficos }\end{array}$ & $\begin{array}{l}\text { Angina de repouso com alterações } \\
\text { dinâmicas do ST }(>0,05 \mathrm{mV}) \\
\text { bloqueio de ramo esquerdo recente, } \\
\text { taquicardia ventricular sustentada }\end{array}$ & $\begin{array}{l}\text { Ondas } \mathrm{T} \text { invertidas }(>0,2 \mathrm{mV}) \\
\text { Ondas } \mathrm{Q} \text { patológicas }\end{array}$ & Eletrocardiograma normal ou inalterado \\
\hline $\begin{array}{l}\text { Marcadores } \\
\text { cardíacos }\end{array}$ & $\begin{array}{l}\text { Elevação acentuada (p. ex., TnT } \\
\text { ou TnI >0,1 ng/ml) }\end{array}$ & $\begin{array}{l}\text { Elevação discreta (por ex., TnT } \\
\text { entre } 0,01 \text { e } 0,1 \mathrm{ng} / \mathrm{ml} \text { ) }\end{array}$ & Normalidade \\
\hline
\end{tabular}


mente. Os marcadores bioquímicos mais sensíveis de lesão miocárdica, como as troponinas, trouxeram subsídios importantes para o diagnóstico e o prognóstico das SIMIs sem supradesnível de ST, levando a uma adaptação, adotada pelas Diretrizes Norte-Americanas, na classificação original de Braunwald. Como se nota na tabela III, a alteração fundamental ocorreu no grupo IIIB, subdividido em IIIBtroponina negativa e IIIB-troponina positiva. Obviamente, o subgrupo IIIB-troponina positiva apresentou pior prognóstico em relação àquele com troponina negativa ${ }^{15,16}$. Recentemente, a Sociedade Espanhola de Cardiologia propôs uma classificação relativamente simples para a estratificação de risco na AI e IAM sem supradesnível do segmento $\mathrm{ST}^{17}$ (tab. IV). Na AI, os fatores de risco para eventos adversos incluem idade, dor contínua em repouso, trombos intracoronarianos ${ }^{18}$, diabetes mellitus ${ }^{5}$ e lesão coronariana complexa ou de múltiplos vasos. Mais recentemente, Antman e cols. ${ }^{19}$ encontraram os seguintes marcadores independentes de pior prognóstico em pacientes com SIMI sem supradesnível de ST: idade $\geq 65$ anos; elevação de marcadores bioquímicos; depressão do segmento $\mathrm{ST} \geq 0.5 \mathrm{~mm}$; uso de ácido acetilsalicílico nos últimos sete dias; presença de três ou mais fatores de risco tradicionais para doença arterial coronariana (DAC) (hipertensão, hipercolesterolemia, diabetes mellitus, tabagismo, história familiar); DAC conhecida; angina grave recente $(<24 \mathrm{~h})$.

\section{Angina instável no idoso}

A ONU estabelece que um indivíduo é categorizado como idoso quando tiver 60 anos ou mais nos países em desenvolvimento e 65 anos ou mais nos países desenvolvi$\operatorname{dos}^{20}$. As doenças cardiovasculares apresentam expressiva morbimortalidade na população idosa. Nos Estados Unidos, os idosos constituem 13\% da população; entretanto, são responsáveis por $65 \%$ das hospitalizações por doença cardíaca. Cerca de $85 \%$ das mortes por IAM ocorrem na população idosa ${ }^{21,22}$. Até os 65 anos, a DAC é muito mais prevalente nos homens e, a partir dos 80 anos, sua prevalência é equivalente em ambos os sexos. Os idosos com SIMI geralmente apresentam perfil de risco diferente dos não-idosos: têm maior prevalência de hipertensão arterial, diabetes mellitus, infarto do miocárdio angina, doença vascular periférica, acidente vascular cerebral (AVC), doença multiarterial e insuficiência cardíaca. Por outro lado, apresentam níveis menos elevados de colesterol e menor prevalência de tabagismo. Geralmente, o idoso se apresenta para o atendimento médico mais tardiamente após o início dos sintomas. No caso das SIMI, ao invés de dor, freqüentemente apresentam os chamados "equivalentes isquêmicos", como dispnéia, mal estar, confusão mental, síncope ou edema pulmonar, e menor elevação das enzimas cardíacas e ocorrência de IAM não $\mathrm{Q}^{23}$. Nas SIMI, os idosos têm maior incidência de complicações, o que implica na necessidade de tratamento mais intensivo. Entretanto, especialmente naqueles acima de 75 anos, freqüentemente a terapêutica mais adequada, com betabloqueador, aspirina, anticoagulante e hipolipemiante não é utilizada. Ainda são menos utilizadas, nos idosos, a terapêutica trombolítica e a revascularização por angioplastia ou por cirurgia ${ }^{24-26}$. No registro do estudo TIMI III ${ }^{27}$, com 3.318 portadores de AI e IAM não Q, 828 pacientes tinham mais de 75 anos. Esses indivíduos receberam menos terapêutica antiisquêmica, e foram menos submetidos à cinecoronariografia, em relação aos mais jovens. E embora apresentassem DAC mais grave e extensa, esses pacientes foram submetidos menos freqüentemente a procedimentos de revascularização miocárdica e tiveram mais eventos adversos em até seis semanas de evolução.

\section{História pregressa}

Pacientes submetidos a procedimentos (angioplastia comou sem stent, e/ou cirurgia de revascularizaçãomiocárdica - CRM) - A recorrência de angina após CRM ou intervenção percutânea pode significar o desenvolvimento de complicações agudas, novas lesões, trombose do stent ou reestenose. Dor torácica até $48 \mathrm{~h}$ após intervenção percutânea é indicativa de obstrução aguda, espasmo coronariano transitório, trombo não oclusivo, oclusão de ramo ou embolização distal. A dor torácica recorrente até seis meses do procedimento é provavelmente relacionada a reestenose; por outro lado, o aparecimento de angina após esse período geralmente se relaciona a nova lesão coronariana. No caso da

Tabela IV - Grupos de risco na angina instável (Sociedade Espanhola de Cardiologia)

1) Risco alto: (probabilidade de infarto agudo do miocárdio, angina refratária ou morte em 30 dias $>5 \%$ )

- Crises acompanhadas de instabilidade hemodinâmica (hipotensão, falência de bomba, disfunção mitral), arritmias, elevação do segmento ST durante a crise ou com alterações marcantes ou persistentes do segmento ST.

2) Risco baixo:

- Ausência de qualquer uma das circunstâncias anteriores.

3) Modificadores de risco:

O risco está aumentado na presença das seguintes circunstâncias:

- Antecedentes de infarto e / ou disfunção ventricular esquerda, antecedentes de revascularização miocárdica, doença vascular periférica, elevação de marcadores enzimáticos (CK-MB, troponinas).

Obs: A presença de crise prolongada de dor (>20min) tem sido incluída entre os marcadores de alto risco porém, as evidências de sua importância clínica como indicador de prognóstico imediato é baixa, se não estiver acompanhada de outros indicadores como alterações eletrocardiográficas ou hemodinâmicas. 
CRM, o aparecimento precoce de dor geralmente se associa a obstrução trombótica do enxerto; após o primeiro mês, e até o primeiro ano pós-CRM, o mecanismo geralmente é o de hiperplasia fibrosa da íntima; após esse período, é indicativo de nova lesão aterosclerótica e/ou degeneração não-trombótica do enxerto. Portanto, nos pacientes com sintomas sugestivos de AI, que já tenham sido submetidos a revascularização miocárdica, especialmente nos que se apresentam com dor em repouso, a conduta intervencionista é indicada. O registro TIMI III comparou a incidência de óbito ou infarto não fatal entre pacientes que apresentaram AI e infarto não Q com ou sem CRM prévia. Os pacientes com CRM prévia tiveram taxas mais elevadas das complicações, tanto na análise de até 10 dias pós-admissão (4,5\% no grupo com CRM prévia vs $2,8 \%$ no grupo sem CRM), quanto na análise após 42 dias $(7,7 \% \text { vs } 5,1 \% \text {, respectivamente })^{28}$.

Fatores de risco para DAC - Embora a presença dos fatores de risco hipertensão arterial sistêmica, diabetes mellitus, dislipidemia, história familiar e tabagismo estejam associados a maior probabilidade de DAC, não há correlação bem definida de sua importância na evolução clínica de pacientes admitidos com SIMI. Em alguns estudos há, inclusive, observações paradoxais indicativas de melhor evolução entre os tabagistas ${ }^{29,30}$. No estudo ESSENCE, a presença de diabetes mellitus não se mostrou como fator prognóstico de risco independente na evolução hospitalar das SIMI ${ }^{31}$. Em estudo realizado em nosso meio, que incluiu prospectivamente 449 pacientes com $\mathrm{AI}^{12}$, a análise dos fatores de risco mencionados, em relação ao desfecho conjugado de IAM e/ou morte durante o período de internação hospitalar (tempo médio de 9,5 dias), não demonstrou correlações significativas. Por outro lado, Antman e cols. ${ }^{19}$ demonstraram que a presença de três ou mais desses fatores em conjunto constitui-se em marcador independente de pior prognóstico.

\section{b) Exame físico}

Habitualmente o exame físico no contexto das SIMI é pobre, trazendo poucas informações importantes. De fato, como regra, pode-se dizer que o exame físico normal é o esperado para as situações de AI e IAM sem supradesnível de ST. A avaliação inicial do paciente consiste em um exame físico geral com medida da pressão arterial e freqüência cardíaca. Habitualmente, o paciente com dor por insuficiência coronariana apresenta-se tenso, desassossegado, fácies de dor, muitas vezes com sudorese e taquipnéico. Pacientes queixando-se de dor precordial e descontraídos, conversando sem preocupação e sem sinais de desconforto, não possuem o substrato mais adequado para se valorizar uma hipótese de SIMI. Como regra, a avaliação isolada do exame físico normal ou com discretas alterações é insuficiente para estratificação de risco, porque mesmo pacientes com lesões multiarteriais ou de tronco de coronária esquerda, podem apresentar exame físico normal ${ }^{32-35}$. No entanto, quando presentes, as alterações no exame físico podem ter implicações importantes na categorização do paciente como de alto risco. Entre esses marcadores de mau prognóstico destacam-se:

1) A presença de sopro mitral, holossistólico ou não, transitório ou não, com ou sem irradiação, com $1^{\mathrm{a}}$ bulha normo ou hipofonética. A constatação de sopro durante os episódios dolorosos ou a intensificação de sopro préexistente reforça sobremaneira o diagnóstico de isquemia ou mesmo rotura de músculo papilar. Quando existe isquemia de músculo papilar com insuficiência mitral pouco importante, via de regra obtém-se o controle clínico inicial do paciente, e a própria insuficiência mitral tende a involuir. Entretanto, a presença de rotura de músculo papilar com importante regurgitação mitral configura uma situação por vezes dramática, onde a estratificação invasiva imediata se impõe. De qualquer modo, é bem demonstrado que a presença de nova insuficiência mitral, ou piora de uma pré-existente, é um marcador de mau prognóstico em pacientes com SIMI ${ }^{17,36}$.

2) A presença, durante os episódios dolorosos, de taquicardia (freqüência cardíaca acima de $100 \mathrm{bpm}$ ), taquipnéia, hipotensão, sudorese, pulsos finos, $3^{\mathrm{a}}$ bulha e estertores pulmonares, também implica em grande área de risco, indica grande envolvimento miocárdico levando a falência cardíaca, selecionando, portanto, uma população de alto risco. O exame físico é útil não apenas na estratificação do risco, mas também no próprio diagnóstico das SIMI, quando existem dúvidas. Assim, a presença de sopro carotídeo uni ou bilateral, diminuição de pulsos periféricos, xantelasma ou xantomas e presença de aneurisma de aorta abdominal reforçam o diagnóstico de doença aterosclerótica coronariana. Assim, a presença de atrito pericárdico sugere pericardite aguda; atrito pleural sugere embolia com infarto pulmonar, diminuição de murmúrio vesicular sugerem pneumotórax; assimetria de pulsos e/ou insuficiência aórtica sugerem dissecção de aorta; clicks ou sopros meso-telessistólicos mitral sugerem prolapso de válvula mitral, sopro sistólico ejetivo paraesternal sugerem miocardiopatia hipertrófica, onda A gigante e $2^{\mathrm{a}}$ bulha hiperfonética sugerem hipertensão arterial pulmonar.

\section{História da doença atual e pregressa. Exame Físico}

\section{Sumário das recomendações}

\section{Recomendação A - Nível de evidência 2}

- Todos os pacientes devem ser avaliados e classificados em probabilidade alta, intermediária ou baixa de apresentar SIMI sem supradesnível do segmento ST (tab. V).

- Todos os pacientes devem ser estratificados e classificados em risco alto, intermediário ou baixo de desenvolver eventos cardíacos maiores (tab. VI).

\section{2) Utilização prévia de medicamentos}

A terapia prévia parece influenciar a evolução e a resposta terapêutica dos pacientes admitidos por SIMI. Os pa- 


\begin{tabular}{|c|c|c|c|}
\hline Variáveis & Probabilidade alta & Probabilidade intermediária & Probabilidade baixa \\
\hline História & $\begin{array}{l}\text { Sintomas sugestivos de isquemia miocárdica } \\
\text { prolongada ( }>20 \text { min }) \text {, em repouso, ou dor } \\
\text { similar a quadro anginoso prévio. } \\
\text { História de DAC, incluindo IAM }\end{array}$ & $\begin{array}{l}\text { Sintomas sugestivos de isquemia } \\
\text { miocárdica como principal manifestação. } \\
\text { Idade }>70 \text { anos. Diabetes mellitus. } \\
\text { Doença vascular periférica }\end{array}$ & $\begin{array}{l}\text { Sintomas não sugestivos de isquemia } \\
\text { miocárdica. Uso recente de cocaína }\end{array}$ \\
\hline Exame físico & $\begin{array}{l}\text { IM transitória, hipotensão, sudorese, } \\
\text { edema pulmonar ou estertores }\end{array}$ & & $\begin{array}{l}\text { Desconforto torácico reproduzido } \\
\text { pela palpação }\end{array}$ \\
\hline ECG & $\begin{array}{l}\text { Infradesnível do segmento } \mathrm{ST}(>0,5 \mathrm{~mm}) \\
\text { novo ou presumivelmente novo, } \\
\text { ou inversão onda } \mathrm{T}>2 \mathrm{~mm} \text { com sintomas }\end{array}$ & $\begin{array}{l}\text { Presença de ondas Q. Segmento ST ou } \\
\text { ondas T anormais antigas }\end{array}$ & $\begin{array}{l}\text { Achatamento ou inversão da onda } \mathrm{T} \\
\text { em derivações com ondas R } \\
\text { predominantes. ECG normal }\end{array}$ \\
\hline Marcadores bioquímicos & TnT, TnI ou CK-MB elevados. & Marcadores normais & Marcadores normais \\
\hline
\end{tabular}

\begin{tabular}{|c|c|c|c|}
\hline \multicolumn{4}{|c|}{ Tabela VI - Estratificação de risco de morte ou infarto em pacientes com síndrome isquêmica aguda sem supradesnível do segmento ST } \\
\hline Características & Alto & Moderado & Baixo \\
\hline História & $\begin{array}{l}\text { Idade }>75 \text { anos } \\
\text { Dor progressiva, sintomas nas últimas } 48 \mathrm{~h}\end{array}$ & $\begin{array}{l}\text { Idade } 70-75 \text { anos. } \\
\text { Infarto prévio, doença vascular } \\
\text { periférica, diabetes mellitus, } \\
\text { cirurgia de revascularização, } \\
\text { uso prévio de ácido acetilsalicílico }\end{array}$ & \\
\hline Dor precordial & Prolongada (>20min), em repouso & $\begin{array}{l}\text { Prolongada (>20min), em repouso mas } \\
\text { com alívio espontâneo ou nitrato }\end{array}$ & $\begin{array}{l}\text { Sintomas novos de angina classe } \\
\text { III ou IV da CCS nas últimas } 2 \\
\text { semanas sem dor em repouso } \\
\text { prolongada (>20 min) }\end{array}$ \\
\hline Exame físico & $\begin{array}{l}\text { Edema pulmonar, piora ou surgimento } \\
\text { de sopro de regurgitação mitral, B3, } \\
\text { hipotensão, bradicardia e taquicardia }\end{array}$ & & \\
\hline Eletrocardiograma & $\begin{array}{l}\text { Infradesnível do segmento } \mathrm{ST} \geq 0,5 \mathrm{~mm} \\
\text { (associada ou não com angina), alteração } \\
\text { dinâmica do ST, bloqueio completo de ramo, } \\
\text { novo ou presumidamente novo. Taquicardia } \\
\text { ventricular sustentada }\end{array}$ & $\begin{array}{l}\text { Inversão onda } \mathrm{T}>2 \mathrm{~mm} \text {. } \\
\text { Ondas Q patológicas }\end{array}$ & $\begin{array}{l}\text { Normal ou inalterado durante } \\
\text { o episódio de dor }\end{array}$ \\
\hline Marcadores séricos de isquemia* & Acentuadamente elevados & Elevação discreta & Normais \\
\hline
\end{tabular}

cientes admitidos com uso prévio de ácido acetilsalicílico apresentam mais freqüentemente diagnóstico final de AI do que o diagnóstico de IAM e evoluem com menor área de infarto e sem desenvolvimento de onda $\mathrm{Q}^{37-39}$. Na fase de registro do estudo TIMI (Thrombolysis in Myocardial Ischemia) III observou-se que, apesar da alta prevalência de DAC prévia em pacientes admitidos por AI ou IAM sem supradesnível de ST, apenas $45 \%$ usavam aspirina e $27 \%$ utilizavam betabloqueadores, enquanto que nitratos e antagonistas dos canais de cálcio eram empregados por cerca de $45 \%$ dos pacientes. Em análise multivariada, o uso prévio de nitratos correlacionou-se com um risco 1,6 vezes maior de óbito ou infarto no $1^{\circ}$ ano subseqüente (IC $95 \%=1,16-2,20$; $\mathrm{p}=0,004)^{40}$. Entretanto, no estudo TIMI IIIB apesar das mulheres terem recebido com maior frequiência nitratos, betabloqueadores e bloqueadores de canais de cálcio e menos aspirina, sua evolução foi semelhante à dos homens e correlacionou-se apenas a outros marcadores de gravidade da doença ${ }^{41}$. Em análise multivariada do estudo PURSUIT, os subgrupos em uso prévio de betabloqueadores, antagonistas dos canais de cálcio ou nitratos apresentaram um risco relativo de óbito ou óbito + infarto do miocárdio não-fatal de $15 \%$ a $40 \%$ maior, quando comparados com pacientes que não utilizavam esses medicamentos. Pacientes com angioplastia prévia apresentaram melhor sobrevida, mas o oposto ocorreu com aqueles submetidos à cirurgia de revascularização miocárdica ${ }^{42}$. Este mesmo tipo de interação foi observada no estudo PRISM-PLUS. A cirurgia de revascularização prévia aumentou em $46 \%$ e a angioplastia reduziu em $32 \%$ a incidência de trombo residual após a infusão de tirofiban, sendo que o efeito benéfico do tirofiban foi significativamente maior entre os pacientes em terapia prévia com betabloqueadores. Constatou-se ainda uma tendência à melhor evolução entre os usuários de ácido acetilsalicílico ${ }^{43,44}$. Em análise retrospectiva dos estudos TIMI IIB e ESSENCE, observou-se que o uso prévio de ácido acetilsalicílico representou importante fator de risco para eventos isquêmicos ${ }^{19}$. 


\section{Utilização prévia de medicamentos}

\section{Sumário das evidências}

\section{Nível de evidência 2}

- Uso prévio de acido acetilsalicílico é um fator de maior gravidade em pacientes com ou suspeita de síndromes isquêmicas miocárdicas instáveis sem supradesnível do segmento ST.

- Uso prévio de betabloqueadores, nitratos e bloqueadores dos canais de cálcio está associado com pior evolução.

\section{3) Eletrocardiograma}

Dados de necropsia têm demonstrado que o eletrocardiograma (ECG) não tem suficiente sensibilidade e especificidade para permitir uma diferenciação confiável entre infarto transmural ou subendocárdico, pois pacientes com infartos transmurais podem não desenvolver ondas $Q$, e ondas $Q$ podem ser vistas em pacientes com achado de infarto subendocárdico (não transmural) á autopsia ${ }^{45}$. Entretanto, a categorização de pacientes em grupos com ondas $Q$ e sem ondas Q baseada no ECG é útil, porque os IAMs com ondas Q são em geral associados a maior dano miocárdico, maior tendência para expansão e remodelamento do infarto e, consequentemente, maior mortalidade ${ }^{46}$. Onda Q no ECG significa atividade elétrica anormal, mas nãoé sinônimo de dano miocárdico irreversível. Por outro lado, a ausência de onda $Q$ pode simplesmente refletir a falta de sensibilidade do ECG convencional de 12 derivações, especialmente na zona posterior do ventrículo esquerdo. Em casos de IAM subendocárdicos confirmados à necropsia, são observadas depressões do segmento ST e/ou alterações na onda T em somente $50 \%$ das vezes ${ }^{47}$. O IAM sem elevação do segmento ST tem maior incidência de obstrução subtotal do vasocoronarianoculpado, e de maior fluxo colateral para azona infartada. Além disso, os pacientes são, na média, maisidosos, e apresentam maior prevalênciaIAM prévio ${ }^{45}$. OIAMnão Q apresenta várias anormalidades aoECG. Alterações no segmentoST e na onda T não são específicas e podem ocorrer numa série de condições que incluem: angina estável e instável, hipertrofia ventricular, pericardite agudae crônica, miocardite, repolarização precoce, alteração eletrolítica, choque, desordem metabólica e efeitodigitálico. OECG seriado pode terum considerável valorna diferenciação dessas condições do IAM não Q. Alterações transitórias favorecem angina ou distúrbios eletrolíticos, enquanto que alterações persistentes favorecem IAM, se outras causas, como choque, digital ou desordens metabólicas, puderem ser descartadas. Em última análise, o diagnóstico de IAM não transmural baseia-se mais na combinação de achados clínicose na elevação das enzimas séricas do que noECG. Pacientes com IAM não Q podem se apresentar com depressão do segmento ST, inversão de onda T ou mesmo sem uma anormalidade bem definidanoECGde 12 derivações.

\section{Angina instável}

Desvios transitórios do segmento ST (depressão ou elevação) e/ou inversão das ondas T ocorrem comumente na AI, mas não sempre. Alterações dinâmicas no segmento ST (depressão ou elevação) ou inversões da onda T durante episódio doloroso, resolvidas pelo menos parcialmente quando os sintomas são aliviados, são importantes marcadores de prognóstico adverso, isto é, subseqüente IAM ou morte ${ }^{48}$. Uma manifestação eletrocardiográfica sutil e infreqüente de AI é a presença de onda U invertida transitória ${ }^{49}$. Pacientes com alterações do ST em derivações ânteroseptais, freqüentemente são portadores de estenose significativa da artéria coronária descendente anterior e constituem um grupo de alto risco ${ }^{50}$. A acurácia diagnóstica de um ECG anormalé aumentada, quando se pode ter um traçado de ECG prévio para comparação. Em geral, essas alterações de ECG se revertem completamente ou parcialmente com o alívio de dor. A persistência dessas alterações por mais de $12 \mathrm{~h}$ pode sugerir IAM não Q. Se o paciente tem um histórico típico de angina estável ou DAC estabelecida (IAM prévio, documentação angiográfica de lesão coronariana ou teste ergométrico prévio positivo), o diagnóstico de AI pode ser baseado nos sintomas clínicos, mesmo na ausência de alterações eletrocardiográficas. É no subgrupo de pacientes sem evidências de DAC prévia e sem alterações de ECG associadas à dor, que o diagnóstico se torna mais difícil.

\section{Monitorização contínua do ECG}

A dor torácica isquêmica nãoé um marcador confiável ou sensível de isquemia aguda miocárdica transitória. Episódios de redução primária do fluxo coronariano podem se associar a alterações variáveis e mínimas do ECG, que precedem os sintomas de dor ou desconforto. Antes do uso disseminado da aspirina e da heparina constatou-se, por monitorização contínua do ECG, que $60 \%$ dos pacientes com AI apresentavam episódios assintomáticos de depressão do segmento $\mathrm{ST}^{51}$. Esses episódios diminuíram para níveis entre 5\% e 20\%, mais recentemente, com o uso de aspirina e heparina ${ }^{50}$. A presença de isquemia ao Holter é um excelente marcador de evolução clínica desfavorável, tanto a curto quanto a longo prazo ${ }^{52-54}$.

\section{Angina variante de Prinzmetal}

O dado mais característico no diagnóstico de angina variante está na elevação do segmento ST na presença de dor, e regressão do supra com a regressão do sintoma. Em alguns pacientes, episódios de depressão do ST podem seguir os episódios de elevação do ST, e são associados com alterações da onda T. A alternância do segmento ST e da onda $T$ é o resultado do retardo isquêmico na condução do estímulo, e pode estar associada a arritmias ventriculares potencialmente letais. Por outro lado, crescimento da onda $R$ pode estar associado à ocorrência de arritmias ventriculares ${ }^{50}$. Muitos pacientes exibem múltiplos episódios de elevação assintomática do segmento ST (isquemia silenciosa). Os desvios do segmento ST podem estar presentes em qualquer derivação. A presença concomitante de elevação do 
ST nas derivações an teriores e inferiores (refletindo isquemia extensa), associa-se a maior risco de morte súbita ${ }^{50}$. Distúrbios transitórios da condução do estímulo podem ocorrer durante episódios de isquemia. A atividade ectópica ventricular é mais comum durante episódios mais longos de isquemia e, freqüentemente, associada a alterações do segmento ST e da onda T, guardando relação com pior prognóstico. Ronan e cols. ${ }^{54}$ demonstraram, que pacientes com ECG inicial normal ou com alterações mínimas e não específicas, apresentaram taxas de 3\% de IAM e 6\% de mortalidade, saltando para $12 \%$ em pacientes já com evidência inicial de IAM no ECG. Dos 1.009 pacientes com IAM, $80 \%$ apresentaram onda $\mathrm{Q}$, novas alterações do segmento ST ou inversão de onda T, e $10 \%$ apresentavam bloqueio de ramo esquerdo (BRE) ou ritmo de marcapasso, dificultando o diagnóstico eletrocardiográfico. Os restantes $10 \%$ tinham ECG normal ou com alterações mínimas não específicas. Esses dados apóiam o estudo de Brush e cols. ${ }^{55}$, que demonstraram que as complicações com risco de vida tinham 23 vezes mais chance de ocorrer em pacientes com evidências de infarto, isquemia, hipertrofia de ventrículo esquerdo, BRE ou ritmo de marcapasso, em relação a pacientes com ECG normal ou com alterações inespecíficas. Novos e aperfeiçoados métodos de aquisição e de interpretação computadorizada do ECG têm melhorado a utilidade desse método em acessar o sinal elétrico cardíaco ${ }^{56}$.

\section{ECG de 12 derivações seriado}

Cerca de $50 \%$ dos pacientes com IAM apresentam-se no Pronto Atendimento com ECG de 12 derivações normal ou não diagnóstico. Durante a fase inicial de hospitalização, cerca de $20 \%$ desses pacientes desenvolvem alterações consistentes com lesão transmural. Assim, o ideal nesta fase inicial é realizar ECGs seriados. Usando monitorização seriada do ST, Krucoff e cols. ${ }^{56}$, analisando critérios de reperfusão ao ECG (comprovada angiograficamente) demonstraram sensibilidade de $89 \%$ e especificidade de $82 \%$. Uma outra forma de medir a onda elétrica cardíaca integra 22 eletrodos de superfície e um programa de computação, no sentido de evidenciar a variação do sinal em cada derivação por amostra de alta freqüência. Com tal metodologia, Justis e Hession ${ }^{57}$ notaram que pacientes com isquemia por oclusão coronariana parcial parecem ter variabilidade de onda elétrica emanando do miocárdio afetado. A sensibilidade para IAM foi de $83 \%$, comparado com o ECG convencional, enquanto que a especificidade foi reduzida para $76 \%$, comparada com $99 \%$ do ECG convencional.

\section{Prognóstico}

No estudo GUSTO IIa, o ECG de apresentação dos pacientes com SIMI teve importância prognóstica em relação à mortalidade precoce ${ }^{53}$.

BRE, hipertrofia ventricular esquerda ou ritmo de marcapasso - mortalidade de $11,6 \%$; depressão do segmento ST $-8 \%$; elevação do segmento ST $-7,4 \%$; inversão da onda T ou ECG normal 1,2\%; no estudo complementar com ECG do Registro TIMI III ${ }^{45}$, em 1.416 pacientes com AI ou IAM não Q observaram-se as seguintes formas de apresentação do ECG: desvio do segmento ST $\geq 1 \mathrm{~mm}$ em 14,3\%; BRE em 19\%; inversão isolada da onda T em 21,9\%; sem essas alterações no ECG-54,9\%.

As seguintes conclusões foram relatadas: pacientes com desvio de $\mathrm{ST} \geq 1 \mathrm{~mm}$ na AI tinham pior prognóstico; os pacientes com desvio de $\mathrm{ST} \geq 1 \mathrm{~mm}$ eram mais velhos; os pacientes com inversão isolada da onda T tinham características semelhante àqueles sem alterações no ECG; doença multiarterial foi encontrada em $66 \%$ dos pacientes com alteração de ST, comparado com $40 \%$ naqueles sem alteração de ECG ( $\mathrm{p}<0,001)$; ausência de estenose coronariana significante varia de $10 \%$, em pacientes com alterações de ST, para $29 \%$ em pacientes sem alterações do ECG, e $34 \%$ em pacientes com BRE; a incidência de IAM não Q varia de $19 \%$ em pacientes sem alterações no ECG inicial, para $39 \%$ em pacientes com alterações do segmento $\mathrm{ST} \geq 1 \mathrm{~mm}$ ( $\mathrm{p}<0,001)$. Nos pacientes com BRE foi de $32 \%$, e naqueles com inversão da onda T isolada, de $31 \%$. A média geral foi de $24,8 \%$; a mortalidade foi de $1 \%$ no hospital e de $2 \%$ a $5 \%$ em 42 dias. Em um ano a mortalidade se elevou para 9,8\% nos pacientes com alterações de $\mathrm{ST} \geq 1 \mathrm{~mm}$, comparado com $5,5 \%$ para pacientes com alterações na onda T ou sem alterações no ECG $(\mathrm{p}<0,001)$ (tabs. VII e VIII).

Graus de alteração do segmento ST e evolução (tab. IX): Um total de 187 pacientes (13\% do grupo total) tinham alterações do segmento $\mathrm{ST} \geq 0,5 \mathrm{~mm}^{45}$. O resultado clínico na evolução foi similar ou até mesmo pior para os pacientes com ST desviado em 0,5 mm, em relação àqueles com desvio $\geq 1 \mathrm{~mm}$.

\section{Análise multivariada (tab.X)}

Foram identificadas sete variáveis como fatores prognósticos independentes de morte ou de IAM em um ano. As duas variáveis relacionadas ao ECG foram o BRE e o desvio do ST $\geq 0,5 \mathrm{~mm}$ (tab. IV) ${ }^{45}$. Em outro modelo, o desvio de ST $\geq 1 \mathrm{~mm}$ foi um fator prognóstico independente, mas com poder discriminatório menor, em relação ao desvio de $0,5 \mathrm{~mm}$. Usando o critério de BRE ou alteração do $\mathrm{ST} \geq 0,5 \mathrm{~mm}$ a taxa de morte ou de IAM em um ano foi de $15,8 \%$. O código de Minnesota não foi utilizado nesse estudo pois foi considerado complexo e sem aplicação clínica. Por outro lado, pacientes com IAM com depressão do segmento ST representavam $11 \%$ dos casos do estudo de Mahon e cols. ${ }^{58}$ que utilizou o Código de Minnesota. Os pacientes com depressão do segmento ST eram mais idosos, em relação ao restante do grupo, e apresentavam maior prevalência de IAM prévio (40\% vs $25 \%$ ) e doença multiarterial ( $71 \%$ vs $47 \%$ ). O grupo com depressão de ST apresentou maior mortalidade hospitalar (31\% vs 17\%, p<0,01) e após 36 meses (56\% vs 32\%, $\mathrm{p}<0,001)$. Cohen e cols. ${ }^{59,60}$ verificaram, em pacientes com IAM Q e AI, que a depressão de segmento ST tinha valor prognóstico para óbito ou IAM. Farkouh e cols. ${ }^{61}$, com- 


\begin{tabular}{|c|c|c|c|c|c|c|c|}
\hline \multicolumn{8}{|c|}{ Tabela VII - Eletrocardiograma e evolução intra-hospitalar ${ }^{14}$} \\
\hline Fatores & $\begin{array}{c}\text { Todos } \\
\text { N (1416) }\end{array}$ & $\begin{array}{c}\text { BRE } \\
\text { N (127) }\end{array}$ & $\begin{array}{c}\text { Alt } S T \geq 1 \mathrm{~mm} \\
\quad \mathrm{~N}(202)\end{array}$ & $\begin{array}{c}\text { Alt } \mathrm{T} \text { isolada } \\
\quad \mathrm{N}(310)\end{array}$ & $\begin{array}{c}\text { Sem alt. ECG } \\
\quad \mathrm{N}(777)\end{array}$ & $\begin{array}{c}\mathrm{p} \\
\operatorname{dos} 4\end{array}$ & $\begin{array}{l}\text { Alt ST } \\
(+ \text { ou }-)\end{array}$ \\
\hline Cateterismo realizado & 62,4 & 45,4 & 66,6 & 65,6 & 62,5 & 0,003 & 0,03 \\
\hline Vaso 0 & 24,0 & 33,5 & 10,4 & 16,7 & 29,1 & & \\
\hline Vaso 1 & 30,1 & 29,6 & 23,3 & 32,9 & 30,7 & $<0,001$ & $<0,001$ \\
\hline Vaso 2 & 22,2 & 14,7 & 32,7 & 25,8 & 19,1 & & \\
\hline Vaso 3 & 23,7 & 22,2 & 33,9 & 24,6 & 21,1 & & \\
\hline Lesão tronco & 7,4 & 4,7 & 15,3 & 7,6 & 5,7 & 0,016 & 0,019 \\
\hline ATC & 20,3 & 5,8 & 23,5 & 22,4 & 20,6 & 0,045 & 0,582 \\
\hline Cirurg - RM & 11,5 & 7,6 & 21,8 & 14,6 & 8,7 & $<0,001$ & $<0,001$ \\
\hline \multicolumn{8}{|l|}{ Evento hospitalar } \\
\hline Morte & 0,6 & 03 , & 1,4 & 1,0 & 0,4 & 0,112 & 0,033 \\
\hline IAM & 1,4 & 0,4 & 1,7 & 1,3 & 1,5 & 0,4 & 0,3 \\
\hline Morte ou IAM & 1,8 & 0,8 & 2,6 & 1,6 & 1,6 & 0,2 & 0,09 \\
\hline Isquemia c/ alt. ECG & 9,5 & 5,6 & 18,2 & 11,4 & 7,5 & $<0,001$ & $<0,001$ \\
\hline Morte/IAM/Alt ECG & 10,5 & 6,4 & 20,2 & 12,6 & 8,3 & $<0,001$ & $<0,001$ \\
\hline Isquemia s/ alt. ECG & 31,6 & 37,0 & 31,2 & 31,6 & 31,0 & 0,3 & 0,93 \\
\hline
\end{tabular}

\begin{tabular}{|c|c|c|c|c|c|c|c|}
\hline \multicolumn{8}{|c|}{ Tabela VIII - Eventos em 42 dias e um ano ${ }^{14}$} \\
\hline & $\begin{array}{l}\text { Todos Pac. } \\
(\mathrm{n}=1416)\end{array}$ & $\begin{array}{c}\text { BRE } \\
(n=127)\end{array}$ & $\begin{array}{l}\text { Alt } \mathrm{ST} \geq 1 \mathrm{~mm} \\
\quad(\mathrm{n}=202)\end{array}$ & $\begin{array}{l}\text { Alt } \mathrm{T} \text { isolada } \\
\quad(\mathrm{n}=310)\end{array}$ & $\begin{array}{l}\text { Sem alt ECG } \\
\qquad(n=777)\end{array}$ & $\begin{array}{c}\mathrm{p} \\
4 \text { vias }\end{array}$ & $\begin{array}{l}\text { Alt St x } \\
\text { s/Alt ST }\end{array}$ \\
\hline \multicolumn{8}{|l|}{42 dias } \\
\hline Morte & 2,4 & 5,2 & 2,5 & 2,8 & 1,8 & 0,198 & 0,091 \\
\hline IAM & 2,2 & 1,8 & 1,5 & 2,4 & 2,3 & 0,725 & 0,41 \\
\hline Morte ou IAM & 4,0 & 6,6 & 3,6 & 3,7 & 3,7 & 0,443 & 0,123 \\
\hline Re-hospitalização por angina & 5,3 & 6,7 & 7,3 & 5,6 & 4,5 & 0,13 & 0,032 \\
\hline Morte/IAM isquemia recorrente & 16,1 & 14,2 & 23,6 & 17,9 & 13,9 & $<0,001$ & $<0,001$ \\
\hline ATC & 20,7 & 3,4 & 24,9 & 23,9 & 20,4 & 0,024 & 0,538 \\
\hline Cir. RM & 13,4 & 10,5 & 25,8 & 16,3 & 10,7 & $<0,001$ & $<0,001$ \\
\hline ATC ou Cir.RM & 33,4 & 12,6 & 50,8 & 39,3 & 30,4 & $<0,001$ & 0,001 \\
\hline \multicolumn{8}{|l|}{ Um ano } \\
\hline Morte & 7,2 & 18,2 & 9,8 & 5,6 & 5,5 & $<0,001$ & $<0,001$ \\
\hline IAM & 4,0 & 6,3 & 6,0 & 3,7 & 3,5 & 0,446 & 0,13 \\
\hline Morte/IAM & 9,5 & 22,9 & 11,0 & 6,8 & 8,2 & $<0,001$ & 0,001 \\
\hline Re-hospitalização por angina & 15,9 & 13,4 & 17,7 & 16,8 & 15,4 & 0,753 & $0,293]$ \\
\hline Morte/IAM ou isquemia recorrente & 28,3 & 34,0 & 36,1 & 30,4 & 25,5 & 0,003 & 0,001 \\
\hline ATC & 22,9 & 7,6 & 25,3 & 26,2 & 22,8 & 0,037 & 0,621 \\
\hline Cir. RM & 16,1 & 10,8 & 27,2 & 17,9 & 14,3 & 0,004 & 0,002 \\
\hline ATC ou Cir. RM & 36,4 & 16,6 & 51,1 & 42,3 & 33,9 & $<0,001$ & 0,001 \\
\hline
\end{tabular}

\begin{tabular}{|c|c|c|c|c|c|}
\hline \multicolumn{6}{|c|}{ Tabela IX - Grau de desvio de ST e evolução ${ }^{14}$} \\
\hline & \multicolumn{4}{|c|}{ Grau de desvio ST } & \multirow[b]{2}{*}{$\mathrm{p}$} \\
\hline & $\begin{array}{l}\geq 2 \mathrm{~mm} \\
(\mathrm{n}=63)\end{array}$ & $\underset{(\mathrm{n}=139)}{\operatorname{1mm}}$ & $\begin{array}{l}0,5 \mathrm{~mm} \\
(\mathrm{n}=187)\end{array}$ & $\begin{array}{l}\text { Nenhum } \\
(\mathrm{n}=900)\end{array}$ & \\
\hline Óbito em 42 dias & 0,8 & 3,0 & 7,1 & 1,1 & 0,002 \\
\hline Óbito ou IAM 42 dias & 2,8 & 3,4 & 10,7 & 2,4 & 0,001 \\
\hline $\begin{array}{l}\text { Óbito/IAM/Isquemia } \\
\text { recorrente } 42 \text { dias }\end{array}$ & 19,5 & 22,7 & 25,8 & 13,0 & $<0,001$ \\
\hline Óbito ou IAM em 1 ano & 14,9 & 9,7 & 16,3 & 6,1 & $<0,001$ \\
\hline
\end{tabular}

parando 424 pacientes admitidos em unidade da dor torácica com pacientes internados em hospital, não encon-

\begin{tabular}{|llr|}
\hline \multicolumn{3}{|c|}{$\begin{array}{c}\text { Tabela X - Análise multivariada. Fatores prognósticos (óbito ou } \\
\text { IAM em um ano com 1.411 pacientes) 45 }\end{array}$} \\
\hline Característica & $\mathrm{RR}(95 \%$ IC) & $\mathrm{P}$ \\
\hline Idade (década) & $1,43(1,26-1,61)$ & $<0,001$ \\
Trombólise - semana prévia & $9,40(2,94-30,01)$ & $<0,001$ \\
BRE & $2,80(1,81-4,32)$ & $<0,001$ \\
ST $\geq 0,5 \mathrm{~mm}$ & $2,45(1,74-3,45)$ & $<0,001$ \\
Outra doença maior & $1,94(1,33-2,84)$ & $<0,001$ \\
Exclusão TIMI IIIb & $5,61(1,74-18,06)$ & 0,004 \\
Nitrato - semana prévia & $1,60(1,16-2,20)$ & 0,004 \\
\hline BRE- bloqueio de ramo esquerdo. \\
\hline
\end{tabular}

traram diferenças significativas nos achados de ECG entre os dois grupos. 


\section{Arritmias}

Paciente com taquicardia (frequiência cardíaca acima de 100 bpm) e com bradicardia (freqüência cardíaca $<50 \mathrm{bpm}$ ) tem pior prognóstico. Extrapolando os dados do estudo GUSTO I, em pacientes com IAM com onda $\mathrm{Q}^{62}$, a fibrilação atrial, embora não seja comum no IAM, é um marcador de pior prognóstico. A taquicardia e a fibrilação ventricular (FV) ocorrem em até $20 \%$ de pacientes com IAM e são associadas a pior prognóstico. No estudo GUSTO I, 10,2\% tinham taquicardia ventricular sustentada, FV ou ambas. Idade avançada, hipertensão arterial, IAM prévio, IAM de parede anterior e fração de ejeção diminuída, foram associados a risco maior de taquicardia ventricular sustentada e FV. Essas arritmias ventriculares associaram-se com maior mortalidade hospitalar, nos acompanhamentos de 30 dias e um ano ${ }^{63}$.

\section{Eletrocardiograma. Sumário das evidências e das recomendações}

\section{Recomendação A}

- Todos os pacientes com, ou suspeita de SIMI, devem realizarECG. Idealmente oECG deve ser realizadoem até 10min após a chegada ao hospital (nível de evidência 2).

- O ECG deve ser repetido, nos casos não diagnósticos, pelo menos uma vez, em até 6 h (nível de evidência 3).

Obs.: na presença de ECG prévio, o mesmo deve ser utilizado para comparação. Qualquer alteração nova ou presumidamente nova do segmento ST ou onda T está associada a maior chance de doença coronariana. Presença de infradesnível de ST $>0,5 \mathrm{~mm}$ está associada a alto risco de eventos cardíacos em pacientes com SIMI. Indivíduos com inversão de onda $\mathrm{T}>2 \mathrm{~mm}$ ou ondas Q patológicas, apresentam risco intermediário de eventos (nível de evidência 2). Alterações dinâmicas do segmento ST (depressão ou elevação do ST $\geq$ $1 \mathrm{~mm}$, ou inversões da onda $\mathrm{T}$ que se resolvem pelo menos parcialmente quando os sintomas são aliviados, são marcadores de prognóstico adverso (nível de evidência 1).

Arritmias: taquicardia(FC>100bpm), bradicardia(FC $<50 \mathrm{bpm}$ ) ou bloqueio completo de ramo novo ou presumidamente novo, são marcadores de pior prognóstico. Presença de ondas Q patológicas novas ou antigas no ECG implicam em risco intermediário (nível de evidência 2).

\section{4) Marcadores bioquímicos de lesão miocárdica e isquemia}

Marcadores bioquímicos são úteis para auxiliar tanto no diagnóstico quanto no prognóstico de pacientes com SIMI. Tradicionalmente, eram mensuradas as enzimas creatinoquinase (CK) total e desidrogenase láctica (LDH). Entretanto, atualmente outros marcadores bioquímicos, constituintes protéicos da célula muscular e sem função enzimática, também têm sido utilizados para este propósito. Portanto, o conjunto destas macromoléculas liberadas para a corrente sangüínea tem sido denominado de marcadores bioquímicos de lesão miocárdica. Quando as células miocárdicas são irreversivelmente danificadas, suas membranas celulares per- dem a integridade, as enzimas se difundem no interstício e vão para os linfáticos e capilares. Se a liberação de proteínas é sempre um indicador de lesão irreversível permanece ainda um tema controverso. Existem evidências, em modelos animais, de que a atividade elevada de CK no plasma não ocorre com dano reversível miocárdico como o induzido por isquemia, mas somente ocorre quando a lesão miocárdica é irreversível, como no infarto. Por outro lado, estudos recentes sugerem que dano miocárdico reversível libera pequenas quantidades de proteínas citoplasmática solúveis (incluindo as troponinas solúveis). Após a lesão miocárdica, a cinética dos marcadores depende de diversos fatores: o compartimento intracelular das proteínas, o tamanho das moléculas, o fluxo regional linfático e sangüíneo e a taxa de depuração do marcador. São estes fatores, em conjunto com as características de cada marcador, que diferenciam o desempenho diagnóstico de cada um para IAM ${ }^{64}$. Em pacientes que se apresentam com quadro sugestivo de SIMI, nos quais o diagnóstico de infarto do miocárdio não está estabelecido, os marcadores bioquímicos são úteis para confirmar o diagnóstico de infarto. Além disso, os mesmos fornecem importantes informações prognósticas, na medida em que existe uma direta associação entre a elevação dos marcadores séricos e o risco de eventos cardíacos a curto e médio prazos ${ }^{65}$.

\section{Creatinoquinase, suas isoenzimas e isoformas}

A enzima creatinoquinase $\mathrm{MB}$ (CK-MB) é o marcador tradicionalmente utilizado, embora tenha diversas limitações conhecidas. Idealmente, a CK-MB deve ser mensurada através de imunoensaio para dosagem da sua concentração no plasma (CK-MB massa) ao invés da sua atividade. Esta mudança no padrão aferição se deve, em parte, a estudos que demonstraram uma maior sensibilidade e especificidade para IAM com o uso de CK-MB massa ${ }^{66}$. Metanálises de diagnósticos retrospectivos de infarto do miocárdio demonstram sensibilidade de $97 \%$ e especificidade de $90 \%$ para diagnóstico de IAM ${ }^{67}$. A CK-MB massa apresenta, como principal limitação, sua elevação após dano em outros tecidos não-cardíacos (falso-positivos), especialmente lesão em músculo liso e esquelético. As subformas da CKMB têm surgido como marcadores precoces (menos de $6 \mathrm{~h}$ ) de lesão miocárdica. Alguns estudos demonstraram que uma relação de CK-MB2/MB1 é mais sensível para o diagnóstico de infarto do miocárdio na admissão e 6h após, quando comparado com CK total, CK-MB atividade, CKMB massa e mioglobina ${ }^{68,69}$. Uma limitação das subformas de CK-MB é sua menor especificidade e a dificuldade técnica para reprodução dos resultados, justificando sua pequena penetração no mercado.

\section{Troponinas}

As troponinas são proteínas do complexo de regulação miofibrilar, que não estão presente no músculo liso. Existem três subunidades: troponina $\mathrm{T}$, troponina I e troponina C. A troponina $\mathrm{C}$ é co-expressa nas fibras musculares esque- 
léticas de contração lenta e não é considerada como um marcador específico cardíaco. Na última década foram desenvolvidas técnicas de imunoensaios com anticorpos monoclonais específicos para troponinas T cardíaca ( $\mathrm{TnTc}$ ) e troponina I cardíaca (TnIc). Os novos ensaios para troponinas cardíacas (TnIc e TnTc) têm sido comparados com CKMB massa em diversos estudos. Acredita-se que esses ensaios têm duas principais vantagens em relação à CK-MB: 1) maior especificidade para lesão miocárdica, na medida em que a CK-MB é encontrada em tecidos não cardíacos, e 2) habilidade em detectar pequenas quantidades de lesão miocárdica, não detectável pelos ensaios de CK-MB. A maioria dos estudos demonstra que troponinas e CK-MB massa têm sensibilidade semelhante para diagnóstico de IAM nas primeiras $24 \mathrm{~h}$, sempre ressaltando um número elevado de pacientes com TnTc e TnIc anormal entre os pacientes sem infarto. Metanálises demonstraram que TnIc tem sensibilidade e especificidade clínica para o diagnóstico de IAM na ordem de $90 \%$ e $97 \%$, respectivamente. Levando-se em consideração as limitações em se estabelecer um padrão-ouro para o diagnóstico de infarto, estima-se que a CK-MB massa e as troponinas tenham um desempenho diagnóstico semelhante para o infarto nas primeiras $12 \mathrm{~h}$ a $24 \mathrm{~h}$ de evolução. As troponinas cardíacas permanecem elevadas por tempo mais prolongado portanto, após $24 \mathrm{~h}$ do início dos sintomas, TnIc e TnTc são significativamente mais sensíveis que CKMB massa. É estimado que em torno de $30 \%$ a $40 \%$ dos pacientes com AI apresentem troponinas elevadas. São escassas as evidências histológicas para definir se este grupo de pacientes tem efetivamente necrose miocárdica. Existe uma tendência forte, na comunidade científica internacional, em acreditar que indivíduos com troponinas elevadas e CK-MB normal tenham "microinfartos" ou algum grau de necrose. Os dados que auxiliam a resolver esse impasse são os inúmeros estudos prospectivos demonstrando que pacientes sem diagnóstico de infarto mas com troponinas elevadas têm um risco maior de morte e de outros eventos cardiovasculares maiores a curto e a médio prazos, semelhantes àquele de pacientes com infarto do miocárdio sem onda $Q^{70,71}$. Elevações desses marcadores são fatores indicativos de pior prognóstico após ajuste para características clínicas, ECG e teste de esforço ${ }^{65,70,71}$. Embora as troponinas sejam importantes fatores prognósticos de risco, elas não devem ser utilizadas isoladamente para definir o risco de pacientes com SIMI. A maior parte dos pacientes que desenvolve complicações apresenta troponinas normais. Nenhum marcador bioquímico é perfeitamente acurado para determinar dano miocárdico ${ }^{72}$. Por outro lado, apesar de qualquer aumento acima de três desvios padrões do normal ser considerado indicativo de lesão ao músculo cardíaco, estas elevações não são sinônimos de lesão isquêmica cardíaca. Níveis anormais de marcadores bioquímicos, incluindo as troponinas, não traduzem obrigatoriamente diagnóstico de IAM ${ }^{70,73}$.

As troponinas também têm valor na avaliação de paci- entes com alterações isquêmicas no ECG ou com clínica sugestiva de dor anginosa (tabs. V e VI). Pacientes com troponinas elevadas acham-se em risco mais elevado de ter eventos cardíacos em um curto período de tempo e estudos preliminares sugerem que eles podem se beneficiar de um manejo mais agressivo.

\section{Mioglobina}

A mioglobina é um marcador muito precoce de necrose miocárdica, precedendo a liberação de CK-MB em $2 \mathrm{~h}$ a $5 \mathrm{~h}$. Como é uma molécula pequena, é liberada na circulação dentro de $1 \mathrm{~h}$ após a morte da célula miocárdica, com valores de pico atingidos em 5 h a $12 \mathrm{~h}$. A mioglobina não é específica para o músculo cardíaco e pode ser liberada em diversas condições, que incluem dano muscular esquelético, distrofia muscular, insuficiência renal, uremia grave, choque, trauma e após cirurgias. Por não ser um marcador cardioespecífico, a principal vantagem deste marcador parece ser na detecção de IAM nas primeiras horas de evolução. Entretanto, um valor alterado nas primeiras horas do início dos sintomas não determina definitivamente infarto agudo, necessitando confirmação de outros marcadores. Por outro lado, pela elevada sensibilidade, precocemente, mioglobina normal pode auxiliar a afastar o diagnóstico de infarto (elevado valor preditivo negativo) ${ }^{64,74}$. Embora estes marcadores (CKMB massa, troponinas e mioglobina) tenham se mostrado importantes fatores prognósticos de eventos cardíacos a curto e a longo prazos, eles não necessitam ser mensurados em conjunto em todos os pacientes com suspeita de SIMI $^{75}$. A mioglobina é um marcador precoce que pode auxiliar em algumas situações específicas quando o paciente apresenta-se prematuramente à emergência (antes de 4h do início dos sintomas) e as troponinas substituem a LDH para detecção de infarto com mais de $24 \mathrm{~h}$ a sete dias de evolução.

Nota: Diagnóstico de IAM pós-intervenção percutânea: aumento da troponina (acima do percentil 99, uma medida no período de 24h) ou aumento CK-MB (acima do percentil 99) em duas amostras consecutivas ou 2 vezes o valor de referência após procedimento.

\section{Marcadores bioquímicos. Sumário das evidên- cias e das recomendações}

\section{Recomendação A}

- Marcador(es) bioquímicos de lesão miocárdica devem ser mensurados em todo paciente com suspeita de SIMI. $\mathrm{O}(\mathrm{s})$ marcador(es) devem ser medidos na admissão e repetidos pelo menos uma vez, 6-9h após (preferencialmente $9-12 \mathrm{~h}$ após início dos sintomas), caso a primeira dosagem seja normal ou discretamente elevada (nível de evidência 2).

- CK-MB massa e troponinas são os marcadores bioquí- 
micos de escolha (nível de evidência 1).

Obs: Idealmente, caso disponíveis, troponina e/ou CK-MB massa devem ser dosadas em todos pacientes com suspeita clínica de SIMI.

\section{Recomendação B1}

- CK-MB atividade isolada ou em associação com CK total pode ser utilizada se CK-MB massa ou troponina não estiverem disponíveis (nível de evidência 2).

- Nos pacientes com outros fatores de alto risco, bem como em grupos de muito baixo risco, as troponinas podem ser dispensáveis (nível de evidência 2).

\section{Recomendação B2}

- Para pacientes que chegam precocemente à emergência (antes de 6h do início dos sintomas), mioglobina e subformas de CK-MB podem ser consideradas em adição a um marcador mais tardio (CK-MB ou troponina) (nível de evidência 2).

\section{Recomendação C}

- Utilização da desidrogenase lática (LDH), aspartato aminotransferase (TGO) para detecção de necrose miocárdica em pacientes com suspeita de SIMI (nível de evidência 1).

\section{5) Ergometria}

O teste ergométrico (TE) precoce constitui um conceito recente na avaliação de pacientes com SIMI, quando estabilizados, auxiliando na estratificação do prognóstico e na conduta terapêutica. Consiste em procedimento seguro, devendo-se utilizar protocolos individualizados e adequados às condições clínicas e biomecânicas do paciente, como os de Rampa, Naughton ou Sheffield (Bruce modificado) em esteira rolante. Também podem ser aplicados em cicloergômetro, utilizando-se cargas progressivas atenuadas e individualizadas (W/min). Além da segurança no procedimento, contribuem para a determinação mais precisa dos níveis máximos de consumo de oxigênio miocárdico, através dos valores do "duplo-produto" $\left(\mathrm{PAS}_{\text {máx }}\right.$ x $\mathrm{FC}_{\text {máx. }}$, e do desprendimento calórico ( $\mathrm{VO}_{2}$ máx.) $\mathrm{em} \mathrm{ml} / \mathrm{kg} / \mathrm{min}$ ou mets que podem desencadear isquemia miocárdica, ou seja, o "limiar isquêmico" 35,61,76-83. A monitorização eletrocardiográfica e registros durante o teste devem ser realizados com as 12 derivações simultâneas tradicionais. A positividade do TEé caracterizada por alterações do segmento ST, no mínimo em duas derivações consecutivas, pela presença de infradesnível $\geq 1,5 \mathrm{~mm}$, ou supradesnível $\geq 2,0 \mathrm{~mm}$. A presença de dor precordial (angina), redução da pressão arterial sistólica e déficit cronotrópico com a progressão do exercício, reforçam o diagnóstico e apontam para maior gravidade da doença. A ergoespirometria ou teste cardiopulmonar pode ser aplicada nestes pacientes e os resultados obtidos através de parâmetros metabólicos permitem detectar a presença de disfunção ventricular esquerda: 1) consumo de oxigênio no pico do esforço $\left(\mathrm{VO}_{2 \text { max. }}\right)=$ reduzido; 2$)$ cinética de oxigênio: $\left(\mathrm{VO}_{2} /(\operatorname{carga}(\mathrm{L} / \mathrm{min} / \mathrm{W})=\right.$ reduzida; 3$)$ pulso de oxigênio: consumo de oxigênio/batimento cardíaco (ml/bat.), equivalente ao volume sistólico, em plateau, durante o exercício ou reduzido no pico do esforço.

Estas variáveis, quando presentes, permitem concluir que as alterações de ST observadas durante o exercício sejam funcionalmente significativas. Estudos têm demonstrado a seguinte acurácia diagnóstica deste teste para a presença de DAC: sensibilidade: 73\%; especificidade: 92\%; valor preditivo positivo: $61 \%$; valor preditivo negativo: $95 \%$. Observa-se uma acurácia diagnóstica muito boa para excluir os pacientes que possam ter apresentado quadro de AI, estabilizada, com redução no tempo de hospitalização.

\section{Importância do teste ergométrico na estratifi- cação de pacientes com dor torácica na emer- gência hospitalar}

Nos setores de emergência de vários hospitais, o manuseio de pacientes com dor torácica passou a ter especial atenção, levando-se em conta que este quadro clínico pode expressar uma isquemia miocárdica, implicando em eventuais complicações e risco de morte. Habitualmente, esses pacientes são transferidos para um unidade coronariana por dois ou três dias para observação. Entretanto, é demonstrado que $70 \%$ desses pacientes não sofreram infarto do miocárdio, e muitos deles apresentam baixo risco de DAC ou mesmo apresentam AI de baixo risco, não necessitando de internação hospitalar. Em 1983, no Hospital St. Agnes em Baltimore (EUA), o Dr. Raymond Bahr introduziu a primeira Unidade de Dor Torácica com um laboratório de ergometria acoplado. Desde então, cerca de mil dessas unidades foram criadas nos EUA, visando um atendimento mais eficaz, mais rápido, mais seguro e menos dispendioso aos pacientes, principalmente àqueles que procuram hospitais gerais ${ }^{76,77}$.Em 1996, o Hospital Pró-Cardíaco (RJ) iniciou o Projeto Dor Torácica executado pelo staff da Unidade de Emergência, com importante participação do Laboratório de Medicina do Exercício, que estabeleceu um regime de sobreaviso de seus médicos ergometristas, diariamente até $22 \mathrm{~h}$, incluindo sábados, domingos e feriados ${ }^{35}$. O TE tem sido aplicado, principalmente, no paciente com dor atípica eECG não diagnóstico, após curva enzimática seriada normal. Pacientes com TE normal recebem alta. Os que apresentam resultado não conclusivo para detecção de DAC são retidos no hospital. O TE é executado, na maioria das vezes, entre $12 \mathrm{~h}$ e $24 \mathrm{~h}$ após a entrada na emergência, e tem como objetivo determinar se o paciente é portador de AI. Aplica-se protocolo de rampa, adaptado às condições biomecânicas do paciente, em esteira rolante, com duração de $10 \mathrm{~min}$, com software de última geração, estabelecendo-se velocidade e inclinação inicial e final, de acordo com o desprendimento calórico máximo previsto, em mets, obtido através do questionário de aptidão física (V.S.A.C.). Oexercícioé interrompido por cansaço, alteração eletrocardiográfica e/ou dor precordial. O protocolo de rampa, com carga progressiva, tem permitido determinar com mais precisão os níveis de consumo de oxigênio miocárdico (duplo-produto) e de desprendimento calórico (mets) desencadeadores da isquemia miocárdica, ou seja, o limiar isquêmico. A monitorização eletro- 
cardiográfica e registros durante o teste são realizados com as 12 derivações simultâneas, tradicionais.

\section{Conclusões}

1) OTE é seguro e de importância na estratificação de pacientes com dor torácica que não tenham sofrido complicações clínicas; 2) a maioria dos pacientes com diagnóstico pré-teste para AI, estabilizada durante a permanência na unidade de dor torácica, apresentou TE positivo, ou seja, com resposta isquêmica clínica (dor com esforço) ou eletrocardiográfica (alterações da repolarização ventricular); 3) o TE com protocolo atenuado e adaptado às condições clínicas e biomecânicas dos pacientes apresentou excelente acurácia diagnóstica para excluir os portadores de AI.

\section{Eletrocardiograma de esforço. Sumário das evidências e dos níveis de recomendações}

\section{Recomendação $A$ - Nível de evidência 2}

- Pacientes de risco baixo (Clínica e ECG) e marcadores bioquímicos normais, devem ser encaminhados para TE após $9 \mathrm{~h}$, idealmente até $12 \mathrm{~h}$, em regime ambulatorial (nível deevidência 2)

- Na impossibilidade de realização do TE e ECG não interpretável, o paciente pode ser estratificado com teste provocativo de isquemia com imagem. (nível de evidência 2)

- Protocolos escalonados em esteira ou cicloergômetro devem ser adaptados às condições do paciente (nível de evidência 3)

\section{6) Ecocardiografia}

A ecocardiografiaé um método complementar de grande utilidade na avaliação da dor torácica na admissão hospitalar ${ }^{84-86}$.É um exame não invasivo e a informação diagnóstica é disponibilizada em curto espaço de tempo ${ }^{87-90}$. Quando o ecocardiograma é realizado durante um episódio de dor precordial, a ausência de uma anormalidade de contração segmentar ventricular é uma evidência contrária à isquemia como causa do sintoma. Por outro lado, a presença de anormalidades de contração segmentar reforça a probabilidade de DAC, sendo indicativa de infarto, isquemia ou ambos, embora possa também ser evidenciada em casos de miocardites ${ }^{91-94}$. Além do mais, etiologias não menos importantes de dor torácica, como dissecção aórtica, estenose aórtica, miocardiopatia hipertrófica e doença pericárdica podem ser avaliadas através do método. Doença coronariana importante é habitualmente encontrada em pacientes com AI. Tais pacientes são geralmente identificados pela história clínica, e alterações eletrocardiográficas reversíveis podem ser detectadas, concomitantes aos episódios de dor. Quando a história e o ECG não são confiáveis, a documentação de anormalidade da contração segmentar ao ecocardiograma, durante ou imediatamente após um episódio doloroso, geralmente confirma o diagnóstico ${ }^{95}$. Sem qualquer risco para o paciente, o ecocardiograma avalia ainda a presença e extensão da disfunção ventricular e, se presente, a gravida- de de anormalidades valvares (insuficiência mitral, freqüentemente associada à etiologia isquêmica) ${ }^{96}$. Estudos realizados ainda na década de 80 já confirmavam a utilidade do ecocardiograma na estratificação de risco de pacientes com dor torácica aguda ${ }^{91,97}$. Sabia e cols. ${ }^{86}$ estudaram 185 pacientes com pelo menos $30 \mathrm{~min}$ de dor torácica ou sintomas equivalentes, de provável etiologia cardiovascular. Disfunção ventricular esquerda foi encontrada em 107 pacientes. Após considerar o impacto da idade, história, exame físico e anormalidades eletrocardiográficas, a presença de disfunção ventricular esquerda ao eco duplicou a informação prognóstica disponível. Fleischman e cols. ${ }^{98}$ avaliaram a capacidade do ecocardiograma na estratificação prognóstica de 513 pacientes que realizaram o exame nos primeiros 30 dias após atendimento em emergência cardiológica. Alterações isquêmicas ao ECG encontravam-se presentes em $48 \%$ dos casos. A presença de disfunção ventricular esquerda (risco relativo $=3,8$ ) e insuficiência mitral importante (risco relativo $=2,4$ ) foram superiores em termos de informação prognóstica independentes quando comparados aos dados de anamnese, exame físico e do ECG. Mohler e cols. ${ }^{99}$ investigaram 92 pacientes com uma taxa de eventos de $60 \%$, o que é típico de uma população de alto risco de IAM. Infarto foi diagnosticado através de enzimas e/ou ECG. AI foi identificada em 15 pacientes através da dosagem de troponina $\mathrm{T}$ ou dor precordial típica, com duração superior a $30 \mathrm{~min}$. Baseado nesse critério, AI pode ter sido diagnosticada em excesso, levando a um baixo valor preditivo negativo do eco em afastar a doença. A peculiaridade do estudo é que os ecocardiogramas só foram considerados positivos se as anormalidades contráteis presentes fossem recentes, quando comparadas às evidenciadas em ecocardiogramas anteriores. Os ecocardiogramas foram anormais em 15 dos 18 pacientes com IAM e em 12 dos 37 pacientes com AI. No grupo de AI, cinco pacientes apresentaram alterações contráteis semelhantes aos ecocardiogramas anteriores e foram, portanto, considerados negativos. No grupo de IAM, 2 pacientes de 3 que não foram detectados ao ecocardiograma receberam terapêutica trombolítica. Todos os pacientes com alteração da contratilidade segmentar recente sofreram um evento cardíaco, resultando em um valor preditivo positivo de $100 \%$ para a ecocardiografia. O valor preditivo negativo foi de $57 \%$, demonstrando que $43 \%$ dos pacientes com eventos não foram detectados pelo método. Os protocolos existentes para estratificação de risco em pacientes com AI são dirigidos à identificação de pacientes de alto risco para eventos cardíacos adversos. Fundamentam-se na avaliação do paciente através de dados de história, exame físico e eletrocardiográficos ${ }^{7,9,100-105}$. Contudo, tais protocolos não observam que a taxa de eventos adversos é relativamente pequena, mesmo para uma população de alto risco ${ }^{103,106,107}$. Além do mais, parâmetros clínicos associados a alto risco possuem especificidade e valor preditivo positivo baixos, ou seja, muitos pacientes classificados como sendo de alto risco, não apresentam eventos adversos ${ }^{103,107}$. Na ocasião em que análises de custos vêm adquirindo importância cres- 
cente, atenção também deve ser dirigida ao diagnóstico dos pacientes de baixo risco, que podem receber alta hospitalar precoce, com conseqüente diminuição nos gastos financeiros. Isto requer definição de parâmetros diagnósticos com alta especificidade para detecção desses pacientes, que são aqueles nos quais a chance de eventos é muito improvável. Neste contexto, o ecocardiograma realizado na admissão hospitalar é mais sensível e específico para o diagnóstico de isquemia miocárdica ${ }^{105,106,108-111}$. Stein e cols. ${ }^{109}$ analisaram 66 pacientes admitidos com diagnóstico de AI que foram submetidos a ecocardiograma nas primeiras $24 \mathrm{~h}$ da internação hospitalar com os seguintes objetivos: 1) identificar pacientes de baixo risco para eventos cardíacos adversos intra-hospitalares; 2) diferenciar os pacientes de baixo risco dos de alto risco. Foram identificados três preditores ecocardiográficos para eventos adversos: índice de movimentação parietal <0,2, fração de ejeção do $\mathrm{VE}<40 \%$ e grau da insuficiência mitral. Um ou mais preditores ecocardiográficos estiveram presentes em 32 (48\%) pacientes. Esses preditores foram específicos, apresentaram alto valor preditivo positivo para identificação de pacientes de alto risco e alto poder de discriminação para pacientes de alto e baixo riscos, no que tange ao aparecimento de eventos adversos (óbito, IAM, ICC e taquiarritmias ventriculares) durante a hospitalização.

\section{Ecocardiografia de estresse}

A ecocardiografia de estresse vem adquirindo aceitação crescente na avaliação de pacientes no departamento de emergência, e precocemente após internação hospitalar ${ }^{110}$. Investigação em 26 pacientes de baixo risco revelou anormalidades da contração segmentar em apenas três pacientes, nenhum dos quais apresentou evento cardíaco ${ }^{111}$. Recentemente, 108 pacientes foram observados por $4 \mathrm{~h}$ com enzimas seriadas e ECG, sendo posteriormente submetidos a TE ou ecocardiograma de estresse com dobutamina. Dez pacientes evidenciaram positividade ao TE, o mesmo acontecendo com oito pacientes ao ecocardiograma de estresse. Os exames foram concordantes em quatro pacientes. Todos os pacientes com ecocardiograma de estresse sem evidência de isquemia estiveram livres de eventos cardíacos ao final de 12 meses de seguimento, bem como $97 \%$ daqueles com TEs negativos ${ }^{112}$. Sitges e cols. ${ }^{113}$ estudaram 132 pacientes com diagnóstico de AI por ecocardiografia de estresse com dobutamina-atropina no $3^{\circ}$ dia de internação hospitalar. Não houve complicações maiores relacionadas ao exame. Os pacientes de alto risco não faziam parte da amostra estudada. Após um ano, a sobrevivência livre de eventos foi de $91 \%$ para os que apresentaram ecocardiograma de estresse negativo, comparado a $57 \%$ para os que evidenciaram positividade ao exame $(\mathrm{p}<0,0001)$. Disfunção ventricular esquerda ( $\mathrm{p}=0,01)$, IAM prévio $(\mathrm{p}=0,03)$ e ecocardiograma de estresse positivo $(\mathrm{p}=0,04)$ foram preditores independentes de eventos cardíacos durante o seguimento.

Em conclusão, o diagnóstico de AI engloba um grupo heterogêneo de pacientes com prognósticos diferentes a curto e longo prazo. Portanto, torna-se imprescindível a estratificação de risco desses pacientes, visando racionaliza- ção da terapêutica e diminuição dos custos relacionados a internações hospitalares prolongadas. Variáveis clínicas e eletrocardiográficas encontram-se bem definidas, classificando os pacientes em baixo, intermediário e alto risco de morte ou IAM não fatal a curto prazo ${ }^{7}$. Mais recentemente, a incorporação da dosagem de troponinas à prática clínica permitiu identificar pacientes com risco elevado de complicações e, assim, permitindo uma estratificação mais segura destes em relação à incidência de eventos, tanto durante a fase hospitalar, quanto após esta fase ${ }^{66,114}$. Por ser um exame acessível, rápido, não invasivo e de baixo custo, a ecocardiografia tem a capacidade de oferecer informação prognóstica adicional aos parâmetros anteriormente citados, através da avaliação da função ventricular global, regional e a identificação de valvopatia associada, podendo ser utilizada rotineiramente na investigação desses pacientes. A ecocardiografia de estresse provou ser um método seguro e que pode ser disponibilizado para os pacientes de baixo e médio risco que se encontrem clinicamente compensados há $24 \mathrm{~h} / 48 \mathrm{~h}$, orientando a conduta a ser seguida de acordo com o resultado do teste.

\section{Ecocardiografia. Sumário das evidências e ní- veis de recomendação}

\section{Recomendação A}

- O ecocardiograma transtorácico deve ser realizado, quando há suspeita clínica, no diagnóstico diferencial com outras doenças, como por exemplo: doenças de aorta, embolia pulmonar, valvulopatias (nível de evidência 3).

- Nos casos de complicações decorrentes de SIMI, como por exemplo: comunicação interventricular e insuficiência mitral (nível de evidência 3).

- Ecocardiografia de estresse é uma alternativa ao TE, nos pacientes com impossibilidade de o realizar (nível de evidência 2).

\section{Recomendação B1}

- Pacientes em vigência de dor torácica podem ser avaliados por ecocardiograma em repouso, para determinar a origem isquêmica ou não da dor (nível de evidência 2).

\section{7) Cardiologia nuclear: estratificação do risco nas primeiras 12h após a chegada ao hospital}

\section{Introdução}

A cardiologia nuclear desempenha um papel definitivamente estabelecido na avaliação diagnóstica, funcional e prognóstica dos pacientes com suspeita ou sabidamente portadores de cardiopatias. Ao longo dos últimos 20 anos, especialmente naqueles indivíduos com DAC, as imagens da perfusão miocárdica pelas técnicas de medicina nuclear têm proporcionado uma contribuição fundamental, para o conhecimento e avaliação da doença isquêmica do coração. As informações adicionais provenientes da função ventricular global, da detecção de alterações na contratilidade segmentar 
e da reserva funcional do miocárdio ventricular esquerdo, também estão claramente estabelecidas. Estes dados integrados possibilitam um melhor manuseio de pacientes em investigação e/ou tratamento para cardiopatias nas quais a perfusão coronariana e a função cardíaca possam estar afetadas direta ou indiretamente ${ }^{115-117}$. No âmbito das SIMI, a cintigrafia miocárdica de perfusão desponta como um instrumento importante na estimativa do significado funcional das estenoses coronarianas angiográficas, na avaliação da eficácia de intervenções terapêuticas, e na estratificação do risco após o infarto do miocárdio. Contudo, a capacidade da cardiologia nuclear em prever a ocorrência de fenômenos agudos (fissura/rotura da placa aterosclerótica com trombose), é ainda limitada, embora venha sendo alvo de novas e intensas pesquisas ${ }^{118-121}$. Estudos recentes têm demonstrado o valor diagnóstico e prognóstico, como também a favorável

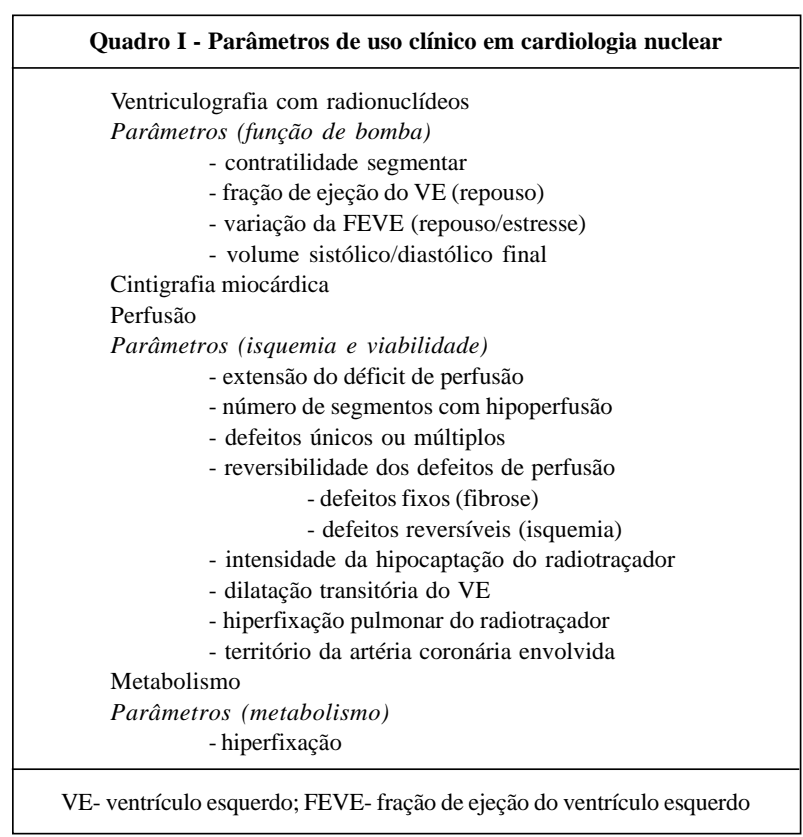

Quadro II - Metodologias para uso clínico em cardiologia nuclear

Reserva coronária (fluxo) e miocárdica (metabolismo)

Cintigrafia miocárdica de perfusão

- convencional (planar)

- tomográfica ("SPECT")

- Tálio-201

- Tecnécio-99m isonitrila (MIBI)/tetrofosmin

- Tecnécio-99m nitroimidazole

- Tecnécio-99m glucarato

Tomografia miocárdica do metabolismo ("PET")

- Flúor-18 deoxiglicose

Reserva do ventrículo esquerdo (contratilidade)

Ventriculografia - equilíbrio (sincronizada com ECG) - primeira passagem

Cintigrafia miocárdica de perfusão (gated SPECT)

- Tálio-201

- Tecnécio-99m isonitrila (MIBI)/tetrofosmin

ECG- eletrocardiograma relação custo-benefício da cintigrafia de perfusão nas SIMI. Estudos da perfusão miocárdica estão sendo incluídos nos algoritmos para triagem e manuseio dos pacientes nessas circunstâncias. Atualmente, nos EUA, médicos em unidades de emergência cada vez mais se utilizam da cardiologia nuclear no auxílio à tomada de decisão em pacientes que são atendidos com dor torácica de origem indeterminada ${ }^{122-126}$.

\section{Metodologia em cardiologia nuclear}

A cardiologia nuclear pode avaliar o coração enfocando os aspectos de perfusão miocárdica, integridade celular, metabolismo miocárdico, contratilidade miocárdica e função ventricular global ou segmentar, como evidenciado no quadro I. Habitualmente, todas essas avaliações são realizadas mediante vários exames. Ultimamente, com a incorporação aos recursos da cardiologia nuclear de equipamentos de última geração (detectores digitais duplos), novos radiofármacos e programas de computador mais sofisticados, essas avaliações podem ser obtidas com apenas um único exame. Em nosso meio os maiores limitantes desses métodos são os equipamentos (gama-câmeras) e os radiotraçadores (tálio-201, tecnécio-99m, isonitrila, tetrofosmin, e.g.) por serem produzidos fora do Brasil e importados para o nosso país. Estes problemas, envolvendo o aspecto de custo-benefício, restringem a utilização em larga escala dos métodos nucleares ${ }^{127-130}$. A disponibilidade e os detalhes dos diversos métodos estão resumidamente expostos no quadro II. Note-se, em itálico, aquelas técnicas em desenvolvimento, ou não disponíveis, ou disponíveis em apenas alguns centros do Brasil, ainda não podendo ser consideradas como procedimentos de rotina. A interpretação dos resultados dos exames, análise qualitativa e quantitativa, bem como os protocolos específicos, em função do radiofármaco utilizado, fogem ao escopo desta revisão e devem ser discutidos em Diretriz específica sobre cardiologia nuclear ${ }^{131-133}$.

\section{Avaliação do paciente com dor torácica no setor de emergência}

Estima-se que 6 milhões de pacientes/ano procuram atendimento de emergência em hospitais nos EUA por quadros de dor torácica aguda. Embora cerca de 50\% desses pacientes sejam internados em unidades coronarianas para definição diagnóstica, somente 10 a $15 \%$ deles efetivamente têm IAM. Dentre este últimos, $2 \%$ a $8 \%$ são liberados inadequadamente do hospital acarretando sérios problemas médico-legais ${ }^{119}$. Vários estudos publicados demonstram que indivíduos com uma cintigrafia miocárdica em repouso considerada de baixo risco, realizada de emergência, determina um risco de eventos cardíacos subsequentes bastante reduzido. Por outro lado, pacientes com uma cintigrafia de alto risco têm uma probabilidade muito aumentada de desenvolverem infarto agudo, serem revascularizados (cirurgia ou angioplastia) ou de apresentarem lesões coronarianas obstrutivas à coronariografia ${ }^{120-122}$. 


\section{Avaliação do paciente com síndromes isquê- micas miocárdicas instáveis}

\begin{abstract}
Alguns estudos têm avaliado a utilização da cintigrafia miocárdica de perfusão em repouso e sob estresse em pacientes com AI e após o infarto do miocárdio (com ou sem supradesnível de ST). Também neste contexto, indivíduos com imagens normais, negativas para isquemia ou com pequenos defeitos de perfusão, tiveram um prognóstico melhor do que os pacientes com imagens consideradas anormais. A informação simultânea da perfusão miocárdica e da função ventricular mediante cintigrafia sincronizada com o ECG (gated SPECT) são muito importantes, pois tanto o valor absoluto da fração de ejeção do ventrículo esquerdo, como a extensão do defeito de perfusão, têm acentuado valor preditivo para ocorrência de eventos cardíacos futuros ${ }^{126}$.

\section{Uso clínico da cardiologia nuclear nos pacien- tes com dor torácica ou SIMI sem supradesní- vel do segmento $S T$}

Em alguns centros médicos no exterior, a cintigrafia miocárdica de perfusão é utilizada para melhorar a capacidade de identificar e estratificar o risco de pacientes no setor de emergência com dor torácica aguda e, especialmente, ECG normal ou não-diagnóstico. A injeção do radiofármaco deve ser realizada em repouso, enquanto o paciente está sintomático (excepcionalmente após o término dos sintomas), e as imagens obtidas até $6 \mathrm{~h}$ após. Estas premissas fazem com que raras instituições médicas no Brasil possam oferecê-la, já que pressupõem disponibilidade de material radioativo, pessoal técnico treinado com o método e pessoal médico experiente na interpretação e valorização das imagens. A cintigrafia miocárdica de perfusão em pacientes com AI é realizada em pacientes considerados de baixo risco, tanto precocemente, $(48 \mathrm{~h} / 72 \mathrm{~h})$ após a alta hospitalar, como com o protocolo de repouso (durante a dor) no setor de emergência e estresse no dia seguinte. As condições clínicas e hemodinâmicas estáveis são primordiais nessa última opção. Algumas das limitações mencionadas anteriormente também se aplicam a estes protocolos, no Brasil.

\section{Conclusões}

Procurar por isquemia miocárdica ou alteração de perfusão rotineiramente, por métodos de imagem radioisotópicos, em pacientes com dor típica, atípica ou indeterminada, com ou sem história prévia de doença coronariana, atendidos em unidades de emergência, atualmente nãoé justificado sob os aspectos clínicos e de custo-benefício. Devem ser consideradas as informações clínicas, fatores de risco para doença coronariana, dados do exame físico, dados laboratoriais já estabelecidos definitivamente (ECG e marcadores bioquímicos), e a possibilidade de etiologia alternativa para o quadro clínico de dor torácica. No entanto, existem dados de literatura, que sugerem a necessidade de avaliação alternativa ou adicional pela cardiologia nuclear (cintigrafia miocárdica de perfusão) nos pacientes com dor torácica aguda e ECG normal ou não-diagnóstico, atendidos num setor de emergência. A probabilidade de ocorrência de doença coronariana, em função dos fatores de risco presentes e dados clínicos prévios e evolutivos dos pacientes, bem como as informações da reserva de perfusão miocárdica, devem fazer parte do algoritmo de decisão visando a orientação diagnóstica adicional e/ou terapêutica. Embora ainda não existam dados suficientes publicados na literatura especializada, a possibilidade de obtenção simultânea de informações sobre a reserva de perfusão e função ventricular esquerda (FEVE e contratilidade segmentar) mediante um único exame, a cintigrafia miocárdica sincronizada como ECG (gated SPECT), parece atraente num cenário onde o diagnóstico diferencial da origem isquêmica da dor torácica é fundamental. Estudos prospectivos em larga escala são necessários, objetivando determinar as contribuições únicas alcançadas pela cardiologia nuclear no contexto de avaliação da dor torácica ou SIMI no setor de emergência.

\section{Cardiologia nuclear. Sumário das evidências e níveis de recomendação}

\section{Recomendação A - Nível de evidência 3}

- Cintilografia miocárdica perfusional em estresse e repouso é uma alternativa ao teste ergométrico, nos pacientes com impossibilidade para o mesmo.

\section{RecomendaçãoB1 - Nivel de evidência 1}

- Pacientes em vigência de dor torácica podem ser avaliados pela cintilografia miocárdica de perfusão em repouso para determinar a origem isquêmica ou não da dor.

\section{Sumário da utilização dos exames subsidiários no IAM sem supradesnível de ST e na AI}

- ECG: na admissão e no mínimo mais um em até 6h.

- Marcadores bioquímicos: na admissão, 6h-9h, opcional na $4^{\mathrm{a}}$ hora e $12^{\mathrm{a}}$ hora.

- Ergometria: pacientes de baixo risco, após 6h de observação, e em até $12 \mathrm{~h}$.

- Ecocardiografia para afastar outros diagnósticos ou suspeita de complicação.

- Teste provocativo de isquemia por imagem (ecocardiografia ou cintilografia miocárdica) como alternativa à ergometria.

\section{Critérios de alta para pacientes de baixo risco, nas primeiras $12 \mathrm{~h}$ de estratificação}

- Sem dor, clinicamente estável,ECG normal ou sem alterações agudas, marcadores bioquímicos não elevados e/ou teste provocativo de isquemia negativo. 


\section{Referências}

1. The TIMI IIIb Investigators. Effects of tissue plasminogen activator and a comparison of early invasive and conservative strategies in unstable angina and nonQ wave myocardial infarction: Results of the TIMI-IIIB trial. Circulation 1994; 89: 1545-56.

2. Théroux P, Fuster V. Unstable angina and non-Q wave myocardial infarction. Circulation 1998; 97: 1195-206.

3. Zaacks SM, Liebson PR, Calvin JE, et al. Unstable angina and non-Q wave myocardial infarction: does the clinical diagnosis have therapeutic implications? J Am Coll Cardiol 1999; 33: 107-18.

4. Bloom BS, Levy YT, Harari A, Fendrick . Direct medical care costs of unstable angina pectoris in a defined population. J Managed Care Pharm 1999; 5: 39-44.

5. Calvin JE, Klein LW, Vandenberg BJ, etal. Clinical predictors easily obtained at presentation resource utilization in unstable angina. Am Heart J 1998; 136: 373-81.

6. Kong DF, Blazing MA. O ônus dos cuidados de saúde na angina instável. Clínicas Cardiológicas da América do Norte 1999; 17: 331-51.

7. Braunwald E. Diagnosing and managing unstable angina. Circulation 1994; 90: 613-22.

8. Braunwald E. Unstable angina: a classification. Circulation 1989; 80: 410-14.

9. Calvin JE, Klein LW, Vandenberg BJ, et al. Risk stratification in unstable angina. Prospective validation of Braunwald classification. JAMA 1995; 75: 136-41.

10. Miltenburg-van Zijl AJ, Simoons ML, Veerhoek RJ, et al. Incidence and follow-up of Braunwald subgroups in unstable angina pectoris. J Am Coll Cardiol 1995; 25: 1286-92.

11. Lopez de SáE, López-Sendon J, Rubio R, et al. Validez de las diferentes classificaciones de la angina inestable. Rev Esp Cardiol 1999; 52(supl I): 46-54.

12. Manenti ER. Estratificação de risco na angina instável: avaliação prospectiva da classificação de Braunwald. Dissertação de mestrado. Porto Alegre, 1998: 147p.

13. Bazzino O, Diaz R, Tajer C, et al. Clinical predictors of in-hospital prognosis in unstable angina: ECLA 3. Am Heart J 1999; 137: 322-31.

14. Armstrong PW, Fu Y, Chang WC, et al, for the Gusto IIB Investigators. Acute coronary syndromes in the GUSTO IIB trial: Prognostic insights and impact of recurrent ischemia. Circulation 1998; 98: 1860-8.

15. Hamm CW, Braunwald E. A classsification of unstable angina revisited. Circulation 2000; 102: 118-22.

16. BraunwaldE, Antman EM, Beasley JW. On behalf of the Committee Members and the task force members of the ACC/AHA guidelines for the management of patients with unstable angina and non-ST-segment elevation myocardial infarction. J Am Coll Cardiol 2000; 36: 970-1062.

17. Bescos LL, Ortiz AF, Zamora HB, et al. Guias de practica clinica de la Sociedad Española de Cardiologia par la angina inestable/infarto sin elevacion ST. Rev Esp Cardiol 2000; 53: 838-50.

18. Freeman MR, Williams A, Chisholm RJ, Armstrong, PW. Intracoronary thrombus and complex morphology in unstable angina: relation to timing angiography and in-hospital cardiac events. Circulation 1989; 80: 17-23.

19. Antman EM, Cohen M, Bernink PJLM, et al. The TIMI risk score for unstable angina/non-ST elevation MI. A method for prognostication and therapeutic decision making. JAMA 2000; 284: 835-42.

20. Organização das Nações Unidas, New York. Problemas dos idosos e velhos, New York, 1980.

21. National center for health statistics: Advance report of final mortality statistics, 1988. Monthly vital statistcs report. Hyattsville, Maryland, Public Health Service 1990; 39(suppl.7): 1-48.

22. National hospital discharge survey. Washington, DC, United States Departament of Health and Human Services, National Center for Health Statistics, 1987.

23. Keller NM, Feit F. Coronary artery disease in the geriatric population. Prog Cardiov Dis 1996; 5: 407-18

24. Glein SK, Boon NA. Coronary artery disease in the elderly. Rev Clin Gerontol 1999; 9: 13-21.

25. ISIS-2 (Second International Study of Infarct Survival) Collaborative Group. Randomized trial of intravenous streptokinase, oral aspirin, both or neither among 17,187 cases of suspected myocardial infarction. Lancet 1988; 2: 525-30.

26. Sokolyk S, Tresch D. Treatment of myocardial infarction in the elderly patients. Compr Ther 1994; 20: 537-44.

27. Stone PH, Thompson B, Anderson HV, et al. Influence of race, sex and age on management of unstable angina and non-Q wave myocardial infarction: The TIMI III Registry. JAMA 1996; 275: 1104-12.

28. Kleiman NS, Anderson, HV Rogers WJ, et al, for the TIMI IIIb investigators. Comparison of outcome of patients with unstable angina and non Q wave myocardial infarction with and without prior coronary artery bypass grafting. Am J Cardiol 1996; 77: 227.

29. Barbash GI, Reiner J, White HD. Evaluation of paradoxic beneficial effects of smoking in patients receiving thrombolytic therapy for acute myocardial infarction: mechanism of the "smoker's paradox" from the GUSTO-I trial, with angiographic insights. Global Utilization of Streptokinase and Tissue-Plasminogen Activator for Occluded Coronary Arteries. J Am Coll Cardiol 1995; 26: 1222-9.

30. Barbash GI, White H, Modan M, et al. Significance of smoking in patients receiving thrombolytic therapy for acute myocardial infarction: experience learned from the international TPA-SK Mortality Trial. Circulation 1993; 87: 53-8.

31. Cohen M, Weatherley B, Lee K, et al. Multivariate analysis of predictors of recurrent ischemic events and death in unstable angina and non $\mathrm{Q}$ wave infarction after treatment with combination antithrombotic therapy: results from the ESSENCE trial. J Am Coll Cardiol 1997; 96(suppl I): I-596.

32. Yeghiazarians Y, Braunstein JB, Askari A, Stone PH. Medical program- unstable angina pectoris. N Engl J Med 2000; 342: 101-14.

33. Braunwald E, Califf RM, Cannon CP, et al. Redefining medical treatment in the management of unstable angina. Am J Med 2000; 108: 41-53.

34. Braunwald E, Brown J, Brown L, et al. Unstable angina- diagnosis and management. Clinical Practice Guidelines. US Department of Health and Human Services. Agency for Health Care Policy and Research. Rockville, MD 1994 (AHCPR publication n 90-0602, guideline n⿳0 10). Circulation 1994; 90: 613-22.

35. Bassan R, Gamarski R, Pimenta L, et al. Eficácia de uma estratégia diagnóstica para pacientes com dor torácica e sem supradesnível do segmento ST na sala de emergência. Arq Bras Cardiol 2000; 74: 405-11.

36. Yusuf S, Flather M, Pogue J, et al. Variations between countries in invasive cardiac procedures and outcomes in patients with suspected unstable angina or myocardial infarction without initial ST elevation - OASIS Registry Investigators. Lancet 1998; 352: 507-14.

37. Kennon S, Suliman A, MacCallum PK, Ranjadayalan K, Wilkinson P, Timmis AD. Clinical characteristics determining the mode of presentation in patients with acute coronary syndromes. J Am Coll Cardiol 1998; 32: 2018-22.

38. Col NF, Yarzbski J, Gore JM, Aplert JS, Goldberg RJ. Does aspirin consumption affect the presentation or severity of acute myocardial infarction? Arch Intern Med 1995; 10: 1386-9.

39. Abdelnoor M, Landmark K. Infarct size is reduced and the frequency of non-Qwave myocardial infarctions is increased in patients using aspirin at the onset of symptoms. Cardiology 1999; 91: 119-26.

40. Cannon CP, McCabe CH, Stone PH, et al., for the TIMI III Registry ECG Ancillary Study Investigators. The electrocardiogram predicts one-year outcome of patients with unstable angina and non-Q-wave myocardial infarction: results of the TIMI III registry ECG ancillary study. J Am Coll Cardiol 1997; 30: 133-40.

41. Hochman JS, McCabe CH, Stone PH, et al., for the TIMI Investigators. Outcome and profile of women and men presenting with acute coronary syndromes: a report from TIMI IIIB. J Am Coll Cardiol 1997; 30: 141-8.

42. Boersma E, Pieper KS, Steyerberg EW, et al., for the PURSUIT Investigators. Predictors of outcome in patients with acute coronary syndromes without persistent ST-segment elevations. Results from an international trial of 9,461 patients. Circulation 2000; 101: 2557-67

43. Zhao XQ, Théroux P, Snapinn SM, Sax FL, for the PRISM-PLUS Investigators Intracoronary thrombus and platelet glycoprotein IIb/IIIa receptor blockade with tirofiban in unstable angina or non-Q-wave myocardial infarction. Angiographic results from the PRISM-PLUS Trial (Platelet Receptor Inhibition for Ischemic Syndrome Management in Patients Limited by Unstable Sign and Symptoms). Circulation 1999; 100: 1609-15.

44. The Platelet Receptor Inhibition for Ischemic Syndrome Management in Patients Limited by Unstable Signs and Symptoms PRISM-PLUS Study Investigators. Inhibition of the platelet glycoprotein IIb/IIIa receptor with tirofiban in unstable angina and non-Q-wave myocardial infarction. NEngl J Med 1998; 338: 1488-97.

45. Antman EM, Braunwald E. Acute Myocardial Infarction. In: Braunwald E. Hear Disease. A Textbook of Cardiovascular Medicine $5^{\text {th }}$ Edition. Philadelphia: WB Saunders Co., 1997: 1184-288.

46. PfefferMA, BraunwaldE. Ventricular remodeling after myocardial infarction. Experimental observations and clinical implications. Circulation 1990; 81: 1161-72.

47. Levine HD. Subendocardial infarction in retrospect: Pathologic cardiographic and ancillary features. Circulation 1985; 72: 790-800.

48. Bosch X, Theroux P, Pelletier GB, et al. Clinical and angiographic features and prognostic significance of early post-infarction angina with and without electrocardiographic signs of transient ischemia. Am J Med 1991; 91: 493-501.

49. Gersh BJ, Braunwald E, Rutherford JD. Chronic coronary artery disease. In: Braunwald E. Heart Disease. A Textbook of Cardiovascular Medicine $5^{\text {th }}$ Edition. Philadelphia: WB Saunders Co., 1997: 289-365.

50. Gottlieb SO, Weisfeldt ML, Ouyang P, et al. Silent ischemia predicts infarction and death during 2 years follow-up of unstable angina. J. Am Coll Cardiol 1987; 10: $756-60$.

51. Moliterno DJ, Granger CB. Differences between unstable angina and acute myocardial infarction. In: Topol EJ. Acute coronary syndromes. New York: Ed Marcel Dekker, 1998: 67-103.

52. Gibler WB. Diagnosis of acute coronary syndromes in the emergency department 
In: Topol EJ. Acute Coronary Syndromes. New York: Ed. Marcel Dekker, 1998: 193-231.

53. Newby LK, Ohman EM, Christenson RH. The role of troponin and other markers for myocardial necrosis in risk stratification. In: Topol EJ. Acute Coronary Syndromes. New York: Ed. Marcel Dekker, 1998: 405-35.

54. Rouan GW, Lee TH, Cook EF, et al. Clinical characteristics and outcome of acute myocardial infarction in patients with initially normal or nonspecific electrocardiogram. Am J Cardiol 1989; 64: 1087-92.

55. Brush JE, Brand DA, Acampora D, et al. Use of the initial electrocardiogram to predict in-hospital complications of acute myocardial infarction. N Engl J Med 1985; 312: 1137-41.

56. KrucoffMW, Green CE, Satler LF, et al. Noninvasive detection of coronary artery patency using continuous ST-segment monitoring. Am J Cardiol 1986; 57: 916-22.

57. Justis DL, Hession WT. Accuracy of 22 lead ECG analysis for diagnosis of acute myocardial infarction and coronary artery disease in the emergency department: a comparison with 12-lead ECG. Ann Emerg Med 1992; 21: 1-9.

58. Mahon NG, Codd MB, McKenna CJ, et al. Characteristics and outcomes in patients with acute myocardial infarction with ST-segment depression on initial electrocardiogram. Am Heart J 2000; 139: 311-9.

59. Cohen M, Hawkins L, Greenberg S, et al. Usefulness of ST-segment changes in greater than or equal to 2 leads on the emergency room electrocardiogram in either unstable angina or non-Q wave myocardial infarction in predicting outcome. Am J Cardiol 1991; 67: 1368-73.

60. Cohen M, Stinnett SS, Weatherley BD, et al. Predictors of recurrent ischemic events and death in unstable coronary artery disease after treatment with combination antithrombotic therapy. Am Heart J 2000; 139: 962-70.

61. Farkouh ME, Smars PA, Reeder GS, et al. A clinical trial of a chest-pain observation unit for patients with unstable angina. Chest Pain Evaluation in the Emergency Room (CHEER) Investigators. N Engl J Med 1998; 339: 1882-8.

62. Crenshaw BS, Ward SR, Granger CB, et al. Atrial fibrillation in the setting of acute myocardial infarction: the GUSTO 1 experience. J Am Coll Cardiol 1997; 30: 406-13.

63. Newby KH, Thompson T, Stebbins A, et al. Sustained ventricular arrhythmias in patients receiving thrombolytic therapy: incidence and outcome. The GUSTO Investigators. Circulation 1998; 98: 2567-73.

64. Lee TH, Goldman L. Serum enzyme assays in the diagnosis of acute myocardial infarction. In: Sox H, Ed. Common Diagnostic Test. Use and interpretation. Philadelphia: ACP Press, 1990: 34-68.

65. Newby LK, Christenson RH, OhmanEM, et al. Value of serial troponin T measures for early and late risk stratification in patients with acute coronary syndromes. Circulation 1998; 98: 1853-59.

66. Mair J, Morandell D, Genser N, Lechleitner P, Dienstl F, Puschendorf B. Equivalent early sensitivities of myoglobin, creatine kinase MB mass, creatine kinase isoform ratios, and cardiac troponins I and $\mathrm{T}$ for acute myocardial infarction. Clin Chem 1995; 41: 1266-72.

67. Christenson RH, Duh SH. Evidence based 68. Puleo PR, Meyer D, Wathen C, et al. Use of a rapid assay of subforms of creatine kinase MB to diagnose or rule out acute myocardial infarction. N Engl J Med 1994; 331: 561-6.

69. Zimmerman J, Fromm R, Meyer D, et al. Diagnostic marker cooperative study for the diagnosis of myocardial infarction. Circulation 1999; 99: 1671-7.

70. Ohman EM, Armstrong PW, Christenson RH, et al. Cardiac troponin T levels for risk stratification in acute myocardial ischemia. GUSTO IIA Investigators. N Engl J Med 1996; 335: 1333-41.

71. Antman EM, Tanasijevic MJ, Thompson B, et al. Cardiac-specific troponin I levels to predict the risk of mortality in patients with acute coronary syndromes. NEngl J Med 1996; 335: 1342-9.

72. Polanczyk CA, Lee TH, Cook EF. Cardiac troponin I as a predictor of major cardiac events in emergency department patients with acute chest pain. J Am Coll Cardiol 1998; 31: 8-14.

73. Jaffe AS, Ravkilde J, Roberts R, et al. It's time for a change to a troponin standard. Circulation 2000; 102: 1216-20.

74. Montague C, Kircher T. Myoglobin in the early evaluation of acute chest pain. Am J Clin Pathol 1995; 104: 472-6.

75. Polanczyk CA, Johnson PA, Cook EF, Lee TH. A proposed strategy for CK-MB and troponin I utilization in the evaluation of acute chest pain. Am J Cardiol 1999; 83: 1175-79.

76. Bahr RD. Acute outpatient care and comprehensive management of acute myocardial ischemia in chest pain emergency departments. Maryland Medical Journal. 1995; 44: 691-3.

77. GraffLG, Dallara J, Ross MA, et al. Impact on the care of the emergency department chest pain patient from the chest pain evaluation registry (CHEPER) Study. Am J Cardiol 1997; 80: 563-8.

78. Myers J, Buchanan N, Smith D, et al. Individualized ramp treadmill - Observations on a new protocol. Chest 1992; 101(suppl 5): 236S-41S.

79. Myers J, Buchanan N, Walsh D, et al. Comparison of the ramp versus standard exercise protocols. J Am Coll Cardiol 1991; 17: 1334-42.
80. Myers J, Walsh D, Herbert W, Ribsi P, Froelicher VF. A nomogram to predictexercise capacity from a specific activity questionnaire and clinical data. Am J Cardiol 1994; 73: 591-6.

81. Winter RJ, Koster RW, Schotveld JH, Sturk A, Straalen JP, Sanders GT. Prognostic value of troponin T, myoglobin, and CK-MB mass in patients presenting with chest pain without acute myocardial infartion. Heart 1996; 75: 235-9.

82. Newby LK, Mark DB. Editorial-The chest pain unit-Ready for prime time? N Engl J Med 1998; 339: 1930-2.

83. Wasserman K, Hansen JE, Sue DY, Casaburi R, Whipp BJ. Principles of Exercise Testing and Interpretation. $3^{\text {rd }}$ Ed. Baltimore: Lippincot \& Wilkins Publishers, 1999: 556p.

84. Peels CH, Visser CA, Kupper AJ, et al. Ulsefulness of two-dimensional echocardiography for imediate detection of myocardial ischemia in the emergency room. Am J Cardiol 1990; 65: 687-91.

85. Sabia P, Abbott RD, Afrookteh A, et al. Importance of two-dimensional echocardiography assessment of left ventricular systolic function in patients presenting to the emergency room with cardiac-related symptoms. Circulation 1991; 84: 1615-24.

86. Sabia P, Afrookteh A, Touchstone DA, et al. Value of wall motion abnormality in the emergency room diagnosis of acute myocardial infarction: a prospective study using two-dimensional echocardiography. Circulation 1991; 84: I-85-92.

87. Feigenbaun H. Role of echocardiography in acute myocardial infarction. Am J Cardiol 1990; 66: 17H-22H.

88. Parisi AF. The case for echocardiography in acute myocardial infarction. J Am Soc Echocardiogr 1988; 1: 173-8.

89. Reeder GS, Seward JB, Tajik AJ. The role of two-dimensional echocardiography in coronary artery disease: a critical apraisal. Mayo Clin Proc 1982; 57: 247-58.

90. Gibson RS, Bishop HL, Stamm RB, et al. Value of early two dimensional echocardiography in patients with acute myocardial infarction. Am J Cardiol 1982; 49: 1110-9.

91. Visser CA, Lie KI, Kan G, et al. Detection and quantification of acute, isolated myocardial infarction by two dimensional echocardiography. Am J Cardiol 1981; 47: 1020-5.

92. Heger JJ, Weyman AE, Wann LS, et al. Cross-sectional echocardiography analysis of the extent of left ventricular asynergy in acute myocardial infarction. Circulation 1980; 61: 1113-8.

93. Ryan T, Vasey CG, Presti CF, et al. Exercise echocardiography: detection of coronary artery disease in patients with normal left wall motion at rest. J Am Coll Cardiol 1988; 11: 993-9.

94. Sawada SG, Ryan T, Conley MJ, et al. Prognostic value of a normal exercise echocardiogram. Am Heart J 1990; 120: 49-55

95. Cheitlin MD, Alpert JS, Armstrong WF, et al. ACC/AHA Guidelines for the clinical application of echocardiography: a report of the American College of Cardiology/American Heart Association Task Force on pratice guidelines (Committee on clinical aplication of echocardiography). Circulation 1997; 95: 1686-744.

96. Califf R, Mark DB. Clinical presentation and diagnostic techniques. In: Fuster V, Ross R, Topol EJ, Ed. Atherosclerosis and coronary artery disease. Philadelphia: Lippincott-Raven Publishers, 1996: 1299-314.

97. Kloner RA, Parisi AF. Acute myocardial infarction: diagnosis and prognostic application of two-dimensional echocardiography. Circulation 1987; 75: 521-4.

98. Fleischmann KE, Goldman L, Robiolo PA, et al. Echocardiographic correlates of survival in patients with chest pain. J Am Coll Cardiol 1994; 23: 1390-6.

99. Mohler III ER, Ryan T, Segar D, et al. Clinical utility of troponin T levels and echocardiography in the emergency department. Am Heart J 1998; 135: 253-60.

100. Lee TH, Cook EF, Weisberg MG, et al. Acute chest pain in the emergency room: Identification of low risk patients. Arch Inten Med 1985; 45: 65-9.

101. Goldman L, Cook EF, Johnson PA, et al. Prediction of the need for intensive care in patients who come to emergency departments with acute chest pain. N Engl J Med 1996; 334: 1498-504.

102. Rizik DG, Healy S, Margulis A, et al. A new clinical classification for hospital prognosis of unstable angina pectoris. Am J Cardiol 1995; 75: 993-7.

103. Lewis WR, Amsterdan EA. Evaluation of the patient with "rule out myocardial infarction". Arch Intern Med 1996; 156: 41-5.

104. KatzDA, Griffith JL, Beshansky JR, Selker HP. The use of empiric clinical datain the evaluation of practice guidelines for unstable angina. JAMA 1996; 276: 1568-74.

105. Visser CA, David GK, Kan G, et al. Two dimensional echocardiography during percutaneous transluminal coronary angioplasty. Am Heart J 1986; 111: 1035-41.

106. Hauser AM, Ganadharan V, Ramos RG, et al. Sequence of mechanical, eletrocardiographic and clinical effects of repeated coronary artery occlusion in human beings: echocardiographic observations during coronary angioplasty. J Am Coll Cardiol 1985; 5: 193-7.

107. Nixon JV, Brown CV, Smitheren TC. Identification of transient and persistent wall motion abnormalities in patients with unstable angina by two-dimensional echocardiography. Circulation 1982; 65: 1497-503.

108. Oh JK, Meloy TD, Seward JB. Echocardiography in the emergency room: Is it feasible, beneficial, and cost-effective? Echocardiography 1995; 12: 163-70. 
109. Stein JH, Neuman A, Preston LM, et al. Improved risk stratification in unstable angina: identification of patients at low risk for in-hospital cardiac events by admission echocardiography. Clin Cardiol 1998; 21: 725-30.

110. Lin SS, Lauer MS, Marwick TH. Risk stratification of patients with medically treated unstable angina using exercise echocardiography. Am J Cardiol 1998; 82: 720-4.

111. Trippi JA, Kopp G, Lee KS, et al. The feasibility of dobutamine stress echocardiography in the emergency department with telemedicine interpretation. J Am Soc Echocardiogr 1996; 9: 113-8.

112. Colon PJ, Guarisco JS, Murgo J, Cheirif J. Utility of stress echocardiography in the triage of patients with atypical chest pain from the emergency department. Am J Cardiol 1998; 82: 1282-4.

113. Sitges M, Paré C, Azqueta M, Bosch X, et al. Feasibility and prognostic value of dobutamine-atropine stress echocardiography early in unstable angina. Eur Heart J 2000; 21: 1063-71.

114. Adams J III. Impact of troponins on the evaluation and treatment of patients with acute coronary syndromes. Curr Opin Cardiol 1999; 14: 310-3.

115. Varetto T, Cantalupi D, Altieri A, et al. Emergency room Technetium- $99 \mathrm{~m}$ sestamibi imaging to rule-out acute myocardial ischemic events in patients with nondiagnostic electrocardiograms. J Am Coll Cardiol 1993; 22: 1804-8.

116. Hilton TC, Thompson RC, Williams HJ, et al. Technetium-99m sestamibi myocardial perfusion imaging in the emergency room evaluation of chest pain. J Am Coll Cardiol 1994; 23: 1016-22.

117. Stratmann HG, Tamesis BR, Younis LT, et al. Prognostic value of predischarge dipyridamole technetium- $99 \mathrm{~m}$ sestamibi myocardial tomography in medically treated patients with unstable angina. Am Heart J 1995; 130: 734-40.

118. Hilton TC, Fulmer H, Abuan T, et al. Ninety-day follow-up of patients in the emergency department with chest pain who undergo initial single-photon emission computed tomographic perfusion scintigraphy with Technetium- $99 \mathrm{~m}$ labeled sestamibi. J Nucl Cardiol 1996; 3: 308-11.

119. Radensky PW, Hilton TC, Fulmer H, et al. Potential cost effectiveness of initial myocardial perfusion imaging for assessment of emergency department patients with chest pain. Am J Cardiol 1997; 79: 595-99.

120. Jain D, Thompson B, Wackers FJ, et al. Relevance of increased lung Thallium-201 uptake on stress imaging in patients with unstable angina and non-Q wave myocardial infarction: Results of the Thrombolysis in Myocardial Infarction (TIMIIIB) study. J Am Coll Cardiol 1997; 30: 421-9.
121. Geleiijbse ML, Elhendy A, Domburg RT, et al. Cardiac imaging for risk stratification with dobutamine-atropine stress testing in patients with chest pain: Echocardiography, perfusion scintigraphy or both? Circulation 1997; 96: 137-47.

122. Kontos MC, Jesse RL, Schimidt KL, et al. Value of acute rest sestamibi perfusion imaging for evaluation of patients admitted to the emergency department with chest pain. J Am Coll Cardiol 1997; 30: 976-82.

123. Iskander $\mathrm{S}$, Iskandrian $\mathrm{AE}$. Risk assessment using single-photon emission computed tomographic technetium-99m sestamibi imaging. J Am Coll Cardiol 1998; 32: 57-62.

124. Heller GV, Stowers AS, Hendel RC, et al. Clinical value of acute rest technetium- $99 \mathrm{~m}$ tetrofosmin tomographic myocardial perfusion imaging in patients with acute chest pain and non-diagnostic electrocardiograms. J Am Coll Cardiol 1998; 31: 1011-17.

125. Brown KA. Do stress echocardiography and myocardial perfusion imaging have the same ability to identify the low-risk patient with known or suspected coronary artery disease? Am J Cardiol 1998; 81: 1050-53.

126. Polanczyk CA, Johnson PA, Hartley LH, et al. Clinical correlates and prognostic significance of early negative exercise tolerance test in patients with acute chest pain seen in the hospital emergency department. Am J Cardiol 1998; 81: 288-92.

127. Kontos MC, Jesse RL, Anderson P, et al. Comparison of myocardial perfusion imaging and cardiac troponin I in patients admitted to the emergency department with chest pain. Circulation 1999; 99: 2073-78.

128. Yeghiazarians Y, Braunstein JB, Askari A, et al. Unstable Angina Pectoris: Review article. NEng J Med 2000; 2: 101-13.

129. Lee TH, Goldman L. Evaluation of the patient with acute chest pain. NEng J Med 2000; 16: 1187-95.

130. Stowers AS, Einsenstein EL, Wackers FJ, et al. An economic analysis of an agressive diagnostic strategy with single photon emission computed tomography myocardial perfusion imaging and early exercise stress testing in emergency department patients who present with chest pain but non diagnostic electrocardiograms: Results from a randomized trial. Ann Emerg Med 2000; 35: 17-25.

131. Pope JH, Aufderheide TP, Ruthazer R, et al. Missed diagnosis of acute cardiac ischemia in the emergency department. NEng J Med 2000; 16: 1163-70.

132. Savonito S, Ardissino D, Morando G, et al. Prognostic value of the admission electrocardiogram in acute coronary syndromes. JAMA 2000; 8: 707-13.

133. Canto JG, Shlipak MG, Rogers W, et al. Prevalence, clinical characteristics, and mortality among patients with myocardial infarction presenting without chest pain. JAMA 2000; 24: 3223-29. 


\section{PARTE II \\ Condutas nos Pacientes de Risco Intermediário e Alto}

\section{1) Internação e alta da Unidade Coronária de Terapia Intensiva}

Todos os pacientes com SIMI de risco intermediário e alto devem ser internados em unidade coronária (UCO), sempre que possível. Idealmente, o paciente deve permanecer na UCO até que seja tomada a conduta definitiva para o seu caso. Caso seja encaminhado para uma intervenção coronária percutânea (ICP), deve voltar à UCO após o procedimento. Caso não ocorra nenhuma complicação, como p.ex. elevação de marcadores bioquímicos de lesão miocárdica, deve receber alta da UCO no dia seguinte. Quando a opção de tratamento for revascularização miocárdica cirúrgica direta, deve preferentemente permanecer na UCO até o momento do procedimento. Nos casos em que é indicado o tratamento clínico medicamentoso, deve receber alta da UCO até o dia seguinte à tomada de decisão, desde que estável sem necessidade de medicação intravenosa.

\section{Recomendação A - Nível de evidência 3}

\section{2) Oxigenioterapia}

Na angina instável (AI), pode haver o aparecimento de hipoxemia durante episódios prolongados de isquemia miocárdica, devido a alterações da relação ventilação-perfusão, secundárias ao aumento da pressão diastólica final do ventrículo esquerdo e formação de edema intersticial e/ou alveolar pulmonar. A hipoxemia agrava a isquemia miocárdica, aumentando a lesão miocárdica. A administração de oxigênio é capaz de limitar a extensão da lesão isquêmica aguda ${ }^{1,2}$. A administração de oxigênio (3L/min) a $100 \%$, por meio de cateter intranasal, habitualmente se constitui em prática rotineira durante os episódios de dor isquêmica prolongada em repouso. Em casos de hipoxemia grave, torna-se necessário monitorar a saturação sangüínea de oxigênio pela oximetria de pulso ou determinar a gasometria arterial, administrandose oxigênio de acordo com esses resultados. A oxigenioterapia deve ser cuidadosa para não eliminar o estímulo respiratório hipóxico na presença de doença pulmonar obstrutiva crônica. Congestão pulmonar, cianose, hipoxemia arterial comprovada, ou insuficiência respiratória associadas, devem receber suplementação de oxigênio e ser cuidadosamente acompanhadas com gasometrias seriadas. Habitualmente, a suplementação de oxigênio é mantida por até $4 \mathrm{~h}$ após o desaparecimento da dor. Naquelas situações em que houver hipoxemia persistente comprovada, essa será mantida conforme a necessidade clínica. Quando desnecessá- ria, a administração de oxigênio por tempo prolongado pode causar vasoconstrição sistêmica e ser prejudicial.

Risco intermediário:

Recomendação A - Nível de evidência 3

Alto risco:

Recomendação A - Nível de evidência 3

\section{3) Analgesia e sedação}

A dor precordial e a ansiedade comumente associada, presentes nas SIMI, geralmente levam a hiperatividade do sistema nervoso simpático. Esse estado hiperadrenérgico, além de aumentar o consumo miocárdico de oxigênio, predispõe ao aparecimento de taquiarritmias ventriculares. Assim, recomenda-se a utilização de analgésicos potentes a pacientes com dor isquêmica, refratários à terapêutica antianginosa ${ }^{3}$. O sulfato de morfina é considerado o analgésico de eleição, sendo administrado por via endovenosa, na dose de $1 \mathrm{mg}$ a $5 \mathrm{mg}$, quando a dor não for aliviada com o uso de nitratos sublingual, ou nos casos de recorrência da dor apesar da adequada terapêutica antiisquêmica. Se necessário, essas doses podem ser repetidas em intervalos de $5 \mathrm{~min}$ 30min, monitorando-se a pressão arterial. A administração em pequenos incrementos tem por objetivo evitar efeitos adversos, como hipotensão e depressão respiratória. Em casos de hipersensibilidade à morfina, essa pode ser substituída pelo sulfato de meperidina em doses fracionadas de $20 \mathrm{mg}-50 \mathrm{mg}$. O emprego rotineiro de ansiolíticos tem sido prática comum em nosso meio. Muitas vezes pode ser dispensável, devendo ser reservado para situações especiais. Estudo clínico randomizado ${ }^{4}$, duplo-cego, envolvendo 131 pacientes do sexo masculino com infarto agudo do miocárdio (IAM), observou que o grau de ansiedade, pressão arterial, frequiência cardíaca e desconforto precordial não diferiram nos pacientes que foram tratados com diazepam ou com placebo. Os derivados diazepínicos têm sido os mais utilizados nessa indicação.

Risco intermediário:

Recomendação A - Nível de evidência 3

Sulfato de morfina

Recomendação B1 - Nível de evidência 3

Benzodiazepínicos

Alto risco:

Recomendação A - Nível de evidência 3

Sulfato de morfina 


\section{Grau de Recomendação B1 - Nível de evidência 3 Benzodiazepínicos}

\section{4) Nitratos}

O emprego de nitratos fundamenta-se em seu mecanismo de ação e na experiência clínica. Não existem estudos clínicos controlados que tenham testado os nitratos na AI, embora seu uso seja universalmente aceito. Os estudos que avaliaram a AI foram pequenos e do tipo observacional ${ }^{5-7}$. Não existem informações claras dos benefícios proporcionados por essa classe de medicamentos no alívio dos sintomas e na redução de eventos adversos maiores (infarto e óbito). Os benefícios terapêuticos dos nitratos estão relacionados aos seus efeitos na circulação periférica e coronariana. O seu efeito venodilatador, diminuindo o retorno venoso ao coração e o volume diastólico final do ventrículo esquerdo, reduz o consumo de oxigênio pelo miocárdio. Adicionalmente, observam-se efeitos de vasodilatação de artérias coronárias, normais ou ateroscleróticas, aumento da circulação colateral coronariana e inibição da agregação plaquetária. Podem ser usados por via oral, sublingual, intravenosa e transdérmica. As vias sublingual e intravenosa são as mais utilizadas para o tratamento dos casos agudos pela facilidade de seu ajuste. Pequenos estudos que compararam as vias de administração não conseguiram estabelecer diferenças significativas entre elas ${ }^{8,9}$. O tratamento é iniciado na sala de emergência administrando-se um nitrato por via sublingual (nitroglicerina, mononitrato de isossorbida ou dinitrato de isossorbida); caso não haja alívio rápido da dor, esses pacientes podem se beneficiar com a administração intravenosa (nitroglicerina e mononitrato de isossorbida são os disponíveis em nosso meio). Os nitratos estão contra-indicados na presença de hipotensão arterial importante (PAS $<100 \mathrm{mmHg}$ ) ou uso prévio de sildenafil nas últimas $24 \mathrm{~h}$. $\mathrm{O}$ uso sublingual de nitroglicerina $(0,4 \mathrm{mg} /$ comp.), dinitrato de isossorbida ( $5 \mathrm{mg} / \mathrm{comp}$.) ou mononitrato de isossorbida (5mg/comp.), não deve ultrapassar três comprimidos, separadas as administrações por intervalos de $5 \mathrm{~min}$. A nitroglicerina IV é empregada na dose de $10 \mu \mathrm{g} /$ min com incrementos de $10 \mu \mathrm{g}$ a cada $5 \mathrm{~min}$ até obter-se melhora sintomática ou redução da pressão arterial (queda da PAS não superior a $20 \mathrm{mmHg}$ ou PAS atingindo $110 \mathrm{mmHg}$ ), ou então aumento da frequiência cardíaca (> $10 \%$ da basal). É de se esperar o aparecimento de tolerância aos efeitos hemodinâmicos do medicamento após $24 \mathrm{~h}$ de uso. O fenômeno de tolerância tem sido atribuído à depleção dos radicais sulfidríla existentes na parede arterial. Esses radicais são responsáveis pela conversão dos nitratos orgânicos em óxido nítrico. Quando se estiver utilizando a via oral, a tolerância poderá ser reduzida com o emprego de doses menores e espaçadas; já com a via intravenosa será necessário o incremento periódico das doses administradas. O tratamento intravenoso deverá ser mantido por $24 \mathrm{~h}-48 \mathrm{~h}$ da última dor anginosa e sua suspensão deverá ser feita de forma gradativa. Para evitar um efeito rebote, habitualmente é feita a passagem da via intravenosa para a via oral.
Risco intermediário:

Recomendação A - Nível de evidência 3

Alto risco:

Recomendação A - Nível de evidência 3

\section{5) Betabloqueadores}

Assim como com os nitratos, a experiência clínica controlada do emprego de betabloqueadores na AI é limitada, embora maior. A evidência de efeitos benéficos baseia-se em seu mecanismo de ação, em estudos clínicos controlados de pequeno porte, e na extrapolação de resultados de estudos em angina crônica e IAM. Os betabloqueadores inibem competitivamente os efeitos das catecolaminas circulantes. $\mathrm{Na} \mathrm{AI}$ seus benefícios estão relacionados a sua ação nos receptores beta-1. Diminuem a freqüência cardíaca, pressão arterial e contratilidade miocárdica, provocando uma redução do consumo de oxigênio pelo miocárdio. Apesar da inexistência de estudos randomizados em larga escala, avaliando a ação sobre desfechos clínicos maiores, como mortalidade, estes fármacos, juntamente com os nitratos, são considerados agentes de primeira escolha no tratamento das SIMI. Na AI foram poucos e de pequeno porte os estudos que compararam betabloqueadores com placebo ${ }^{10-12}$. Embora estudos limitados não tenham conseguido detectar uma redução da mortalidade, o mesmo não ocorre no infarto do miocárdio agudo ou recente. Nessa situação os estudos clínicos controlados conseguiram demonstrar uma redução significativa na mortalidade. Metanálise de cinco pequenos estudos feita por Yusuf e cols. ${ }^{13}$ avaliando a utilização da terapêutica betabloqueadora em 4.700 pacientes com AI, mostrou uma redução de $13 \%$ no risco relativo de progressão para IAM. Na ausência de contra-indicações, a terapêutica betabloqueadora deve ser iniciada imediatamente. A administração preferencial deve ser intravenosa, seguida pela via oral, nos casos de dor persistente ou em pacientes de alto risco, ou, apenas oral, naqueles de risco intermediário ou baixo. São usados vários regimes terapêuticos na dependência do betabloqueador selecionado. Não existem evidências da superioridade de um betabloqueador sobre outro.

O quadro abaixo relaciona as doses de metoprolol e atenolol, os mais usados em nosso país com a indicação.

Metoprolol: IV-5mg (1min-2min) acada 5min até completar a dose máxima de $15 \mathrm{mg}$. VO-50mg-100mg a cada $12 \mathrm{~h}$, iniciada 15min após a última administração IV.

Atenolol: $\quad$ IV $-5 \mathrm{mg}(1 \mathrm{~min}-2 \mathrm{~min})$ a cada $5 \mathrm{~min}$ até completar a dose máxima de 10mg. VO-25mg-50mg a cada $12 \mathrm{~h}$, iniciada 15 min após a última administração IV.

Durante a administração intravenosa deverá ser monitorada a frequiência cardíaca, pressão arterial, ECG e ausculta pulmonar. São consideradas contra-indicações a presen- 
ça de distúrbio importante da condução atrioventricular, antecedentes de asma brônquica ou insuficiência ventricular esquerda aguda.

\section{Risco intermediário:}

\section{Recomendação A - Nível de evidência 2}

\section{Alto risco:}

\section{Recomendação A - Nível de evidência 2}

\section{6) Antagonistas dos canais de cálcio}

Os antagonistas dos canais de cálcio, embora considerados como grupo singular, na verdade constituem um grupo heterogêneo de fármacos que possuem em comum ação vasodilatadora. Esse grupo de fármacos com ação antiisquêmica diminui o fluxo de cálcio através da membrana celular, reduzindo a contratilidade miocárdica e vascular, a velocidade de condução A-V e a atividade do nó sinusal. Existem três subgrupos de antagonistas dos canais de cálcio, quimicamente distintos e com efeitos farmacológicos diferentes, quais sejam: os derivados diidropiridínicos (protótipoé a nifedipina e, como derivado de terceira geração, $\mathrm{o}$ anlodipino), as fenilalquilaminas (verapamil) e os benzotiazepínicos (diltiazem). Agem bloqueando os canais de cálcio tipo L. Esses agentes se diferenciam em relação à sua capacidade de produzir vasodilatação, redução da contratilidade miocárdica e retardo na condução atrioventricular. Os efeitos benéficos nas SIMI se devem a uma combinação das suas ações, diminuindo o consumo de oxigênio pelo coração, a pós-carga, a contratilidade e a frequiência cardíaca ao lado de uma melhoria da oferta de oxigênio, pelo aumento do fluxo coronariano provocado pela dilatação das artérias coronárias. A vasodilatação coronariana originada é semelhante e independe do agente usado. A nifedipina e o anlodipino ocasionam mais vasodilatação arterial periférica; o verapamil pode induzir bloqueio atrioventricular; o diltiazem retarda a condução atrioventricular.

Para controlar os sintomas ${ }^{14,15}$ esses medicamentos são tão eficientes quanto os betabloqueadores, porém não reduzem a incidência de angina refratária, infarto ou óbito. Uma metanálise dos efeitos dos antagonistas dos canais de cálcio na $\mathrm{AI}$ sugere que esses fármacos não previnem o aparecimento de IAM nem reduzem a mortalidade ${ }^{16}$, ao contrário, parecem acentuá-los. Até o momento foram avaliados na AI apenas os representantes de primeira geração. Essas ações deletérias foram observadas com todas as classes de antagonistas do cálcio ${ }^{17-19}$ testados com essa indicação. Por outro lado, em casos de infarto do miocárdio sem supradesnível do segmento ST, existem evidências de que o diltiazem e o verapamil possam ter um efeito protetor ${ }^{20,21}$. Devido a essas características não é recomendado o emprego rotineiro de antagonistas dos canais de cálcio e é contraindicado, em particular, o uso isolado da nifedipina. Os demais têm seu uso reservado para situações especiais. Podem ser usados para tentar controlar sintomas isquêmicos refratários em pacientes que já estão recebendo nitratos e betabloqueadores em doses plenas e adequadas, ou em pacientes que não toleram o uso de nitratos ou betabloqueadores (principalmente nos casos de contra-indicação) ou ainda nos casos de angina variante. A dose padrão da nifedipinaéde $10 \mathrm{mg}$ três vezes ao dia, verapamil $80 \mathrm{mg}-120 \mathrm{mg}$ três vezes ao dia, diltiazem $60 \mathrm{mg}$ três a quatro vezes ao dia. $\mathrm{Na}$ AI, o diltiazem tem sido o bloqueador de cálcio mais utilizado. A nifedipina não deve ser empregada, pois tem sido a mais relacionada à ocorrência de eventos adversos graves. Em pacientes com comprometimento importante da função ventricular esquerda ou com alterações da condução atrioventricular, os antagonistas dos canais de cálcio devem ser evitados, mesmo quando usados isoladamente. Em portadores de disfunção ventricular esquerda deve ser evitada sua associação a agente betabloqueador por sua ação comum e sinérgica na redução da contratilidade miocárdica.

\section{Risco intermediário:}

Recomendação A - Nível de evidência 2

Derivado não-dihidropiridínico em casos de contraindicação aos betabloqueadores

\section{Recomendação C - Nível de evidência 1}

Derivados dihidropiridínicos de início de ação rápida em pacientes sem uso adequado de betabloqueadores

\section{Alto risco:}

\section{Recomendação A - Nível de evidência 2}

Derivados não-dihidropiridínico em casos de contra-indicação aos betabloqueadores

Angina de Prinzmetal

\begin{abstract}
Recomendação B1 - Nível de evidência 2
Derivados não-dihidropiridínico de ação prolongada na presença de isquemia refratária em pacientes em uso adequado de nitratos e betabloqueadores e sem contra-indicações (disfunção ventricular importante)
\end{abstract}

\section{Recomendação B2 - Nível de evidência 2}

Derivados não-dihidropiridínicos de ação prolongada como substitutos de betabloqueadores

Derivados dihidropiridínicos de início de ação rápida em pacientes em uso adequado de betabloqueadores

\section{Recomendação C - Nível de evidência 1}

Derivados dihidropiridinicos de início de ação rápida em pacientes sem uso adequado de betabloqueadores

\section{7) Agentes antiplaquetários}

\section{a) Aspirina}

A trombose coronariana tem papel de destaque no desencadeamento e na progressão dos quadros de SIMI, sendo essencial o emprego de antitrombóticos no tratamento de pacientes com essas síndromes. A aspirina é o antiplaquetário de excelência, devendo ser sempre prescrito, exceção a raros casos de contra-indicação (alergia ou intolerância, sangramento ativo, hemofilia, úlcera péptica ativa), ou alta probabilidade de sangramento gastrointestinal ou gêni- 
to-urinário. A aspirina bloqueia a formação de tromboxane $\mathrm{A}_{2}$ (substância vasoconstritora e protrombótica), interferindo no metabolismo do ácido aracdônico e inibindo a formação da ciclo-oxigenase 1, enzima fundamental ao processo de agregação plaquetária. Analisando conjuntamente os dados de quatro estudos clínicos controlados que reuniram mais de 2.000 pacientes com AI tratados com aspirina, observou-se uma redução do desfecho combinado óbito e/ou infarto nãofatal de $11,8 \%$ (controle) para 6,9\% (aspirina) ${ }^{22-25}$. Com o emprego de doses baixas são raros os efeitos colaterais gastrointestinais. Dispnéia e náuseas são os mais citados. A dose inicial recomendada de $200 \mathrm{mg}$ deve ser mastigada, sendo assim absorvida por intermédio da via sublingual, para que se obtenham rapidamente altos níveis sanguiíneos de aspirina. Em nosso meio, a dose de manutenção diária mais utilizadaé a de $200 \mathrm{mg}$, em tomada única junto ao almoço, embora doses baixas quanto $75 \mathrm{mg}$ /dia sejam também consideradas eficazes ${ }^{26}$. Entre todos os medicamentos relacionados para o tratamento da AI, a aspirina é a mais consistentemente documentada como benéfica, independente do delineamento do estudo, duração do seguimento e doses empregadas ${ }^{22-25}$.

\section{Risco intermediário:}

\section{Grau de recomendação A - Nível de evidência 1}

\section{Alto risco:}

\section{Grau de recomendação $A$ - Nível de evidência 1}

\section{B) Derivados tienopiridínicos}

A ticlopidina e o clopidogrel são antagonistas da ativação plaquetária mediada pelo difosfato de adenosina (ADP), importante via para agregação plaquetária. Também reduzem o nível de fibrinogênio circulante e bloqueiam parcialmente os receptores de glicoproteína IIIb/IIIa, impedindo sua ligação ao fibrinogênio e ao fator von Willebrand. São medicamentos com potente ação antiplaquetária. Atualmente, são empregados como substitutos preferenciais para a aspirina, em casos de intolerância ou alergia a esta, embora no futuro possam ter novas indicações. Tem seu início de ação retardado (12h-24h), sendo o clopidogrel o que age mais rapidamente. A ticlopidina foi testada na AI no início da década de 90, em um estudo que reuniu 652 pacientes ${ }^{27}$. Observou-se uma redução no número de óbitos e/ou infarto não-fatal em seis meses, de $13,6 \%$ para $7,3 \%(\mathrm{p}=0,01)$. Nesse estudo, que precedeu as recomendações terapêuticas atualmente adotadas, não foram empregadas no grupo controle aspirina e/ou heparina. $\mathrm{O}$ clopidogrel, embora eficaz e discretamente superior à aspirina, no tratamento da DAC crônica, como demonstrado pela redução de $8,7 \%$ no risco relativo de eventos maiores no estudo CAPRIE 28 (Clopidogrel versus Aspirin in Patients at Risk of Ischemic Events), ainda carece de informações sobre

\footnotetext{
* Nota dos coordenadores: após as decisões destas Diretrizes, os resultados deste estudo foram divulgados, demonstrando uma diminuição de $20 \%$ (RR 0,80; $95 \%$ IC 0,72-0,89; p=0,00005) na incidência dos eventos (óbito cardiovascular, IM e acidente vascular cerebral), a favor do grupo clopidogrel + aspirina em relação ao grupo aspirina + placebo
}

sua ação na fase aguda. O estudo CURE ${ }^{29}$ (Clopidogrel in Unstable angina to prevent Recurrent Events), que o empregou em associação com a aspirina nessa indicação, deverá ter seus resultados publicados nos próximos meses*. Além de uma ação mais rápida, o clopidogrel apresenta menos efeitos colaterais do que a ticlopidina. Além de alergia e intolerância gastrointestinal, são descritos neutropenia e plaquetopenia, reversíveis com a suspensão do tratamento. Foram relatados raros casos de púrpura trombocitopênica trombótica, mais freqüentemente associada à ticlopidina. Adose recomendada de ticlopidina é a de $250 \mathrm{mg}$ duas vezes ao dia, e de clopidogrel $300 \mathrm{mg}$ como ataque e $75 \mathrm{mg}$ /dia como manutenção. Enquanto não se conhecem os resultados mais recentes sobre sua utilização na fase aguda, sua indicação é restrita aos casos de intolerância à aspirina, quer por hipersensibilidade ou por contra-indicações gastrointestinais importantes.

\section{Risco intermediário:}

\section{Clopidogrel}

Recomendação A - Nível de evidência 1

Contra-indicação à aspirina

Ticlopidina

Recomendação A - Nível de evidência 2

Contra-indicação à aspirina

Alto risco:

Clopidogrel

Recomendação A - Nível de evidência 1

Contra-indicação à aspirina

Ticlopidina

Recomendação A - Nível de evidência 2

Contra-indicação à aspirina

\section{C) Antagonistas dos receptores de glicopro- teína IIb/IIIa}

A ativação dos receptores existentes na superfície das plaquetas (ao redor de 80.000 para cada plaqueta) constituise no mecanismo final e obrigatório de ativação plaquetária, independente da via utilizada. A alteração morfológica sofrida pelo receptor aumenta a sua afinidade para ligar-se à molécula de fibrinogênio, elemento que funciona como ponte de ligação entre duas plaquetas, processo que denominamos agregação plaquetária. Os antagonistas desses receptores impedem a ligação do fibrinogênio aos receptores ativados, bloqueando o processo de agregação plaquetária e a formação do trombo plaquetário. Esses fármacos têm sido utilizados em situações clínicas com grande potencial de ativação plaquetária, como intervenções coronarianas percutâneas complexas ou não, SIMI sem supradesnível do segmento ST e IAM com supradesnível de ST, em associação aos fibrinolíticos ou à angioplastia primária. Estão liberados para uso clínico três agentes de uso intravenoso, abciximab, tirofiban e eptifibatide, estando apenas os dois primeiros disponíveis no mercado nacional. Embora pertencendo a uma mesma categoria têm propriedades farmacocinéticas e farmacodinâmicas muito diferentes. $\mathrm{O}$ abciximabé 
um anticorpo monoclonal que atua como bloqueador nãocompetitivo e irreversível dos receptores de GP IIb/IIIa. Quando administrado, tem uma meia-vida plasmática curta de $5 \mathrm{~min}-10 \mathrm{~min}$, pois a molécula rapidamente se liga aos receptores plaquetários. Sua meia-vida biológica é de 6h$12 \mathrm{~h}$ após a injeção de um bolus isolado. Com doses terapêuticas, consegue-se o bloqueio de $80 \%-90 \%$ dos receptores de superfície. Uma semana após sua utilização, 50\% desses receptores ainda permanecem bloqueados. A dose recomendada é de $0,25 \mathrm{mg} / \mathrm{kg}$ em bolus, seguida de uma administração de $0,125 \mu \mathrm{g} / \mathrm{kg}$ durante $12 \mathrm{~h}$. O tirofiban é um derivado sintético, não-peptídeo, de molécula pequena, que possui em sua estrutura molecular uma seqüência RGD (arginina-glicina-aspartato), sitio de reconhecimento das integrinas, presente nas proteínas adesivas do tipo fibrinogênio, fator von Willebrand e vetronectina, entre outras. A capacidade da GP IIb/IIIa de enlaçar as proteínas adesivas é decorrente da presença dessa seqüência comum. Age competitivamente no receptor celular IIb/IIIa, impedindo sua ligação ao fibrinogênio. A dose recomendada é a de $0,4 \mu \mathrm{g} / \mathrm{kg} / \mathrm{min}$ por $30 \mathrm{~min}$, seguida da dose de manutenção de $0,1 \mu \mathrm{g} / \mathrm{kg} / \mathrm{min}$ por $48 \mathrm{~h}-96 \mathrm{~h}$. No caso de se iniciar a utilização do medicamento na sala de hemodinâmica, deve-se iniciar com a dose de $10 \mu \mathrm{g} / \mathrm{kg}$ administrada em bolus em $3 \mathrm{~min}$, seguida de $0,15 \mu \mathrm{g} / \mathrm{kg} / \mathrm{min}$ durante 48h-96h. O eptifibatide é um heptapeptídeo cíclico sintético, derivado do veneno de víboras. Pertence à família das desintegrinas e possui em sua molécula a seqüência KGD (lisina-glicina-aspartato), que mimetiza a estrutura do fibrinogênio, atuando como antagonista competitivo e reversível do receptor GP IIb/IIIa. O eptifibatide apresenta rápida dissociação e clearance aumentado, diminuindo os riscos de sangramento. Devido ao pequeno tamanho de sua molécula não causa imunogenicidade, permitindo novas administrações caso necessárias. A dose empregada no estudo mais recente, o ESPRIT ${ }^{30}$ (Enhanced Suppression of the Platelet IIb/IIIa Receptor with Integrilin Therapy), em 2.064 pacientes submetidos a implante de stents eletivo ou de emergência, é a de dois bolus de $180 \mu \mathrm{g} / \mathrm{kg}$, separados por um intervalo de $10 \mathrm{~min}$, e a administração de $2 \mu \mathrm{g} / \mathrm{kg} / \mathrm{min}$ a partir do término do primeiro bolus durante 18h-24h. A ação benéfica desses fármacos foi bem demonstrada em inúmeros estudos de prevenção de complicações em intervenções coronarianas percutâneas complexas, muitos incluindo substancial número de pacientes com AI. Em estudos específicos de AI, dois estudos com tirofiban, PRISM ${ }^{31}$ (Platelet Receptor Inhibition in Ischemic Syndrome Managemen) e PRISM PLUS ${ }^{32}$ (Platelet Receptor Inhibition in Ischemic Syndrome Management in Patients Limited by Unstable Signs and Symptoms) e um com eptifibatide, PURSUIT ${ }^{33}$ (Platelet Glycoprotein IIb/IIIa in Unstable Angina: Receptor Suppression Using Integrilin Therapy) documentaram sua eficácia nessa indicação. Ambos os agentes reduziram a taxa de desfechos compostos que incluíam isquemia refratária, novo infarto e óbito. O tirofiban foi empregado como pré-tratamento no estudo TACTICSTIMI $18^{34}$ (Treat Angina with Aggrastat and determine Cost of Therapy with an Invasive or Conservative Stra- tegy. Thrombolysis In Myocardial Infarction) que analisou o valor da intervenção precoce em 2.200 pacientes com AI. Esse estudo mostrou uma melhor evolução do grupo submetido à estratégia intervencionista precoce, sendo mais freqüente a intervenção coronariana percutânea (41\%). Com a estratégia invasiva, considerando seis meses de observação, houve $22 \%$ de redução no desfecho primário (morte + infarto + reintervenção + nova internação) em relação à conservadora, respectivamente, $15,9 \%$ vs 19,4\% (OR- 0,78, p=0,025). Quanto ao desfecho morte + infarto agudo, houve $26 \%$ de redução com a estratégia invasiva vs a conservadora $(\mathrm{p}=0,049)$. Foram mais beneficiados os pacientes que apresentavam segmento ST infradesnivelado ou elevação dos níveis de troponina $\mathrm{T}$. Os autores consideraram que o tirofiban contribuiu para a melhor evolução do grupo que recebeu intervenção precoce. O abciximab foi avaliado em muitos estudos que incluíam também casos de AI. Com essa indicação específica foi avaliado no estudo GUSTO IV ${ }^{35}$ ACS (The Global Use of Strategies To Open occluded coronary arteries, number IV. Acute Coronary Syndromes), que incluiu 7.800 pacientes, randomizando-os para dois regimes de administração de abciximab, 24h e 48h, ou placebo. Esse estudo foi idealizado para avaliar o abciximab na ausência de procedimentos de intervenção percutânea. Não conseguiu demonstrar redução no numero de óbito e/ou infarto nãofatal em 30 dias, mesmo naqueles que apresentavam troponina elevada. Especula-se que a administração prolongada possa ter ocasionado um efeito pró-inflamatório indesejável. Esses resultados contrariaram a expectativa da maioria dos investigadores atuantes na área de isquemia miocárdica. Baseado fundamentalmente no estudo CAPTURE ${ }^{36}$ (c7E3Fab Anti Platelet Therapy in Unstable Refractory Angina), onde foi administrado abciximab por $18 \mathrm{~h}$ a $24 \mathrm{~h}$ antes da intervenção percutânea, em pacientes com AI refratária ao tratamento padrão, o uso do abciximab só estaria indicado, quando houvesse indicação de uma intervenção percutânea dentro de, no máximo, 24h. Esses tratamentos aumentam o risco de sangramento, muitas vezes relacionado aos locais de punção. Nenhum estudo mostrou aumento de sangramento intracerebral. A trombocitopenia é uma complicação rara. Deve ser ressaltado, que o emprego desse grupo de fármacos não exclui o uso concomitante e necessário de aspirina e heparina.

\section{Risco intermediário:}

Não estão indicados

\section{Alto risco:}

\section{Tirofiban e Eptifibatide \\ Recomendação A - Nível de evidência 1}

Abciximab (apenas como pré-tratamento para intervenção coronariana percutânea, durante as $12 \mathrm{~h}$ prévias e nos casos em que esteja planejada).

\section{Recomendação A - Nível de evidência 1}




\section{8) Inibidores da enzima de conversão da angio- tensina}

São potentes fármacos utilizados no tratamento da hipertensão arterial, insuficiência cardíaca e alguns grupos de pacientes com DAC. São utilizados com êxito na insuficiência cardíaca, hipertensão arterial, diabetes mellitus, disfunção ventricular esquerda pós-IAM e mesmo no infarto agudo recente sem manifestações de insuficiência cardíaca. $\mathrm{O}$ estudo HOPE ${ }^{37}$ (The Heart Outcomes Prevention Evaluation study) demonstrou que pacientes com doença arterial aterosclerótica importante, atingindo mais freqüentemente o território coronariano e independentemente da fase em que se encontravam, beneficiavam-se com o uso de ramipril $10 \mathrm{mg} /$ dia a longo prazo. Em cinco anos observou-se redução do risco relativo de óbito de $26 \%$ (p<0,001), infarto $20 \%$ $(\mathrm{p}<0,001)$ e acidente vascular cerebral $32 \%(\mathrm{p}<0,001)$. Embora não empregados rotineiramente na AI, têm sua indicação reconhecida no controle da hipertensão arterial sistêmica e da disfunção ventricular esquerda. Os mais prescritos e suas doses-alvo/dia são: o captopril, 100mg-150mg, enalapril, 20mg, ramipril, 10mg, e lisinopril, 20mg.

\section{Risco intermediário:}

\section{Recomendação B1 - Nível de evidência 1}

\section{Alto risco: \\ Presença de disfunção ventricular esquerda Grau de recomendação $A$ - Nível de evidência 1}

\section{9) Antitrombínicos}

Embora haja alguma discordância ${ }^{38}$, predomina hoje o conceito de que a erosão (fissura), ou a rotura da placa aterosclerótica seja mecanismo essencial que dispara os eventos fisiopatológicos que se exteriorizam clinicamente como, respectivamente, AI e IAM com ou sem supradesnível do segmento $\mathrm{ST}^{39,40}$. Com a fissura, mais ou menos extensa da placa aterosclerótica, os elementos figurados do sangue bem como os fatores de coagulação são expostos ao contato com o material subendotelial, levando à ativação, adesão e agregação plaquetária, e à geração acelerada de trombina, como mecanismos essenciais de trombose subseqüente localizada no local da fissura. Esses dois mecanismos (plaquetário e trombínico) atuam de forma sinérgica, potenciando-se mutuamente para a manutenção e ampliação do processo de trombose. Entre outros efeitos, a trombina é um potente ativador plaquetário, assim como o fator Xa da cascata coagulante; além disso, ativação da cascata trombínica, pelos fatores Va e Xa, ocorre ao nível da membrana plaquetária. Além desses distúrbios fisiopatológicos que ocorrem nos locais de lesão vascular detonadora do evento clínico, há evidências convincentes de que, em pacientes com SIMI, seja vigente um estado protrombótico transitório de características sistêmicas ${ }^{41,42}$. Finalmente, deve ser considerado que o incremento da atividade trombínica em pacientes com SIMI tem conotação prognóstica negati- va $^{43,44}$. Por todos esses aspectos, é lógico que se tenha estabelecido a noção de, em concomitância à terapêutica antiplaquetária, utilizar-se o fármaco antitrombótico padrão, a heparina, não-fracionada (HNF), para o tratamento rotineiro de pacientes com as diversas modalidades de SIMI. Embora por um mecanismo indireto, o principal efeito anticoagulante da heparina é dependente de sua ligação específica à antitrombina, ocorrida mediante atuação de uma sequiência pentassacarídea presente em cerca de um terço das moléculas de heparina. O complexo heparina-antitrombina altera-se do ponto de vista estereotáxico, permitindo o acoplamento simultâneo tanto à trombina como ao fator $\mathrm{Xa}$, assim neutralizados. Essa alteração conformacional da molécula do complexo heparina-antitrombina somente é possível quando a heparina contiver um mínimo de 18 unidades polissacarídeas, correspondendo em torno de 6.000 dáltons. Metanálise de seis estudos randomizados realizados até 1996, referenda a conduta virtualmente generalizada durante a década passada, de se tratar pacientes SIMI sem supradesnível de ST pela combinação de AAS e $\mathrm{HNF}^{45}$. No conjunto de 1.353 pacientes, observou-se risco relativo (RR) de óbito e IAM não-fatal de 0,67 - HNF + AAS vs AAS - mas com intervalo de confiança (IC) ultrapassando a unidade $(0,44-1,02)$, portanto, com $\mathrm{p}=0,06$. Assim, a conclusão da metanálise baseou-se na forte tendência observada quanto ao benefício, inclusive pelo comportamento bastante homogêneo dos estudos individualizados. Nesses estudos, o regime de heparinização mais utilizado foi o convencional, com injeção inicial de 5000 UI, seguida de infusão de 1000 $\mathrm{UI} / \mathrm{h}$, e ajuste do TTPa para dobrar o valor controle. Embora seja teoricamente recomendável ajustar as doses pelo peso do paciente, de forma a permitir anticoagulação mais eficaz em termos do valor de TTPa desejado ${ }^{46}$, não há demonstração de vantagens clínicas com esse regime terapêutico. Já injeções intermitentes de HNF mostraram-se efetivas apenas em um relato, mas não no estudo RISC, nem em outro menor, pregresso ${ }^{47}$. Rotina bastante generalizada é a de ajustar-se o regime de heparinização para valores de TTPa entre 1.5-2.0 vezes o controle laboratorial (50s a 70s), de acordo com a estratégia do estudo TIMI- $3{ }^{48}$. Durante investigações para compreender-se a estrutura da heparina convencional (HNF), verificou-se que suas cadeias polissacárides podem ser despolimerizadas por meio de vários processos físicos e químicos, de forma a se obter compostos também heterogêneos, porém de peso molecular mais baixo, que recebem o nome genérico de heparinas fracionadas $(\mathrm{HF})^{49,50}$. Por definição, uma HF deve ter peso molecular médio inferior a 8.000 dáltons, e com pelo menos $60 \%$ de suas moléculas também atendendo a esse critério ${ }^{51}$. Tipicamente, são obtidos compostos com peso molecular entre 2.000 e 10.000 dáltons, a partir da HNF, que possuem de 5.000 a 30.000 dáltons. Como já citado, a atividade antitrombótica essencial da HNF consiste em potenciar a antitrombina, que pertence ao sistema naturalmente desenvolvido para se contrapor às tendências coagulantes. Estimulada por sua ligação à HNF, a antitrombina inativa os fatores IIa e Xa. As HF também possuem a mesma sequiência polissacáride que permite a ligação à antitrombina-III. Contudo, com peso molecular médio de 4.000 a 6.000 dáltons, menos de 25\%-50\% de suas 
moléculas terão unidades com 18 monossacárides (peso molecular $>6.000$ dáltons). Em consequiência, a antitrombina ligada à HF não terá quase capacidade de se ligar, simultaneamente, à trombina (fator-II), apenas conservando intacta sua propriedade de ligar-se ao fator Xa, inativando-o. Estaúltima característica, comum às HF, embora em grau variável, confere-lhes a singular capacidade de exercer efeito antitrombótico, sem alterar substancialmente (a não ser em altas doses) os testes de coagulação, usualmente empregados, para monitorar o efeito terapêutico da HNF. Ademais, não alterando significativamente o tempo de coagulação, a HF apresenta menor potencial de efeitos colaterais hemorrágicos, quando comparada ao risco de induzir sangramentos da HNF. Outra diferença marcante deriva do fato de as HF não se ligarem às proteínas plasmáticas, às superfícies celulares (plaquetas, macrófagos e osteoblastos) e ao endotélio de forma tão intensa (20 vezes menos) como a HNF. Com isso, evita-se a inativação não-específica, variável individualmente e de acordo com estados patológicos, por proteínas plasmáticas (inclusive o fator-4 plaquetário), que constitui o principal mecanismo de clearance da HNF, conseguindo-se, para a HF, quando administrada por via subcutânea, muito maior biodisponibilidade ( $80 \%-90 \%$ HF vs $30 \%$ HNF). Além disso, a meia-vida da HF prolonga-se acetuadamente com relação à da HNF. Um corolário clínico geral dessas características é que, com a HF, torna-se possível administrá-la subcutaneamente, em doses esparsas uma ou duas vezes ao dia, inclusive ambulatorialmente, e obter-se dose-resposta estável e previsível, com ação terapêutica mais constante, dispensando-se assim a monitoração de efeitos anticoagulantes por testes laboratoriais. Três HFs são disponíveis no Brasil para uso clínico, todas testadas em estudos internacionais, multicêntricos, prospectivamente desenhados para comparar sua eficácia clínica com a da HNF no tratamento de pacientes com SIMI: a nadroparina, a dalteparina, e a enoxaparina. O estudo FRAX.I.S permitiu concluir-se que a nadroparina, usada por apenas $6 \pm 2$ dias, possibilita resultados comparáveis, em termos de eficácia e segurança clínica, aos obtidos com HNF utilizada durante o mesmo período, em pacientes com SIMI sem supradesnível de ST, para evitar um conjunto de complicações isquêmicas (englobadas as mais relevantes: óbito e IAM não fatal). Por outro lado, não há benefício em se prolongar o tratamento com essa HF e, previsivelmente, incrementarse o risco de complicações hemorrágicas sérias. Caracteristicamente, nesse estudo de grande porte, não foram confirmadas as expectativas mais otimistas de superioridade da nadroparina sobre a HNF, derivadas de estudo preliminar anterior. Três grandes estudos internacionais, multicêntricos, foram já divulgados sobre o uso de dalteparina neste contexto. No estudo FRISC (FRagmin during InStability in Coronary artery disease) ${ }^{52}$, pacientes em número de 1.506 , recrutados durante as primeiras $72 \mathrm{~h}$ de quadro clínico de AI ou IAM não-Q, foram randomizados para receber ácido acetisalicílico ou dalteparina (120 UI/kg, sc, 2x/dia) + AAS durante a $1^{\mathrm{a}}$ fase, até seis dias. $\mathrm{Na} 2^{\mathrm{a}}$ fase, até o dia 45 do evento, receberam dalteparina (7.500 UI s.c/dia) ou placebo injetado subcutaneamente. $\mathrm{O}$ desfecho composto primário no $6^{\circ}$ dia (morte + IAM não fatal + revascularização urgente) foi reduzido no grupo recebendo dalteparina + AAS, em comparação àquele recebendo apenas AAS: $5.4 \%$ vs $10,3 \%, \mathrm{p}=0,005$. O benefício ainda era aparente no $40^{\circ}$ dia após o evento ( $\mathrm{p}=0,005)$, mas não após seis meses $(\mathrm{p}=0,18)$.

No estudo FRIC (FRagmin In unstable Coronary artery disease), verificada a superioridade da dalteparina combinada ao ácido acetilsalicílico, sobre o uso deste último isoladamente, restava comparar sua eficácia diretamente contra a HNF na AI e no IAM não-Q. Para isso, nesse estudo FRIC ${ }^{35}, 1.482$ pacientes foram novamente admitidos até 72h do início de um desses contextos clínicos, e randomizados para tratamento com dalteparina ou HNF durante seis dias, e, na fase crônica, para dalteparina ou placebo, até o $45^{\circ}$ dia. As doses de dalteparina foram idênticas às do estudo FRISC, enquanto a HNF foi administrada apenas na fase aguda, em doses de 5.000 UI iniciais EV, seguidas de 1.000 $\mathrm{UI} / \mathrm{h}$ EV até $48 \mathrm{~h}$, e depois até o $6^{\circ}$ dia, 12.500 UI SC 2 x/dia. As taxas de ocorrência do desfecho primário composto por morte, IAM não fatal e angina recorrente ao final dos seis dias foram estatisticamente similares $(\mathrm{p}=0,33)$ nos dois grupos: 7,6\% para $\mathrm{HNF}$ e 9,3\% para dalteparina. Também foram superponíveis as taxas de ocorrência de intervenções de revascularização miocárdica, e de sangramentos graves. Finalmente, em ambos os grupos (placebo e dalteparina), ao final da fase crônica a taxa de eventos compostos primários foi a mesma (12,3\%). Portanto, à semelhança do constatado com a HNF, a dalteparina adicionada ao ácido acetilsalicílico mostra-se nitidamente superior ao tratamento com ácido acetilsalicílico isoladamente (estudo FRISC). Como no caso da nadroparina, com a dalteparina não se conseguiu demonstração de superioridade sobre a HNF, na fase inicial do tratamento (estudo FRIC). Novamente, não houve benefício demonstrável com o tratamento prolongado após a fase aguda (ambos os estudos). No estudo FRISC-II, além da comparação das estratégias terapêuticas invasiva vs nãoinvasiva, foi analisado o tratamento prolongado com dalteparina administrada subcutaneamente, em duas doses diárias, ajustadas por peso e sexo do paciente, contra placebo ${ }^{54,55}$. Inicialmente, 2.267 pacientes em três países escandinavos, com AI ou IAM não-Q, durante período de pelo menos cinco dias, receberam, de maneira aberta, dalteparina, em duas doses diárias. Em seguida, foram alocados randomicamente para receber placebo ou dalteparina por período prolongado (três meses) e, simultâneo, também aleatoriamente para o tratamento invasivo precoce (após período de alguns dias de estabilização) ou conservador. Verificou-se redução relativa de risco da ordem de $47 \%$, quanto ao desfecho primário composto de óbito ou IAM não fatal no grupo tratado não-invasivamente, e apenas até o $1^{\circ}$ mês de tratamento prolongado com dalteparina $(\mathrm{RR}=0,53 \mathrm{IC}$ $0,35-0,80, \mathrm{p}=0,002$ ). Esse benefício restringiu-se ao grupo de pacientes de mais alto risco, caracterizado por elevação dos níveis de troponina-T, em análise post-hoc ${ }^{54}$. Entretanto, mesmo esse efeito benéfico restrito, não se manteve no seguimento mais prolongado, nessa coorte tratada nãoinvasivamente: ao final dos três meses, $8,0 \%$ e $6,7 \%$ dos pacientes, respectivamente, nos grupos placebo e dalteparina, apresentaram um evento primário (óbito ou IAM não 
fatal), correspondendo a RR=0,81, IC 0,6-1,1, p=0,17). Combinando-se aos eventos mais sérios a necessidade de revascularização, redução significante do risco (13\%) foi observada apenas enquanto perdurou o tratamento (três meses), mas não se manteve aos seis meses de seguimento.

Os resultados do estudo FRISC-II, embora não demonstrem qualquer vantagem do uso prolongado de dalteparina, abrem perspectivas promissoras de que: a) essa heparina fracionada possa ter benefício inicial em subgrupos de pacientes com mais elevado risco de eventos graves; b) seu uso, combinado a intervenções de revascularização miocárdica, possa conferir benefício significante pelo menos nas primeiras fases de evolução. Essas hipóteses atraentes requerem estudos especificamente desenhados, para testá-las de forma conclusiva. Dois estudos de grande porte compararam a enoxaparina com a HNF, em termos de eficácia clínica e segurança, no tratamento de pacientes com AI e IAM não-Q. No estudo ESSENCE (Efficacy and Safety of Subcutaneous Enoxaparin In Non-Q wave Coronary Events), multicêntrico, com desenho randômico, duplo-cego, controlado por placebo, 3.171 pacientes na fase aguda da AI e do IAM não-Q foram recrutados em 176 hospitais ${ }^{56}$. Todos os pacientes foram tratados com ácido acetilsalicílico e aleatoriamente alocados para receber, durante $48 \mathrm{~h}$ a 8 dias, enoxaparina $(1 \mathrm{mg} / \mathrm{kg}$, em duas doses subcutâneas diárias) ou HNF em infusão endovenosa contínua (5.000 UI injeção inicial e, em seguida, titulação para TTPa entre $55 \mathrm{~s}-85 \mathrm{~s}$ ). Vale realçar, que entre $12 \mathrm{~h}$ e $48 \mathrm{~h}$ após início do tratamento $84 \%$ dos pacientes recebendo HNF já mantinham TTPa dentro do ou mesmo ultrapassando o limite anticoagulante desejado. $\mathrm{O}$ desfecho composto primário consistiu de óbito, IAM não-fatal e angina recorrente, com alteração de ECG dinâmica ou requerendo revascularização miocárdica. A incidência do desfecho após 14 dias foi de $19,8 \%$ e $16,5 \%$, respectivamente, para a HNF e a enoxaparina, correspondendo a significante $(\mathrm{p}=0,019)$ redução de risco (16,2\%). O RR e correspondente IC $95 \%$ foi $0,80(0,67-$ 0,96). Esse benefício ainda era manifesto após 30 dias: 23,3 $\%$ vs $19,8 \%$ de eventos nos dois grupos respectivos, conferindo à enoxaparina, portanto, redução de risco da ordem de $15 \%$ sobre a HNF: $R R=0,81, I C 0,68-0,96, p=0,02$. É importante ressaltar, que, pela persistência do benefício aos 30 dias, não pareceu ocorrer o fenômeno rebote, descrito quando da suspensão do tratamento com $\mathrm{HNF}^{57}$. A incidência de sangramento grave foi equivalente nos dois grupos: $6,5 \%$ vs $7,0 \%$, mas a de sangramento leve predominou no grupo tratado com enoxaparina (13,8\%), em comparação com o da $\mathrm{HNF}(8,8 \%)$, principalmente devido a equimoses no local de aplicação subcutânea. Além disso, análise prospectivamente contemplada de subgrupo com maior risco de eventos isquêmicos (depressão de ST, revascularização prévia, doença multivascular, uso anterior de ácido acetilsalicílico) evidenciou mais nítido benefício, estatisticamente significante, da enoxaparina em relação à HNF. Não obstante esses aspectos positivos, cabe assinalar que a discriminação estatística dos resultados de eficácia entre enoxaparina e $\mathrm{HNF}$ foi determinada pelas taxas menos elevadas de angina recorrente, mas não por redução significante do risco de óbito ou IAM. Assim, após 30 dias, as reduções de
$19,8 \%$ quanto a óbito e de $25,5 \%$ quanto a IAM não fatal, não foram estatisticamente significantes ${ }^{56}$. Já se relatou o acompanhamento até um ano dos pacientes incluídos no estudo ESSENCE ${ }^{58}$. As taxas de aproveitamento relativas ao número inicial de pacientes estudados foram de $91,4 \%$ e de $92,5 \%$, respectivamente, nos grupos tratados com enoxaparina e HNF. O risco do desfecho composto de óbito, IAM não-fatal ou isquemia recorrente manteve-se menor no grupo tratado na fase do estudo com enoxaparina $(n=1617)$ vs o do grupo que recebeu HNF $(n=1.584)$ : $32 \%$ vs $35,7 \%$ $(\mathrm{p}=0,022), \mathrm{com} \mathrm{RR}=0,87$. Durante esse período de um ano, as taxas de procedimentos diagnósticos invasivos e de revascularização miocárdica (percutânea ou cirúrgica) foram significativamente menores no grupo tratado com enoxaparina $(55,8 \%$ e $35,9 \%)$, em comparação com as verificadas no grupo tratado com $\operatorname{HNF}(59,4 \%$ e $41,2 \%)$ - $\mathrm{p}=0,036$ para o cateterismo diagnóstico e $\mathrm{p}=0,002$ para os procedimentos de revascularização. No estudo TIMI 11B, 3.910 pacientes com AI ou IAM não-Q foram randomizados para se testar a eficácia e a segurança do tratamento com enoxaparina, comparativamente à $\mathrm{HNF}^{59}$. Diferentemente do estudo ESSENCE, todos os pacientes no grupo alocado para enoxaparina receberam injeção endovenosa inicial de 30mg desta HF. Como no estudo ESSENCE, por até 8 dias os pacientes receberam, em formato duplo-cego, enoxaparina ou HNF. Entretanto, novamente em distinção ao estudo ESSENCE, no trabalho TIMI 11B, após esse período, ocorreu nova randomização. Um grupo continuando a receber enoxaparina e o outro passando a receber placebo, por até 43 dias. O desfecho primário composto (morte, IAM não fatal e angina recorrente) foi estipulado prospectivamente aos 14 e 43 dias. Com 14 dias, observou-se redução de $15 \%$ na taxa de eventos compostos primários com uso de enoxaparina (14,2\%), em comparação ao emprego de HNF (16,7\% - p=0,03. Ao cabo de 43 dias, verificou-se tendência não estatiscamente significante à manutenção desse benefício $(\mathrm{p}=0,06)$, sendo as taxas de eventos de $17,3 \%$ e 19,7\%, respectivamente, para enoxaparina e HNF. Seria possível admitir-se que esse benefício conferido pela enoxaparina fosse apenas devido ao fato de não se obter nível adequado de heparinização com a HNF. No entanto, a superioridade, considerando-se o desfecho composto, persistiu em análise post hoc para todos os subgrupos desse estudo, sendo estatisticamente significante quando se observava a diferença no subgrupo hiper-heparinizado ${ }^{60}$. Com os dois estudos tomados isoladamente, registrava-se nítida tendência, mas sem alcançar-se nível de significância estatística para redução da taxa de eventos mais graves, isto é, morte e infarto não fatal, usando-se enoxaparina em comparação com o emprego de HNF. Não havia suficiente número de pacientes e de eventos mais graves óbito e IAM não-fatal - e correspondente poder estatístico para se detectar eventuais diferenças entre os dois regimes terapêuticos confrontados, quanto a esse aspecto clinicamente crucial. Em publicação sobre os estudos ESSENCE e TIMI-11B, registrou-se que a metanálise dos resultados das duas investigações fora prospectivamente planejada ${ }^{61}$. Para esta análise conjunta, 92\% dos pacientes arrolados para o estudo ESSENCE foram considerados com base em resultados disponíveis aos 43 dias de seguimento. Assim, por combinação de resultados, relativa a 7.081 pacientes, 
observou-se consistente benefício associado à enoxaparina, com RRR da ordem de $13 \%-18 \%$ desde a $1^{\mathrm{a}}$ semana, até o $43^{\circ}$ dia de seguimento, em comparação com a HNF. Previsivelmente, os resultados combinados evidenciaram que o uso de enoxaparina associava-se a risco significativamente mais elevado de complicações hemorrágicas menores, mas não de eventos graves dessa natureza. Em síntese, contrastando com os resultados dos estudos que exploraram os efeitos clínicos da dalteparina e da nadroparina, essas investigações com enoxaparina evidenciam que esta heparina fracionada possa acarretar benefícios mais expressivos do que os conferidos pelo tratamento padrão com HNF. Essa vantagem é certamente real para a combinação de complicações isquêmicas - morte, IAM e angina recorrente grave - e muito provavelmente aplica-se também em termos dos eventos mais graves, óbito e IAM não-fatal, de acordo com os resultados analisados para eficácia e segurança clínica. Parece inquestionável, à luz das evidências expostas, que as heparinas fracionadas empregadas por tempo curto (até cerca de sete dias), associam-se a efeitos benéficos no mínimo equivalentes aos proporcionados pelo uso de HNF, também nesse prazo, sempre tratando-se todos os pacientes com ácido acetilsalicílico. A eficácia, para redução de complicações miocárdicas isquêmicas, assim conseguida com esses dois regimes antitrombínicos adicionados ao antiplaquetário ácido acetilsalicílico,é verificada com segurança clínica também comparável em termos de complicações hemorrágicas. Essa conclusão é análoga àquela alcançada no contexto do tratamento e prevenção de complicações tromboembólicas periféricas, comparando-se a HNFe várias heparinas de baixo peso molecular ${ }^{62,63}$. De fato, para evitar a recorrência de tromboembolismo, as heparinas comportamse homogeneamente, a despeito de, em forma muito intrigante, constatar-se menor mortalidade geral em associação às fracionadas ${ }^{63}$. Essas conclusões coadunam-se também com o conceito de um verdadeiro efeito de classe, comum tanto à HNF como às diversas heparinas fracionadas estudadas. Esse conceito foi tacitamente incorporado à revisão sistemática e à metanálise recentemente publicadas sobre o assunto ${ }^{64,65}$. Esse conceito é discutível, em termos genéri$\cos ^{66}$, e bastante indefinido quando aplicado ao contexto das heparinas, uma vez que, como referido acima, há nítidas diferenças estruturais, farmacocinéticas, e fármaco-dinâmicas entre elas, refletindo-se em potenciais discriminações de emprego e efeitos clínicos. Além de as diferenças biológicas entre as várias heparinas constituírem potenciais contribuintes, a própria concepção e formato geral dos estudos realizados devem ser fator responsável pela discriminação dos resultados clínicos obtidos até o momento. Isso é patente quando se observam o diferenciado risco do grupo controle em cada estudo, os variados regimes de HNF (e os correspondentes níveis de alteração dos parâmetros de anticoagulação), e demais características clínicas diversificadas de cada um das grandes pesquisas realizadas. Assim, por exemplo, é possível que, além de outras distintas propriedades, a enoxaparina atue beneficamente sobre o risco em pacientes com SIMI, antagonizando especificamente a elevação do fator de von Willebrand ${ }^{67,68}$. Em síntese, para tratar pacientes internados com AI/IAM-SSST, de risco intermediário ou alto:

\section{$H N F$ - Recomendação A - Nível de evidência 1 $H F$ - Recomendação A - Nível de evidência 1}

Importante recordar que no paciente de alto risco, submetido a tratamento com bloqueadores IIb/IIIa, deve-se dar preferência à utilização da HNF.

Dois outros compostos, a hirudina e a bivalidurina, ainda não disponíveis no Brasil, têm propriedades antitrombínicas diretas, potencialmente úteis em pacientes com síndromes de trombocitopenia induzida pela heparina. Combinando-se os resultados de três estudos, OASIS- ${ }^{69}$ com os obtidos no TIMI-9B e GUSTO-II-b, demonstra-se redução de $22 \%$ no RR de óbito/IAM após $72 \mathrm{~h}$ ( $\mathrm{p}=0,0004)$, de $16 \%$ após uma semana $(\mathrm{p}=0,002)$, e de $10 \%$ após 35 dias $(\mathrm{p}=0,016)$. O conjunto dessas evidências é compatível com a noção de que a hirudina, um antitrombínico direto, poderia representar alternativa mais eficaz do que a HNF para se tratar pacientes com SIMI, mantendo-se razoável perfil de segurança. Entretanto, não há vantagens operacionais de uso, requerendo-se monitoração do efeito anticoagulante e administração endovenosa. É possível também que suas vantagens de combinação direta, comparativamente à HNF, sejam parcialmente contrabalançadas por limitações pelo menos teoricamente plausíveis: "exaustão" da disponibilidade, pois a ligação à trombina é irreversível, e insuficiência de doses para antagonizar a ativação plaquetária induzida pela trombina, nas concentrações propiciadas pelo uso clínico (por sua vez balizado pelo risco de complicações hemorrágicas). Assim poder-se-ia explicar, provavelmente, a atenuação do benefício inicialmente observado nos estudos citados. Revisão sistemática dos resultados de estudos divulgados usando hirulog em pacientes com todos os tipos de SIMI (inclusive os pacientes que pertenceriam o estudo TIMI-8) foi recentemente publicada, englobando-se um total de 5.674 pacientes em seis estudos ${ }^{70}$. Desses, 4.603 casos relacionavam-se a procedimentos eletivos de revascularização percutânea, e 1.071 outros apresentavam vários tipos de SIMI. Métodos metanalíticos foram empregados para comparar resultados de quatro estudos randomizados comparativos de hirulog com HNF, em 4.973 pacientes, verificando-se que o primeiro associou-se a significativa $(\mathrm{p}=0,02)$ redução da razão de chances de óbito ou IAM (OR=0,73, IC=0,57-0,95) aos 30-50 dias de seguimento. Também ocorreu, com hirulog, diminuição significante da razão de chances de hemorragia grave, em comparação com a HNF (OR=0,41 IC 95\% = 0,32-0,52, $\mathrm{p}<0,001)^{70}$. Portanto, os autores consideraram que a bivalirudina constituiria agente antitrombínico de eficácia, no mínimo comparável à da HNF, porém com melhor perfil de segurança para uso clínico em pacientes com SIMI. Todavia, deve-se considerar que os estudos incluídos na metanálise eram bastante heterogêneos, e que os resultados obtidos muito provavelmente, influenciados pelo grande contingente (87\%) de pacientes tratados com angioplastia coronariana por via percutânea, relatados no estudo HAS (Hirulog Angioplasty Study). Algumas das limitações apontadas para a hirudina, já mencionadas, aplicam-se também a este outro antitrombínico direto, no que se refere a facilidade de uso e ausência de estudos de custo-eficácia-benefício.

Portanto, hirudina e bivalirudina deverão ser emprega- 
das em pacientes de risco intermediário ou alto, em lugar das heparinas, quando houver ocorrido a síndrome de trombocitopenia induzida:

\section{Antitrombínicos diretos}

\section{Recomendação grau A - Nível de evidência 2}

\section{0) Diagnóstico e estratificação de risco com métodos complementares}

Em pacientes com SIMI, a estratificação de risco deve ser espaço processo contínuo, desde a avaliação clínica inicial, passando pelos exames laboratoriais já discutidos nestas Diretrizes, e culminando com os complementares expostos a seguir. Os métodos complementares, a serem empregados durante os primeiros dias após o diagnóstico, neste contexto, podem ser divididos em duas categorias: a) o exame hemodinâmico intravascular, com realização de cinecoronariografia, de ventriculografia de contraste radiológico, e de medida das pressões intracardíacas. Em essência, permite a direta visibilização da luz coronária e a avaliação da função ventricular diastólica, e sistólica global (fração de ejeção) e regional ${ }^{71}$; b) Exames “não-invasivos", como o teste ergométrico com eletrocardiografia, o ecocardiograma e os exames nucleares.

Em contraposição ao exame intravascular, que proporciona informações anatômicas da circulação coronariana, estes métodos avaliam a ocorrência de isquemia miocárdica. Assim, a abordagem é funcional, e a presença ou ausência de lesão coronariana é indiretamente avaliada pela correspondente ocorrência ou não de isquemia. Esses métodos também fornecem subsídios indiretos (ergometria) ou diretos (ecocardiografia e nucleares) sobre a função ventricular. Ambas as categorias de métodos são empregadas para complementação diagnóstica e prognóstica, no sentido de se definir a melhor conduta médica para pacientes com risco intermediário ou elevado de complicações. Observa-se atualmente intensa controvérsia quanto aos méritos relativos de duas estratégias cardiológicas fundamentais, baseadas no respectivo uso inicial e preferencial de cada uma dessas categorias de exames, para avaliar pacientes com essas características clínicas ${ }^{72,73}$. Pela chamada estratégia "invasiva" precoce, os pacientes de risco intermediário/alto são rotineiramente abordados, tão logo quanto possível, com o método intravascular ${ }^{74}$. Esta estratégia objetiva complementar a estratificação prognóstica e a identificação da mais apropriada forma de tratamento (clínico, revascularização percutânea ou cirúrgica), pela anatomia coronariana desvendada angiograficamente e pelo estudo combinado da função ventricular.

Corolário direto desta conduta é a freqüente possibilidade de revascularização miocárdica, por via percutânea ou cirúrgica, se possível e indicada, com base em resultados anatômicos da coronariografia.

A estratégia "invasiva" precoce permite identificar corretamente: a) os cerca de $10 \%$ - $20 \%$ de pacientes sem lesões ou com obstruções coronarianas não significantes hemodinamicamente $(<50 \%)$, e que podem ter alta hospitalar rápida, com excelente prognóstico; b) os 5\%-10\% de pacien- tes com lesão troncular esquerda significante e os $40 \%-50 \%$ dos pacientes com envolvimento multiarterial (com ou sem disfunção global ventricular), que usualmente têm manifesto benefício por revascularização miocárdica.

Pela estratégia "não-invasiva", pacientes de risco intermediário ou alto são estabilizados por tratamento clínico, e submetidos precocemente aos exames funcionais, nãointravasculares. Somente quando há indícios clínicos de isquemia recorrente, ou resultados anormais dos testes "não-invasivos", são os pacientes encaminhados para cinecoronariografia. Apesar de vários trabalhos randomizados e observacionais terem abordado a questão, não há presentemente consenso quanto à melhor estratégia ${ }^{35,74-78}$. Em grande parte, essa incerteza deve-se aos estudos, mesmo os randomizados, que foram muito variados em aspectos de seleção de pacientes, tempo decorrido para o estudo coronariográfico e a conseqüente intervenção de revascularização, terapêuticas concomitantes, e mesmo interpretação dos resultados. Em conseqüência, os resultados são expressivamente muito heterogêneos e discrepantes em múltiplos pontos muito relevantes. Para exemplificar, no estudo FRISC-II, os pacientes randomizados para o braço "intervencionista", eram revascularizados após vários dias - (em média 4 para ICP e 8 para cirurgia - de "passivação" das lesões coronarianas, por tratamento clínico que incluía o uso de heparina fracionada; obviamente, esse protocolo de estudo difere radicalmente daqueles empregados em estudos em geral analisados correlatamente, como o TIMIIIIB $^{74}$ e o VANQWHISH ${ }^{75^{*}}$. Também, as técnicas integrantes e os regimes terapêuticos coadjuvantes aos processos de revascularização nos vários estudos foram muito diversos. De forma sintética, pode-se concluir que : a) ambas as estratégias têm mérito clínico indiscutível; b) muitos pacientes, em realidade, somente serão tratados de forma otimizada pelo concurso complementar dessas duas abordagens; c) a adoção de cada uma delas, mesmo quando existe conduta rotineira em determinado serviço de cardiologia, deve passar sempre pelo crivo da individualização racional e judiciosa, para pacientes e circunstâncias específicas.

A seguir, são discutidos aspectos básicos de recomendações de cada método complementar:

\section{A) Estudo hemodinâmico e cineangiocardiográfico de con- traste radiológico de rotina}

\section{Risco intermediário: \\ Recomendação B2 - Nível de evidência 2 \\ Alto risco:}

\section{Recomendação A - Nível de evidência 2}

\footnotetext{
* Nota dos coordenadores: após as decisões destas Diretrizes, foram divulgados os resultados do estudo "TACTICS-TIMI 18", que comparou estratégia inicial invasiva ou conservadora em pacientes com SIMI sem supradesnível de segmento ST submetidos a tratamento com bloqueador IIb/IIIa, demonstrando vantagens significativas a favor da estratégia invasiva. As vantagens são bastantes evidentes nos pacientes que tinham troponina elevada além do percentil $99 \%$, mas não nos outros. (referência 35).
} 
Observação 1 - As recomendações de grau A para todo paciente de alto risco (mesmo baseado em fatores clínicos simples) são especialmente realçadas quando ocorre: instabilidade hemodinâmica e/ou elétrica, refratariedade ao tratamento medicamentoso otimizado, e recorrência espontânea ou provocada (testes "não-invasivos" de estresse) de isquemia miocárdica, subjetiva ou objetivamente detectada.

Observação 2 - Conforme citado acima, não existe consenso sobre o tempo mais apropriado para a realização do estudo intravascular, havendo desde condutas de indicação imediata até aquelas que preconizam genericamente o período de internação hospitalar.

Não se deve indicar a angiografia coronariana de rotina - mesmo para pacientes com risco intermediário/alto, nas seguintes situações: em pacientes com intensa ou extensa co-morbidade, ou reduzida expectativa de vida (e.g. insuficiência respiratória, renal, hepática, câncer de prognóstico fechado); e em pacientes, que, "a priori" recusem perspectivas de tratamento por revascularização miocárdica.

\section{Recomendação C - Nível de evidência 3}

Conforme exposto no tópico de tratamento antiplaquetário $^{31-35,37}$, há evidências bastante convincentes de que os inibidores do complexo GP-IIb/IIIa sejam coadjuvantes terapêuticos valiosos em pacientes submetidos a exames intravasculares diagnósticos e terapêuticos, particularmente quando se detecta a presença de trombo intracoronário.

\section{Recomendação A - Nível de evidência 2}

\section{B) Exames não-intravasculares, para diagnóstico de isquemia e prognosticação:}

\section{1) Teste ergométrico (TE).}

O TE eletrocardiográfico pode constituir a abordagem essencial em pacientes de risco intermediário, quando não são disponíveis outros recursos não-invasivos e a estratégia intravascular não estiver indicada. Além de oferecer subsídios diagnósticos, tem reconhecido valor prognóstico; testes positivos associam-se a maior incidência de eventos coronarianos em um ano, quando comparados a TE negativo. O exame não deve ser realizado em pacientes com alterações persistentes de ST-TeT. As principais alterações no TEindicativas de maior risco são: 1) trabalho <5 mets; 2) desnivelamento de ST >1mm, especialmente se associado a sintomas ou em baixa carga; 3 ) resposta de PA inadequada (PAS máx. $<110 \mathrm{mmHg}$ ou aumento $<30 \mathrm{mmHg}$ em relação ao repouso).

Outras alterações menos padronizadas são: déficit cronotrópico, número de derivações acometidas, extrasístoles ventriculares repetitivas.

\section{Risco intermediário:}

\section{Recomendação A - Nível de evidência 2}

Alto risco: antes de $48 \mathrm{~h}$

Grau de recomendação C - Nível de evidência 3

Portanto, TE como estratégia precoce $(<48 \mathrm{~h})$ é contra- indicado formalmente em pacientes de alto risco. Entretanto, o TE realizado após 48h de plena estabilização do quadro clínico, ainda durante a internação, poderá ser indicado em pacientes submetidos à cinecoronariografia, quando for necessária avaliação funcional de lesão conhecida ou estabelecimento de risco antes da alta hospitalar. O teste deve ser realizado em ambiente hospitalar por pessoal com reconhecida experiência no método.

\section{Alto risco: após $48 \mathrm{~h}$}

\section{Recomendação B2 - Nível de evidência 3}

\section{2) Exames ecocardiográficos}

O ecocardiograma transtorácico, de baixo custo e fácil execução à beira do leito, é exame de eleição em pacientes internados com risco intermediário ou alto, de acordo com a estratégia não-intravascular, para avaliação da função ventricular global e da contratilidade regional, derivando elementos prognósticos muito relevantes e precoces.

\section{Recomendação B1 - Nível de evidência 2}

Em circunstâncias especiais, necessita ser substituído ou complementado peloexame transesofágico, porexemplo, quando háimpossibilidade técnica de avaliação pelo transtorácico.

\section{Recomendação B2 - Nível de evidência 2}

O teste ecocardiográfico de estresse (TEE) permite a verificação das anormalidades regionais transitórias da contração, indicativas de isquemia induzida. O estresse farmacológico com administração de dobutamina é seguro e eficaz neste contexto, e também propicia informações prognósticas. Entretanto, aplicam-se a este método as mesmas restrições de cautela e mesmo de contra-indicações expostas para o TE. São consideradas respostas indicativas de maior risco: a incapacidade de aumentar ou a diminuição da FE $>5 \%$ ao esforço e defeitos regionais de contração durante o estresse. Respostas de melhora de contração segmentar em áreas dissinérgicas, com doses iniciais de dobutamina (5 a $10 \mu \mathrm{g} / \mathrm{kg} / \mathrm{min}$ ), identificam viabilidade miocárdica nessas regiões "atordoadas" pela isquemia pregressa.

\section{Risco intermediário:}

A) Em pacientes nos quais persistem dúvidas, após serem submetidos a TE

\section{Recomendação A - Nível de evidência 2}

B) Como $1^{a}$ opção

Recomendação B2 - Nível de evidência 2

\section{Alto risco:}

\section{Recomendação C - Nível de evidência 3}

Nota: Podem ser consideradas promissoras perspectivas de uso de técnicas de microbolhas para avaliar a perfusão miocárdica regional ecocardiograficamente. Esse método ainda se encontra em fase de investigação para efeito de padronização técnica e validação clínica, principalmente em outros contextos de doença coronariana ${ }^{79,80}$. 


\section{3) Métodos de medicina nuclear}

Estes métodos, englobando a cintilografia miocárdica de perfusão (CMP) e a ventriculografia nuclear, têm excelente potencial em identificar pacientes com coronariopatia obstrutiva grave e com risco elevado de eventos graves no seguimento a curto prazo ${ }^{81,82}$. A angiocardiografia nuclear é o método disponível mais acurado para avaliação da função biventricular. A CMP é especialmente indicada em pacientes nos quais há dificuldades para a interpretação adequada do ECG de esforço: presença de desnivelamentos significativos de ST durante manobras respiratórias e alterações posturais; sobrecarga ventricular esquerda; bloqueios de ramo; presença de áreas extensas eletricamente inativas; uso de fármacos que alteram a repolarização ventricular ou dificultam a interpretação eletrocardiográfica (digitálicos, betabloqueadores, antiarrítmicos, antidepressivos); moléstias cardíacas e não-cardíacas associadas a alterações eletrocardiográficas basais. De particular interesse é a possível realização precoce deste exame em pacientes sem condição de executar esforço físico, com ampla margem de segurança (apesar da recente instabilização de sua coronariopatia), empregando-se "estresse" vasodilatador com dipiridamol ou adenosina. Com esta modalidade de estresse o exame detecta, sem necessidade de induzir-se isquemia, a heterogeneidade regional de fluxo provocada pela coronariopatia obstrutiva. Neste sentido, o exame cintilográfico é potencialmente superior, inclusive, à ecocardiografia de estresse. Deve ser ainda destacado, que, recentemente tornou-se possível, sincronizando-se o estudo cintilográfico tomográfico ao ECG (gated-SPECT), avaliar a função sistólica regional e medir a fração de ejeção ventricular com exame único. Há demonstração clara de efetividade e segurança clínica da CMP, quando empregada em pacientes estabilizados clinicamente após o evento inicial, conforme estudos utilizando as técnicas planar ou tomográfica, ${ }^{201}$ tálio ou ${ }^{99 \mathrm{~m}} \mathrm{Tc}$-sestamibi, e esforço físico dinâmico ou estresse farmacológico ${ }^{83-88}$. Os vários estudos são consistentes na demonstração de que pacientes com diagnóstico de AI, que apresentam cintilografia normal durante estresse, pertencem a subgrupo com risco notadamente reduzido de eventos graves, de cerca de $1 \%$ em um ano, enquanto a detecção de defeitos reversíveis expressa prognóstico muito desfavorável, com taxa de eventos da ordem de $20 \%$ para o mesmo prazo de seguimento. Finalmente, há inequívoca demonstração, na literatura, e na experiência de muitos centros, de que os métodos de CMP, principalmente à base de tálio-201 (mas também, em muitas circunstâncias, com compostos marcados por Tc-99m), sejam muito valiosos para detecção de viabilidade miocárdica em regiões ventriculares discinérgicas. Isso pode ocorrer em condições de miocárdio atordoado (stunned myocardium) - após isquemia aguda, e subseqüente recanalização arterial - ou de hibernação miocárdica - em vigência de isquemia crônica.

\section{Resumo das indicações da Cintilografia Miocardica de Perfusão}

Risco intermediário:

A) Em pacientes nos quais persistem dúvidas após a realização de TE, ou impossibilitados de submeter-se ao TE Grau de recomendação A - Nível de evidência 2

B) Como $1^{a}$ opção

Recomendação B2 - Nível de evidência 2

Risco alto:

A) Antes das primeiras $48 \mathrm{~h}$ de estabilização do paciente: Grau de recomendação C - Nível de evidência 3

B) Para identificação da presença/extensão de isquemia em pacientes que não podem realizar cateterismo, ou quando seus resultados não são suficientes para estabelecimento de condutas.

Recomendação A Nível de evidência 2

C) Após o cateterismo, para identificação da artéria relacionada ao evento (região a ser revascularizada), elou estratificação de risco

Recomendação A - Nível de evidência 1

D) Em pacientes com regiões ventriculares discinérgicas, em que se torna necessário comprovar ou excluir a presença de miocárdio viável, para guiar a conduta terapêutica.

Recomendação A - Nível de evidência 1

Resumo das indicações da angiocardiografia nuclear (pacientes de risco intermediário e alto)

A) Identificação de envolvimento do VD: Recomendação B1 - Nível de evidência 3

B) Avaliação da função de VD $e$ VE

Recomendação A - Nível de evidência 1

\section{1) Revascularização miocárdica}

\section{a) Revascularização cirúrgica}

A revascularização miocárdica controla a isquemia persistente e evita a progressão para IAM. Alivia os sintomas, previne as complicações isquêmicas e melhora a capacidade funcional e o prognóstico. Pode ser realizada tanto por intervenção cirúrgica como por intervenção coronariana percutânea. Suas indicações têm variado de acordo com as diversas correntes de opinião, desde aquelas em que se adotam posições extremamente conservadoras, até àquelas que prevêem seu uso indiscriminado. São observadas variações regionais na sua indicação que vão de $0,2 \mathrm{a} 36 \%{ }^{77}$. Em relação às modalidades de intervenção, no passado, as indicações para cirurgia predominavam. Entretanto, o desenvolvimento da angioplastia e, mais recentemente, o emprego de stents, fez com que predominassem as intervenções coronarianas 
percutâneas, sempre que fosse possível seu emprego. Ainda assim, permanece elevado o numero de doentes que se beneficiam com a revascularização cirúrgica precoce.

As indicações para revascularização cirúrgica na AI são semelhantes àquelas adotadas para pacientes com angina crônica estável. O emprego da revascularização cirúrgica deve levar em consideração a anatomia coronariana (grau de obstrução, localização da lesão e importância do vaso) e a função ventricular esquerda. Também influenciam na tomada de decisão a expectativa de vida, doenças associadas, gravidade dos sintomas e quantidade de miocárdio viável em risco.

\section{Risco intermediário:}

\section{Recomendação A - Nível de evidência: 1}

Lesão de tronco da artéria coronária esquerda

Doença triarterial com função ventricular diminuída (fração de ejeção <0,50).

Lesão biarterial com comprometimento proximal da artéria descendente anterior e função ventricular diminuída (fração de ejeção <0,50) ou presença de isquemia provocada

Lesão uni ou biarterial, sem comprometimento proximal da artéria descendente anterior, com critérios de alto risco nos testes não-invasivos e extensa área de miocárdio em risco (pode receber tratamento alternativo com intervenção coronária percutânea)

\section{Recomendação B1 - Nível de evidência 2}

Lesão uni ou biarterial sem comprometimento proximal da artéria descendente anterior mas com área moderada de musculatura viável e isquemia nos testes não-invasivos (pode receber tratamento alternativo com intervenção coronariana percutânea)

Lesão uniarterial com comprometimento proximal importante da artéria descendente anterior (pode receber tratamento alternativo com intervenção coronária percutânea) Doença multiarterial em diabéticos

\section{Recomendação B1 - Nivel de evidência 3}

Reoperação para pacientes com estenoses múltiplas em enxertos, particularmente quando houver comprometimento do fluxo para a artéria descendente anterior

\section{Recomendação C - Nível de evidência 3}

Estenoses coronárias não-significativas $(<50 \%)$

\section{Alto risco:}

\section{Recomendação A - Nivel de evidência: 1}

Lesão de tronco da artéria coronária esquerda

Doença triarterial com função ventricular diminuída (fração de ejeção <0,50)

Lesão biarterial com comprometimento proximal da artéria descendente anterior e função ventricular diminuida (fração de ejeção <0,50), ou quando há presença de isquemia provocada em teste já existente, ou por ter sido realizado para avaliar miocárdio atordoado.

Lesão uni ou biarterial, sem comprometimento proximal da artéria descendente anterior, com critérios de alto risco nos testes não-invasivos e extensa área de miocárdio em risco (pode receber tratamento alternativo com intervenção coronárias percutânea)

\section{Recomendação B1 - Nível de evidência 2}

Lesão uni ou biarterial sem comprometimento proximal da artéria descendente anterior mas com área moderada de musculatura viável e isquemia nos testes não-invasivos (pode receber tratamento alternativo com intervenção coronariana percutânea)

Lesão uniarterial com comprometimento proximal importante da artéria descendente anterior (pode receber tratamento alternativo com intervenção coronariana percutânea) Doença multiarterial em diabéticos

\section{Recomendação B1 - Nível de evidência 3}

Reoperação para pacientes com estenoses múltiplas em enxertos, particularmente quando houver comprometimento do fluxo para a artéria descendente anterior

\section{Recomendação C - Nível de evidência 3 \\ Estenoses coronárias não-significativas ( $<50 \%)$}

\section{b) Revascularização Miocárdica por Via Percutânea(In- tervenção Coronariana Percutânea-ICP)}

Registra-se, atualmente, contínuo e intenso crescimento numérico das indicações de ICP no contexto. Entre vários fatores, esse procedimento se deve ao fato de ter-se tornado mais eficaze seguro com implante de stents $^{89}$ eemprego coadjuvante de bloqueadores do complexo GP-IIb/IIIa ${ }^{37,90-93}$ (v. antiplaquetários), de forma a ampliar-se o leque de indicações para as intervenções coronarianas percutâneas. Assim, aborda-se com mais segurança pacientes multiarteriais, portadores de disfunção ventricular grave e lesões anatomicamente mais complexas. Idealmente, o procedimento deve ser realizado pelo menos $24 \mathrm{~h}$ após o desaparecimento dos sintomas clínicos. O índice de sucesso, de complicações maiores e de eventos isquêmicos graves, após ICP, é influenciado favoravelmente por estabilização inicial.Em oposição, os resultados são afetados negativamente pela refratariedade ao tratamento clínico. Outros aspectos que influenciam a indicação de ICP no contexto são: 1) extensão da doença coronariana (uni, bi, ou triarterial); 2) importância anatômica do vaso; 3 ) número de lesões a serem abordadas; 4) características morfológicas da lesão; 5) dificuldade técnica do procedimento; 6) quantidade de miocárdio em risco; 7) condições clínicas do paciente; 8) doenças associadas.

Deve-se ainda considerar que, principalmente no que se refere à escolha entre este método e o da revascularização cirúrgica, fatores circunstanciais relativos à experiência de cada centro podem ser decisivos para os resultados a obtidos. Este método de revascularização miocárdica é recomendado em:

a) Pacientes com lesões uni ou biarteriais, com significante lesão proximal em artéria descendente anterior, e com grande área de miocárdio em risco por testes funcionais

Grau de recomendação A - Nível de evidência 2

b) Pacientes com lesões multiarteriais, anatomia coronária favorável, função ventricularnormale sem diabetes mellitus

Grau de recomendação A - Nível de evidência 2 
c) Pacientes uni ou biarteriais, mas sem envolvimento proximal da artéria descendente anterior, porém com moderada área de miocárdio em risco e isquemia pelos testes funcionais.

Grau de recomendação B1 - Nível de evidência 3

d) Pacientes com lesão focal ou múltiplas estenoses em enxertos aorto-coronarianos de veia safena, e que são candidatos de alto risco para reoperação cirúrgica.

\section{Grau de recomendação B1 - Nível de evidência 2}

e) Pacientes com lesões tri ou biarteriais, lesão proximal de artéria descendente anterior, função ventricular deprimida $(\mathrm{FE}<50 \%)$ ou diabetes mellitus, mas com anatomia favorável para abordagem percutânea.

\section{Grau de recomendação B2 - Nível de evidência 2}

Nota: Não se deve empregar a ICP nas seguintes circunstâncias:

- Pacientes com estenoses coronárias insignificantes hemodinamicamente (redução de diâmetro luminal inferior a $50 \%)$

- Pacientes com significante lesão em tronco de coronária esquerda candidatos a cirurgia.

-Pacientes uni ou biarteriais sem significante lesão proximal emDA, ou com sintomas atípicos para isquemia miocárdica, ou que não receberam terapia clínica adequada, ou naqueles que não demonstraram isquemia por testes funcionais.

\section{Recomendação C - Nivel de evidência 3}

\section{Referências}

1. Maroko PR, Radvany P, Braunwald E, et al. Reduction of infarct size by oxygen inhalation following acute coronary occlusion. Circulation 1975; 52: 360-8.

2. Madias JE, Hood WB Jr. Reduction of precordial ST-segment elevation in patients with anterior myocardial infarction by oxygen breathing. Circulation 1976; 53(suppl I): I-198-200.

3. BraunwaldE, Brown J, Brown L, et al. Unstable angina: diagnosis and management. Clinical practice guideline number 10. Rockville (MD): US Department of Health and Human Services, Agency for Health Care Policy and Research and the National Heart, Lung, and Blood Institute 1994. AHCPR Publication Nº. 94-0602.

4. Dixon RA, Edwards IR, Pilcher J. Diazepam in immediate post-myocardial infarct period. A double blind trial. Br Heart J 1980; 43: 535-40.

5. DePace N, Herling IM, Kotler MN, Hakki AH, Spielman SR, Segal BL. Intravenous nitroglycerin for rest angina. Potential pathophysiologic mechanisms of action. Arch Intern Med 1982; 142: 1806-9.

6. Kaplan K, Davison R, Parker M, Przybylek J, Teagarden JRML. Intravenous nitroglycerin for the treatment of angina at rest unresponsive to standard nitrate therapy. Am J Cardiol 1983; 51: 694-8.

7. Roubin G, Harris PJ, Eckhardt I. Intravenous nitroglycerine in refractory unstable angina pectoris. Aust NZ J Med 1982; 12: 598-602.

8. Curfman G, Heinsimr JA, Loznerr EC, Fung HL. Intravenous nitroglycerin in the treatment of spontaneous angina pectoris: a prospective randomized trial. Circulation 1983; 67: 276-82.

9. Dellborg M, Gustafsson G, Swedberg K. Buccal versus intravenous nitroglycerin in unstable angina pectoris. Eur J Clin Pharmacol 1991; 41: 5-9.

10. Gottlieb S, Weisfeldt ML, Ouyang P, et al. Effect of the addition of propanolol to therapy with nifedipine for unstable angina pectoris: a randomized, doubleblind, placebo-controlled trial. Circulation 1986; 73: 331-7.

11. Telford A, Wilson C. Trial of heparin versus atenolol in prevention of myocardial infarction in intermediate coronary syndrome. Lancet 1981; 1: 1225-8.

12. Lubsen JTJ. Eficacy of nifedipine and metoprolol in the early treatment of unstable angina in the coronary care unit: findings from the Holland Interuniversity Nifedipine/metoprolol Trial (HINT). Am J Cardiol 1987; 60: 18A-25A.

13. Yusuf S, Witte J, Friedman L. Overview of results of randomized trials in heart disease: unstable angina, heart failure, primary prevention with aspirin and risk factor modifications. JAMA 1988; 260: 2259-63.

14. Theroux P,Taeymans Y,MorissetteD, etal. Arandomized study comparing propranolol and diltiazem in the treatment of unstable angina. J Am Coll Cardiol 1985; 5: 717-22.
15. Parodi OSI, Michelassi C, et al. Comparison of verapamil and propanolol therapy for angina pectoris at rest. A randomized, multiple crossover, controlled trial in the coronary care unit. Am J Cardiol 1986; 57: 899-906.

16. Held PYS, Furberg CD. Calcium channel blockers in acute myocardial infarction and unstable angina: an overview. Br Med J 1989; 299: 1187-92.

17. Lubsen JTJ. Efficacy of nifedipine and metoprolol in the early treatment of unstable angina in the coronary care unit: findings from the Holland Interuniversity Nifedipine/ metoprolol Trial (HINT). Am J Cardiol 1987; 60: 18A-25A.

18. Smith NLRG, Psaty BM, et al. Health outcomes associated with beta-blocker and diltiazem treatment of unstable angina. J Am Coll Cardiol 1998; 32: 1305-11.

19. Yusuf S, Witte J, Friedman L. Overview of results of randomized trials in heart disease: unstable angina, heart failure, primary prevention with aspirin and risk factor modifications. JAMA 1988; 260: 2259-63.

20. Yusuf S, Held P, Furberg C. Update of effects of calcium antagonists in myocardial infarction or angina in light of the second Danish Verapamil Infarction Trial (DAVIT-II) and other recent studies. Am J Cardiol 1991; 67: 1295-7.

21. Boden W, Van Gilst W, Scheldewaert R, et al. Secondary prevention with diltiazem once daily versus placebo in patients with acute myocardial infarction treated with thrombolysis. Lancet 2000 (in press).

22. Lewis H, Davis J, Archibald D, et al. Protective effects of aspirin against acute myocardial infarction and death in men with unstable angina. N Engl J Med 1983; 309: 396-403

23. Cairns J, Gent M, Singer J, et al. Aspirin, sulfinpyrazone or both in unstable angina: results of a Canadian Multicenter Trial. NEngl J Med 1985; 313: 1369-75.

24. The RISC Group. Risk of myocardial infarction and death during treatment with low dose aspirin and intravenous heparin in men with unstable angina. Lancet 1990; 336: 827-30.

25. Theroux P, Ouimet H, McCans J, et al. Aspirin, heparin, or both to treat acute unstable angina. N Engl J Med 1988; 319: 1105-11.

26. Clarke RJ, Mayo G, Price P, Fitzgerald GA. Suppression of thromboxane A2 but not of systemic prostacyclin by controlled-release aspirin. N Engl J Med 1991; 325: 1137-41.

27. Balsano F, Rizzon P, Violi F, et al. Antiplatelet treatment with ticlopidine in unstable angina. A controlled multicenter clinical trial. The Studio della Ticlopidina nell'Angina Instabile Group. Circulation 1990; 82: 17-26.

28. CAPRIE Steering Committee. A randomized blinded trial of clopidogrel versus aspirin in patients at risk of ischemic events. Lancet 1996; 348: 1329-39.

29. The Clopidogrel in Unstable angina to prevent Recurrent Events (CURE) trial programme. Rationale, design and baseline characteristics including a meta-analysis of the effects of thienopyridines in vascular disease. Eur Heart J 2000; 21: 2033-41.

30. Novel dosing regimen of eptifibatide in planned coronary stent implantation (ESPRIT): a randomised, placebo-controlled trial. The ESPRIT Investigators. Enhanced Suppression of the Platelet IIb/IIIa Receptor with Integrilin Therapy. Lancet 2000; 356: 2037-44.

31. A comparison of aspirin plus tirofiban with aspirin plus heparin for unstable angina. Platelet Receptor Inhibition in Ischemic Syndrome Management (PRISM) Study Investigators. N Engl J Med 1998; 338: 1498-505.

32. Inhibition of the platelet glycoprotein IIb/IIIa receptor with tirofiban in unstable angina and non-Q-wave myocardial infarction. Platelet Receptor Inhibition in Ischemic Syndrome Management in Patients Limited by Unstable Signs and Symptoms (PRISM-PLUS) Study Investigators. N Engl J Med 1998; 338: 1488-97.

33. Inhibition of platelet glycoprotein IIb/IIIa with eptifibatide in patients with acute coronary syndromes. The PURSUIT Trial Investigators. Platelet Glycoprotein IIb/IIIa in Unstable Angina: Receptor Suppression Using Integrilin Therapy. NEngl J Med 1998; 339: 436-43.

34. Cannon CP, Weintraub WS, Demopoulos LA, et al. for the TACTICS-Thrombolysis in Myocardial Infarction 18 Investigators. Comparison of Early Invasive and Conservative Strategies in Patients with Unstable Coronary Syndromes Treated with the Glycoprotein IIb/IIIa Inhibitor Tirofiban. N Engl J Med 2001; 344: 1879-1887.

35. Topol, E. GUSTOIV ACS. Presented at XXIInd Congress of the European Society of Cardiology. August 27-30, 2000; Amsterdam, The Netherlands.

36. Randomised placebo-controlled trial of abciximab before and during coronary intervention in refractory unstable angina: the CAPTURE Study. Lancet 1997; 349: 1429-35.

37. Yusuf S, Sleight P, Pogue J, Bosch J, Davies R, Dagenais G. Effects of an angiotensin-converting-enzyme inhibitor, ramipril, on cardiovascular events in highrisk patients. The Heart Outcomes Prevention Evaluation Study Investigators. N Engl J Med 2000; 342: 145-53.

38. Maseri A, Sanna T. The role of plaque fissures in unstable angina: fact or fiction? Eur Heart J 1988; 19(suppl K): K2-K4.

39. Davies MJ, Thomas A. Plaque fissuring: The cause of acute myocardial infarction, sudden ischemic death, and crescendo angina. Br Heart J 1985; 53: 363-3.

40. Fuster V, Badimon L, Cohen M, et al. Insights into the pathogenesis of acute ischemic syndromes. Circulation 1988; 77: 1213-20.

41. Meade TW, Ruddock V, Stirling Y, Chakrabarti R, Miller GJ. Fibrinolytic activity, clotting factors, and long-term incidence of ischaemic heart disease in the Northwick Park Heart Study. Lancet 1993; 342: 1076-9.

42. Prins MH, Hirsh J. A critical review of the relationship between impaired fibrinolysis and myocardial infarction. Am Heart J 1991; 122:5 45-51. 
43. Thompson S, Kienast J, Pyke S, Haverkate F, van de Loo JC. Hemostatic factors and the risk of myocardial infarction or sudden death in patients with angina pectoris. N Engl J Med 1995; 332: 635-41.

44. Ardissino D, Merlini PA, Eisenberg PR, Kottke-Marchant K, Crenshaw BS, Granger CB. Coagulation markers and outcome in acute coronary syndromes. Am Heart J 1998; 136: S7-S18.

45. Cairns JA, Lewis HD, Meade TW, Sutton GC, Theroux P. Antithrombotic agents in coronary artery disease. Fourth ACCP Consensus Conference on Antithrombotic Therapy. Chest 1995; 108(Suppl 4): 380S-400S.

46. Raschke RA, Reilly BM, Guidry JR, Fontana JR, Srinavas S. The weight-based heparin dosing nomogram compared with a "standard care" nomogram: a randomized controlled trial. Ann Intern Med 1993; 119: 874-81.

47. Neri-Serneri GG, Gensini GF, Poggesi L, et al. Effect of heparin, aspirin, or alteplase in reduction of myocardial ischaemia in refractory unstable angina. Lancet 1990; 335: 615-8.

48. The TIMI IIIB Investigators. Effects of tissue plasminogen activator and a comparison of early invasive and conservative strategies in unstable angina and non-Q-wave myocardial infarction. Circulation 1994; 89: 1545-56.

49. Hirsh J, Levine MN. Low molecular weight heparin. Blood 1992; 79: 1-17.

50. Fareed J, Jeske W, Hoppensteadt D, Clarizio R, Walenga J. Low molecular weight heparins: Pharmacologic profile and product differentiation. Am J Cardiol 1998; 82: $3 \mathrm{~L}-10 \mathrm{~L}$.

51. Linhardt RJ, Gunay NS. Production and chemical processing of low molecular weight heparins. Seminars in Thrombosis and Hemostasis 1999; 25(suppl 3): 5-16.

52. Fragmin during Instability in Coronary Artery Disease (FRISC) Study Group Low-molecular-weight heparin during instability in coronary artery disease (FRISC). Lancet 1996; 347: 561-8.

53. Klein W, Buchwald A, Hillis SE, et al. Comparison of low molecular weight heparin with unfractionated heparin acutely and with placebo for 6 weeks in the management of unstable coronary artery disease. Circulation 1997; 96: 61-8.

54. FRagmin and Fast Revascularisation during InStability in Coronary artery disease (FRISC II) Investigators. Long-term low-molecular-mass heparin in unstable coronary-artery disease. FRISC II prospective randomised multicentre study. Lancet 1999; 354: 701-7.

55. FRagmin and Fast Revascularisation during InStability in Coronary artery disease (FRISC II) Investigators. Invasive compared with non-invasive treatment in unstable coronary-artery disease. FRISC II prospective randomised multicentre study. Lancet 1999; 354: 708-15.

56. Cohen M, Demers C, Gurfinkel EP, et al. A comparison of low-molecular-weight heparin with unfractionated heparin for unstable coronary artery disease. NEngl J Med 1997; 337: 447-52

57. Theroux P, Waters D, Lam J, Juneau M, McCans J. Reactivation of unstable angina after the discontinuation of heparin. N Engl J Med 1992; 327: 141-5.

58. Goodman SG, Cohen M, Bigonzi F, et al. Randomized trial of low molecular weight heparin (enoxaparin) versus unfractionated heparin for unstable coronary artery disease: one-year results of the ESSENCE Study. Efficacy and Safety of Subcutaneous Enoxaparin in Non-Q Wave Coronary Events. J Am Coll Cardiol 2000; 36: 693-8.

59. Antman EM, McCabe CH, Gurfinkel EP, et al. Enoxaparin prevents death and cardiac ischemic events in unstable angina/non-Q-wave myocardial infarction. Results of the thrombolysis in myocardial infarction (TIMI) 11B Trial. Circulation 1999; 100: 1593-601.

60. Bozovich GE, Gurfinkel EP, Antman EM, McCabe CH, Mautner B. Superiority of enoxaparin versus unfractionated heparin for unstable angina/non-Q-wave myocardial infarction regardless of activated partial thromboplastin time. Am Heart J 2000; 140: 637-42.

61. Antman EM, Cohen M, Radley D, et al. Assessment of the treatment effect of enoxaparin for unstable angina/non-Q-wave myocardial infarction. TIMI 11B-ESSENCE Meta-Analysis. Circulation 1999; 100: 1602-8.

62. Mismetti P, Laporte-Simitsidis S, Tardy B, et al. Prevention of venous thromboembolism in internal medicine with unfractionated or low-molecular-weight heparins: a meta-analysis of randomised clinical trials. Thrombo Haemost 2000; 83: 14-9.

63. Dolovich LR, Ginsberg JS, Douketis JD, Holbrook AM, Cheah G. A meta-analysis comparing low-molecular-weight heparins with unfractionated heparin in the treatment of venous thromboembolism: examining some unanswered questions regarding location of treatment, product type, and dosing frequency. Arch Intern Med 2000; 160: 181-8

64. Kaul S, Shah PK. Low molecular weight heparin in acute coronary syndrome: evidence for superior or equivalent efficacy compared with unfractionated heparin? J Am Coll Cardiol 2000; 35: 1699-712.

65. Eikelboom JW, Anand SS, Malmberg K, Weitz JI, Ginsberg JS, Yusuf S. Unfractionated heparin and low-molecular-weight heparin in acute coronary syndrome without ST elevation: a meta-analysis. Lancet 2000; 355: 1936-42.

66. Furberg CD, Herrington DM, Psaty BM. Are drugs within a class interchangeable? Lancet 1999; 354: 1202-4

67. Montalescot G, Phillippe F, Ankri A, et al. Early increase of von willebrand factor predicts adverse outcome in unstable coronary artery disease: beneficial effects of enoxaparin. Circulation 1998; 98: 294-9.

68. Montalescot G, ColetP, Lison L, etal. Effect of various anticoagulant treatments on von Willebrand Factor release in unstable angina. J Am Coll Cardiol 2000; 36: 110-4.

69. Organisation to Assess Strategies for Ischemic Syndromes (OASIS-2) Investigators. Effects of recombinant hirudin (lepirudin) compared with heparin on death, myocardial infarction, refractory angina, and revascularisation procedures in patients with acute myocardial ischaemia without ST elevation: a randomised trial. Lancet 1999; 353: 429-38.

70. Kong DF, Topol EJ, Bittl JA, et al. Clinical outcomes of bivalirudin for ischemic heart disease. Circulation 1999; 100: 2049-53.

71. ACC/AHA Guidelines for coronary Angiography. A report of the American College of Cardiology/ American Heart Association Task Force on Practice Guidelines(Committee on Coronary Angiography). J Am Coll Cardiol 1999; 33: 1756-817.

72. Marin-Neto JA, Ayres-Neto EM. Cinecoronariografia: quando não é e quandoé preciso indicar. In: Manual de Cardiologia. SOCESP. Timerman A, César LAM, Ferreira JFM, Bertolami MC. Eds. São Paulo: Editora Atheneu 2000: 207-211.

73. Feres F, Marin-Neto JA. Angiografia de contraste: ainda o método padrão para estratificação de risco em pacientes com syndrome isquêmica miocárdica instável em nosso meio? In: Nicolau JC, Marin-Neto JA. Síndromes Isquêmicas Miocárdicas Instáveis (SIMI). Eds. São Paulo: Editora Atheneu 2001 (no prelo).

74. Effects of tissue plasminogen activator and a comparison of early invasive and conservative strategies in unstable angina and non-Q-wave myocardial infarction: results of the TIMI IIIB /trial. Thrombolysis in Myocardial Ischemia. Circulation 1994; 89: 1545-56

75. Boden WE, O'Rourke RA, Crawford MH, et al. Outcomes in patients with acute non-Qwave myocardial infarction randomly assigned to an invasive as compared with a conservative management strategies Veterans Affairs Non-Q Wave Infarction Strategies in Hospital(VANQWISH) Trial Investigators. N Engl J Med 1998; 338: 1785-92.

76. McCullough PA, et al. Medicine vs Angioplasty in Thrombolytic Exclusion (MATE); a prospective, randomized trial of triage angiography in acute coronary syndromes ineligible for thrombolytic therapy. J Am Coll Cardiol 1998; 32: 596-605.

77. Yusuf S, Flather M, Pogue J, et al. for the OASIS (Organisation to Assess Strategies for Ischaemic Syndromes) Registry Investigators. Variations between countries in invasive cardiac procedures and outcomes in patients with suspected unstable angina or myocardial infarction without initial ST elevation. Lancet 1998; 352: 507-14.

78. Fragmin and Fast Revascularization during In Stability in Coronary Artery Disease (FRISCII) Investigators. Invasive compared with non-invasive treatment in unstable coronary-artery disease: FRISC II prospective randomise multicenter study. Lancet 1999; 354: 708-15.

79. Kaul S. Myocardial contrast echocardiography: 15 years of research and development. Circulation 1997; 96: 3745-60.

80. Morcerf F, Moraes A, Carrinho M, et al. Adenosine contrast echocardiography in 936 consecutive patients with suspected coronary artery disease: Experience of a single center. J Am Coll Cardiol 2000; 35(supp A): 413A.

81. Amanullah AM. Noninvasive testing in the diagnosis and management of unstable angina. Int J Cardiol 1994; 47: 95-103

82. Miller DD. Risk stratification in unstable angina pectoris. In: Zaret BL, Beller GA. Nuclear Cardiology. State of the Art and Future Directions. Eds. St. Louis, USA: Mosby Inc., 1999: 490-9.

83. Freeman MR, Chisholm RJ, Armstrong PW. Usefulness of exercise electrocardiography and thallium scintigraphy in unstable angina pectoris in predicting the extent and severity of coronary artery disease. Am J Cardiol 1988; 62: 1164-70.

84. Zhu YY, Chung WS, Botvinick EH, et al. Dipyridamole perfusion scintigraphy: the experience with its application in one hundred seventy patients with known or suspected unstable angina. Am Heart J 1991; 121: 33-43.

85. Brown KA. Prognostic value of Thallium-201 myocardial perfusion imaging in patients with unstable angina who respond to medical treatment. J Am Coll Cardiol 1991; 17: 1053-7.

86. Madsen JK, Stubgaard M, Utne HE, et al. Prognosis and Thallium-201 scintigraphy in patients admitted with chest pain without confirmed acute myocardial infarction. Br Heart J 1988; 59: 184-9.

87. Stratmann HG, Younis LT, Wittry MD, Amato M, Miller DD. Exercise technetium-99m myocardial tomography for the risk stratification of men with medically treated unstable angina pectoris. Am J Cardiol 1995; 76: 236-40.

88. Amanullah AM, Lindvall K, Bevegard S. Prognostic significance of exercise thallium-201 myocardial perfusion imaging compared to stress echocardiography and clinical variables in patients with unstable angina who respond to medical treatment. Int J Cardiol 1993; 39:71-78.

89. Bonnier L, Ribeiro EE, Serruys P, et al. Safety and efficacy of stenting in MVD or surgery for stable and unstable angina. Analysis of the ARTS trial. Presented at XXIInd Congress of the European Society of Cardiology. August 27-30, 2000; Amsterdam, The Netherlands.

90. The EPIC Investigators. Use of a monoclonal antibody directed against the platelet glycoprotein IIb/IIIa receptor in high-risk coronary angioplasty. N Engl J Med 1994; 330: 956-61.

91. The EPILOG Investigators. Platelet glycoproteino IIb/IIIa receptor blockade and low-dose heparin during percutaneous coronary revascularization. N Engl J Med 1997; 336: 1689-96.

92. The RESTORE Investigators. Effects of platelet glycoprotein IIb/IIIa blockade with tirofiban on adverse cardiac events in patients with unstable angina or acute myocardial infarction undergoing angioplasty. Circulation 1997; 96: 1445-53.

93. The EPISTENT Investigators. Randomized placebo-controlled and balloonangioplasty-controlled trial to assess safety of coronary stenting with use of platelet glycoprotein IIb/IIIa blockade. Lancet 1998; 352: 87-92. 